\begin{abstract}
(1)
Hacettepe University Graduate School of Social Sciences

Department of Information Management
\end{abstract}

\title{
ASSESSING THE DIFFUSION OF NANOTECHNOLOGY IN TURKEY: A SOCIAL NETWORK ANALYSIS APPROACH
}

\author{
Hamid Derviş
}

Ph.D. Dissertation

Ankara, 2014 


\title{
TÜRKIYE' DE NANOTEKNOLOJI YAYILIMININ DEĞERLENDİRILMESİ: BİR SOSYAL AĞ ANALİZI YAKLAȘIMI
}

\author{
Hamid Derviş
}

Doktora Tezi

Hacettepe Üniversitesi Sosyal Bilimler Enstitüsü

Bilge ve Belge Yönetimi Bölümü

Ankara, 2014 


\section{KABUL VE ONAY}

Hamid Derviş tarafından hazırlanan "Assessing the diffusion of nanotechnology in Turkey: A social network analysis approach" başlıklı bu çalışma, 20 Ocak 2014 tarihinde yapılan savunma sınavı sonucunda başarılı bulunarak jürimiz tarafından Doktora tezi olarak kabul edilmiştir.

Prof. Dr. Aydın ERAR (Başkan)

Prof. Dr. Yaşar TONTA (Danışman)

Prof. Dr. Serap KURBANOĞLU

Doç. Dr. Umut AL

Doç. Dr. Yurdagül ÜNAL

Yukarıdaki imzaların adı geçen öğretim üyelerine ait olduğunu onaylarım.

Enstitü Müdürü
Prof. Dr. Yusuf ÇEİK




\section{BILLDIRIMI}

Hazırladığım tezin tamamen kendi çalışmam olduğunu ve her alıntıya kaynak gösterdiğimi taahhüt eder, tezimin/raporumun kâğıt ve elektronik kopyalarının Hacettepe Üniversitesi Sosyal Bilimler Enstitüsü arşivlerinde aşağıda belirttiğim koşullarda saklanmasına izin verdiğimi onaylarım:

曰 Tezimin/Raporumun tamamı her yerden erişime açılabilir.

ㅁ Tezim/Raporum sadece Hacettepe Üniversitesi yerleșkelerinden erişime açılabilir.

Tezimin/Raporumun ........ yıl süreyle erişime açılmasını istemiyorum. Bu sürenin sonunda uzatma için başvuruda bulunmadığım takdirde, tezimin/raporumun tamamı her yerden erişime açılabilir.

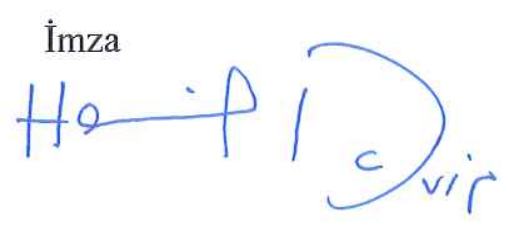

Hamid Derviş 


\section{ACKNOWLEDGEMENTS}

I would like to express my gratitude toward Prof. Dr. Yaşar Tonta during my research for his dedicated review and corrections; also, I would like to thank the members of the jury: Prof. Dr. Serap Kurbanoğlu, Prof. Dr. Aydın Erar, Associate Prof. Dr. Umut Al and Associate Prof. Dr. Yurdagül Ünal. Last, but not least, I would like to express my appreciation to the Department of Information Management of Hacettepe University for their unwavering support during my studies. 


\begin{abstract}
Hamid Derviş. Assessing the Diffusion of Nanotechnology in Turkey: A Social Network Analysis Approach. Ph.D. Dissertation, Ankara, 2014.
\end{abstract}

This dissertation assesses the diffusion of nanoscience and nanotechnology in the scientific community in the last decade using Social Network Analysis (SNA) in Turkey. This dissertation aims to evaluate the flow of knowledge diffusion of nanotechnology among scientists by using ethnographic methods, co-words analysis and by focusing on an invisible college in the scientific community in terms of citation analysis in Turkey. A total of 10,062 articles and reviews were extracted from WoS (2664 between 2000 and 2005, and 7398 between 2006 and 2011) using a compound text query. Results compiled from co-authorship network analysis comprised a high closeness centrality indicating the smallworld phenomenon which facilitates the diffusion of nano-related technology in Turkey. We discovered the scientists who are instrumental in the diffusion of nanotechnology knowledge in the network. We test the hypotheses that: (1) prolific authors stimulate the diffusion of nanotechnology in network structure; (2) dissemination of nanotechnology is more diffusive within sub-clusters than that of the whole network structure; and (3) taxonomy identified by co-word analysis in the research process matches the findings at the global level. Universities with the highest co-occurrence in terms of centralities in the network structure were studied. Then, we compared the results from each period to investigate the rate of diffusion of nano-related technology in Turkey. We found out that research on nano-related technology is done in a wide spectrum from Materials to Biomedical Sciences. Moreover, we found that TÜBİTAK and the Ministry of Development $(\mathrm{MoD})$ have increased their funding support. We corroborate the findings by interviewing the key scientists or authors who are instrumental in the diffusion of nanorelated technologies in Turkey. We collected and elaborated on 10 interviewees' responses using a qualitative method (Latent Semantic Analysis). Outcomes indicated that scientists' 
behavior who participated in interviews share similar patterns matching their co-authorship maps. It was concluded that the diffusion of nano-related technology is steadily progressing due to scientific collaboration among scientists through social network.

\section{Key words}

Social network analysis, Nanotechnology, Science mapping, Latent semantic analysis, overlay maps, Ethnographic interviews 


\section{ÖZET}

Hamid Derviş. Türkiye'de Nanoteknoloji Yayılımının Değerlendirilmesi: Bir Sosyal A $\breve{g}$ Analizi Yaklaşımı. Doktora Tezi, Ankara, 2014.

Bu tez, Sosyal Ağ Analizi metodunu (SNA) kullanarak son on yılda Türkiye'de nanobilim ve nanoteknolojinin yayılmasını ölçmektedir. Bu tez aynı zamanda, etnografik yöntemler, eş kelime analizi, bilim dünyasındaki "invisible college" ilişkilerine odaklanarak ve atıfları inceleyerek bilim insanları arasında nanoteknoloji bilgisinin yayılımını ve akışını değerlendirmeyi amaçlamaktadır. Tezde bileşik bir sorgu cümlesi ile "Web of Science"da yayınlanmış (WoS) 10.062 makale ve eleştiri yazısı (2664 tanesi 2000-2005 yılları arasında, 7398 tanesi ise 2006-2010 yılları arasında yayınlanmış) incelenmiştir. Eş yazarlık ağ analizi sonuçlarına göre yakınlık merkeziliği katsayısı yüksektir. Bu da Türkiye'de nanoteknolojinin yayılımını kolaylaştıran "küçük dünya" olgusunun varlığına işaret etmektedir. Ağda nanoteknolojinin yayılımında etkili olan bilimciler olduğunu bulduk. Araştırma hipotezi nanoteknolojinin yayılımını gösteren sosyal ağ özellikleri incelenerek test edilmiştir. Hipotez üç aşamada sınanmıştır: (1) Üretken yazarlar ağ yapısında nanoteknoloji yayılımını tetiklemektedir; (2) Nanoteknolojinin yayılımı alt kümelerde daha hızlıdır; ve (3) Eş kelime analiziyle elde edilen taksonomi küresel düzeydeki bulgularla benzerlik göstermektedir. A $\breve{g}$ yapısı içinde en yüksek merkezilik derecesine sahip olan üniversiteler üzerinde çalışılmıştır. Sonra, Türkiye'de nano teknolojilerin yayılma hızını analiz etmek için her iki dönemin sonuçları karşılaştırılmıştır. Nanoteknoloji alanı ile ilgili araştırmaların Malzeme Bilimi ile Biyomedikal Bilim arasında geniş bir yelpazede yapıldığı sonucuna ulaşılmıştır. Bunun yanı sıra, TÜBİTAK ve Kalkınma Bakanlığının nano teknolojilere yönelik mali desteklerinin arttı̆̆ gözlenmiştir. Türkiye'de nano teknolojilerin yayılmasında etkili olan tanınmış bilimciler ile yapılan yüz yüze görüşmelerle analiz sonuçları doğrulanmıştır. Yapılan 10 görüşmede verilen cevaplar niteliksel analiz yöntemi olan Gizli Anlam Analizi yöntemi kullanılarak analiz edilmiştir. Sonuçlar görüşmelere katılan bilimcilerin genellikle kendi grupları (küme) içinde çalışmayı tercih ettiklerini göstermektedir. Bilimciler arasındaki bilimsel işbirliğinin sosyal 
ağlar aracılığıyla artmasına bağlı olarak nano teknolojinin yayılımının devam etmekte olduğu sonucuna varılmıştır.

\section{Anahtar Sözcükler}

Sosyal ă̆ analizi, Nanoteknoloji, Bilim haritalama, Gizli anlam analizi, Bindirme haritalar, Etnografik görüşmeler 
TABLE OF CONTENTS

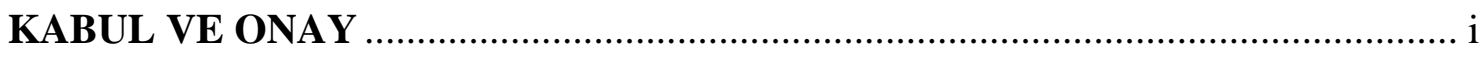

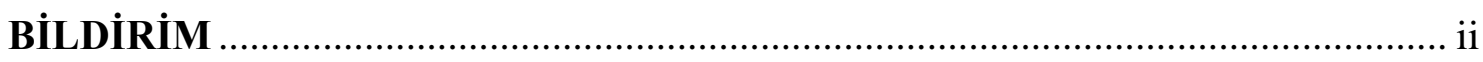

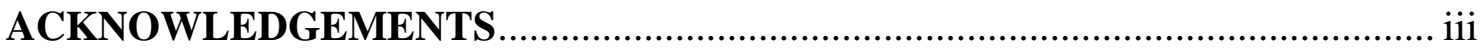

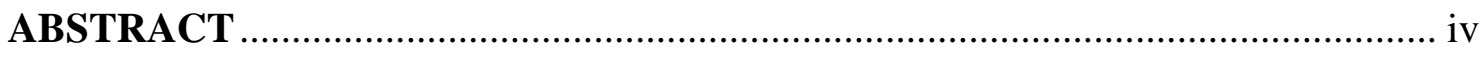

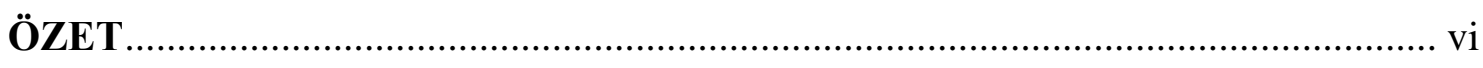

TABLE OF CONTENTS ................................................................................. vii

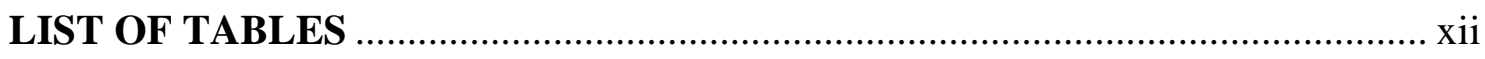

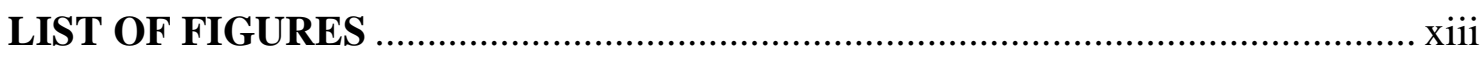

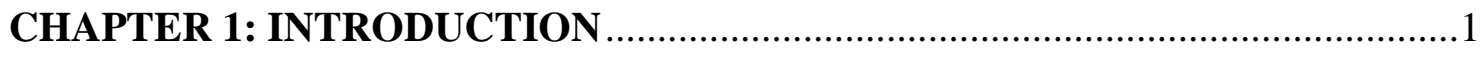

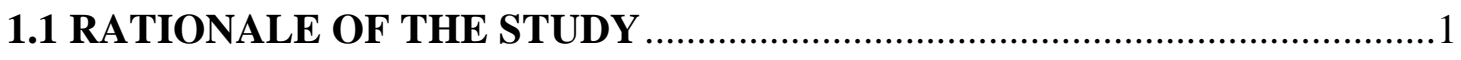

1.2 RESEARCH PROBLEM …………………………..................................

1.3 CONCEPTUAL MODEL FOR RESEARCH PROBLEM: DIFFUSION

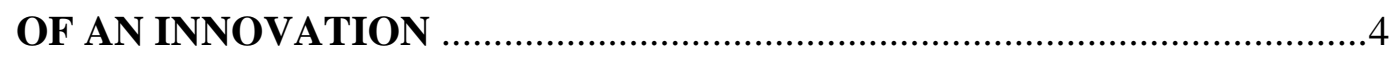

1.4 RESEARCH QUESTIONS AND HYPOTHESES .........................................

CHAPTER 2: LITERATURE REVIEW ………….......................................... 10

2.1 SOCIAL NETWORK ANALYSIS AND ITS THEORETICAL BASICS .....10

2.2 THE “SMALL WORLD” PHENOMENON ………………..............................11

2.3 THE DIFFUSION OF INNOVATIONS ....................................................

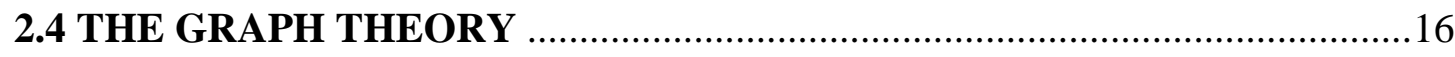

2.5 CO-WORD ANALYSIS: MAPPING THE COGNITIVE STRUCTURE

OF NANO-RELATED TECHNOLOGIES....................................................19

2.6 NANOTECHNOLOGY DEVELOPMENT IN TURKEY ………...................19 
2.7 GROWTH AND DIFFUSION OF NANOTECHNOLOGY

AT THE GLOBAL LEVEL

2.8 MAPPING THE DIFFUSION OF THE KNOWLEDGE .............................22

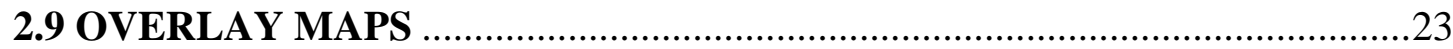

2.10 ETHNOGRAPHIC METHOD: LATENT SEMANTIC ANALYSIS

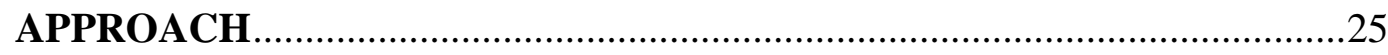

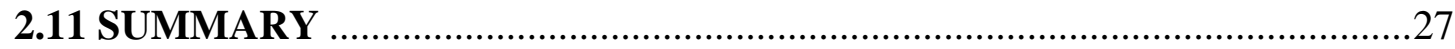

CHAPTER 3: RESEARCH METHOD AND DATA PROCESSING ………….......28

3.1 SOCIAL NETWORK ANALYSIS: STATISTICAL RESULTS .....................29

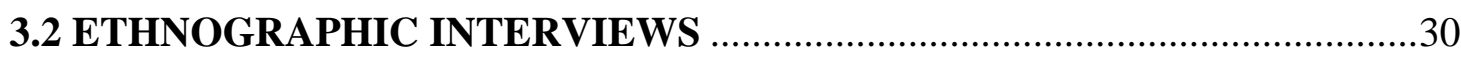

3.3 LATENT SEMANTIC ANALYSIS APPROACH …………….......................

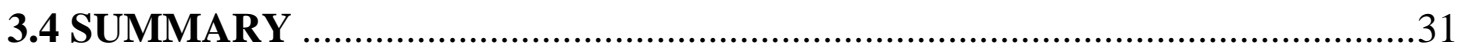

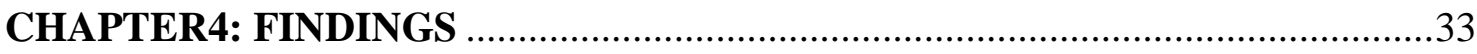

4.1 GOVERNMENTAL AGENCIES' SUPPORT .................................................33

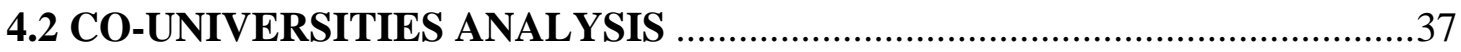

4.3 THE RATE OF DIFFUSION: 2000-2011 ………………………………........

4.4 NETWORK OF NANO-RELATED TECHNOLOGY IN TURKEY:

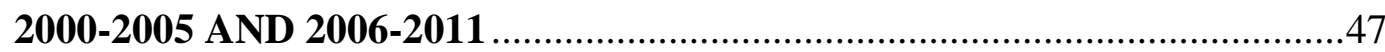

4.5 NETWORK OF PUBLICATIONS IN NANO-RELATED

TECHNOLOGY IN TURKEY: 2000-2005 AND 2006-2011 ……...................50

4.6 NETWORK OF NANO-RELATED TECHNOLOGY IN SELECTED

UNIVERSITIES: 2000-2005

4.7 NETWORK OF NANO-RELATED TECHNOLOGY IN SELECTED

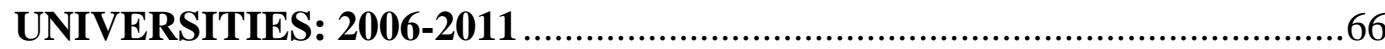

4.8 SUMMARY OF NANO-RELATED TECHNOLOGY IN SELECTED

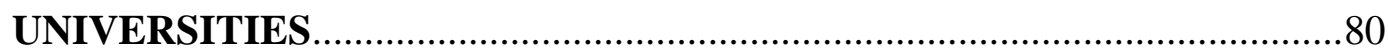


4.9 CO-AUTHORSHIP ANALYSIS OF UNIVERSITIES:

2000-2005 AND 2006-2011

4.10 CO-AUTHORSHIP ANALYSIS OF SELECTED AUTHORS:

2000-2005 AND 2006-2011.

4.11 FRACTIONAL COUNTING OF CO-AUTHORSHIP:

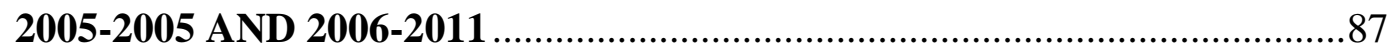

4.12 CO-CITATION ANALYSIS: 2000-2005 AND 2006-2011 ……...................90

4.13 JOURNALS CO-CITATION ANALYSIS: 2000-2005 AND 2006-2011_.......92

4.14 CO-WORD ANALYSIS: 2000-2005 AND 2006-2011 …………………….....94

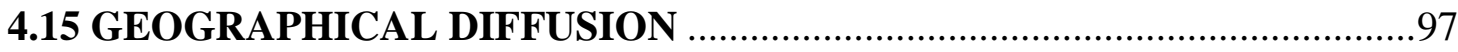

4.16 ETHNOGRAPHIC INTERVIEWS:

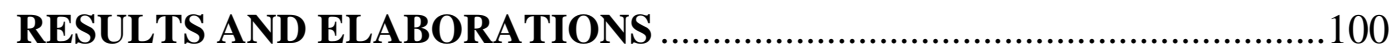

4.17 ETHNOGRAPHIC ELABORATION OF THE CO-AUTHORSHIP

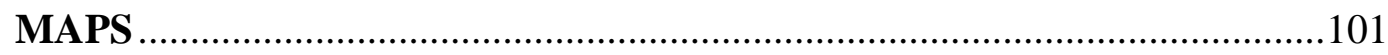

4.18 SUMMARY OF THE FINDINGS ...........................................................107

4.19 COMPARISON OF FINDINGS WITH RELEVANT STUDIES .................107

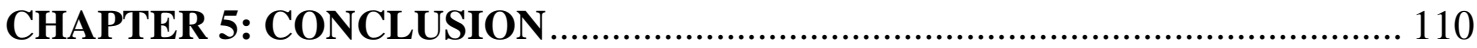

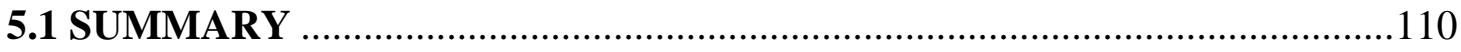

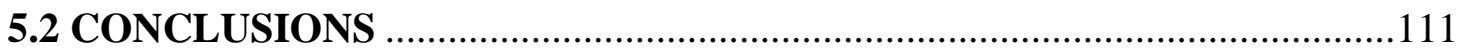

5.3 STRENGTHS AND WEAKNESSES OF THE THESIS.................................113

5.4 RECOMMENDATIONS ………………………….................................114

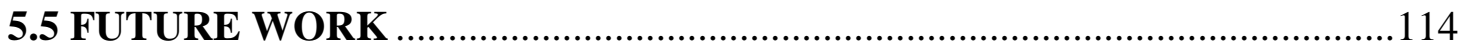

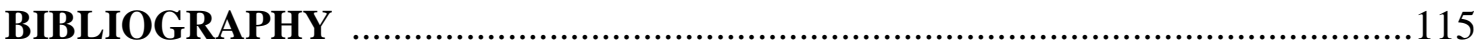

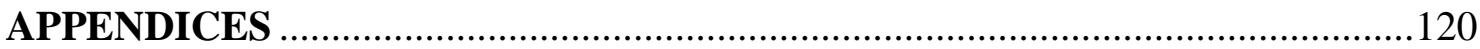

APPENDIX A: QUERY FORMATION USED TO FIND THE

PUBLICATIONS OF TURKISH RESEARCHERS ON

NANOSCIENCE AND NANOTECHNOLOGY ON THE WEB 
APPENDIX B: SUBJECT CONSENT FORM

APPENDIX C: STRUCTURED INTERVIEW QUESTIONS

APPENDIX D: SEMI-STRUCTURED INTERVIEW QUESTIONS.....................125

APPENDIX E: LIST OF WORDS USED IN NANOTECHNOLOGY:

2000-2005

APPENDIX F: LIST OF WORDS USED IN NANOTECHNOLOGY:

2006-2011

APPENDIX G: THE MOST COLLABORATING UNIVERSITIES

WORKING ON NANO-RELATED TECHNOLOGY (2000-2011) 


\section{LIST OF TABLES}

Table 1. Matrix presentation of the incomplete graph depicted in Figure 4 .18

Table 2. Number of nano-related articles published and total funds received by several universities

Table 3. Top 15 universities with highest co-occurrence in Turkey

Table 4. Centrality coefficients of the network structure: 2000-2005 and 2006-2011 ......44

Table 5. Number of new and cumulative adopters between 2000 and 2011 ...................46

Table 6. Degree centralities of network structure based on WoS categories..... .48

Table 7. Centralities coefficients of the top 15 universities' publications on nano-related technology, 2000-2005 and 2006-2011

Table 8. Network properties of top 15 Turkish authors based on co-authorship degree centralities: 2000-2005

Table 9. Network properties of top 15 authors based on degree centralities: 2006-2011....86

Table 10. Highly prolific scholars in nano-related technology: 2000-2005 and 2006-2011

Table 11. The most co-cited papers in nano-related technology in Turkey, 2000-2005 .....91

Table 12. The most co-cited papers in nano-related technology in Turkey, 2006-2011 .....91

Table 13. Factor analysis of co-words in the titles of nano-related articles produced in Turkey between 2000 and 2005

Table 14. Eigenvalues of the top two factors from 2000-2005

Table 15. Factor analysis of co-words in the titles of nano-related articles produced in Turkey: 2006-2011.

Table 16. Eigenvalues of the top three factors from 2006-2011

Table 17. One-to-many similarity comparison based on the question "Where would you like to see yourself in this social structure map?"

Table 18. One-to-many similarity comparison based on the question "With whom do you usually collaborate in scientific activities? And why?" 


\section{LIST OF FIGURES}

Figure 1. The diffusion of innovations by time according to Rogers ................................ 5

Figure 2. (a) Random graph network, (b) Scale-free network ..................................... 13

Figure 3. (a) Directed Graph, (b) Scale-free network ........................................... 17

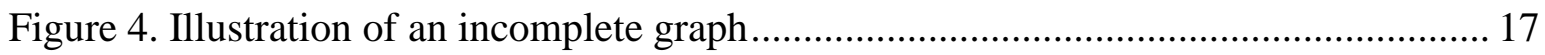

Figure 5. Global map of science based on ISI subject categories ................................... 24

Figure 6. Representation of matrix reduction in using Singular Value Decomposition ...... 26

Figure 7. Number of nano-related technologies publications in Turkey: 2000-2011 ......... 34

Figure 8. Number of scientific publications of universities in nano-related technologies in Turkey between 2000 and 2011 Source: Web of Science (as of November 2013).

Figure 9. Density map of collaboration on nano-related technology among universities in

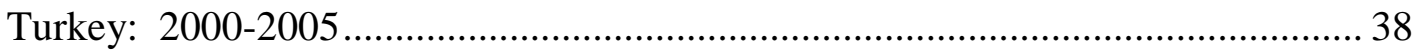

Figure 10. Cluster density map of collaboration on nano-related technology within

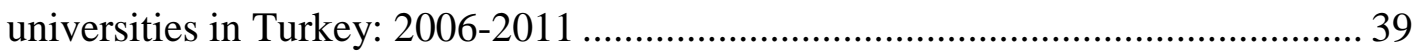

Figure 11. Collaboration of universities based on their co-occurrences frequency in

Turkey: 2000-2005

Figure 12. Collaboration of universities based on their co-occurrence frequency

in Turkey: 2006-2011

Figure 13. Comparison of co-occurrence frequency of selected universities in two periods: 2000-2005 and 2006-2011

Figure 14. Betweenness and closeness centrality of selected universities in two periods: 2000-2005 and 2006-2011 45

Figure 15. Adoption rate of collaborations between 2000-2011 46

Figure 16. Profile of universities based on subject category in nano-related technology 
overlaid on map of science in Turkey: 2000-2005

Figure 17. Profile of universities based on subject category in nano-related technology overlaid on map of science in Turkey: 2006-2011.

Figure 18. Degree centralities of selected universities in two periods: 2000-2005 and 2006-2011 52

Figure 19. Publication profiles overlaid on the map of science of METU, 2000-2005 53

Figure 20. Publication profiles overlaid on the map of science of Bilkent University, 2000-2005

Figure 21. Publication profiles overlaid on the map of science of Hacettepe University, 2000-2005 55

Figure 22. Publication profiles overlaid on the map of science of Ondokuz May1s University, 2000-2005 56

Figure 23. Publication profiles overlaid on the map of science of Ankara University, 2000-2005 57

Figure 24. Publication profiles overlaid on the map of science of Gazi University, 2000-2005 57

Figure 25. Publication profiles overlaid on the map of science of ITU, 2000-2005

Figure 26. Publication profiles overlaid on the map of science of Gebze Institute of Technology, 2000-2005 59

Figure 27. Publication profiles overlaid on the map of science of Dokuz Eylül

University, 2000-2005

Figure 28. Publication profiles overlaid on the map of science of Marmara University, 2000-2005 61

Figure 29. Publication profiles overlaid on the map of science of Abant Izzet Baysal University, 2000-2005 
Figure 30. Publication profiles overlaid on the map of science of Kırıkkale University, 2000-2005

Figure 31. Publication profiles overlaid on the map of science of Ege University,

2000-2005

Figure 32. Publication profiles overlaid on the map of science of Erciyes University, 2000-2005 64

Figure 33. Publication profiles overlaid on the map of science of Kocaeli University, 2000-2005 65

Figure 34. Publication profiles overlaid on the map of science of Bilkent University, 2006-2011 66

Figure 35. Publication profiles overlaid on the map of science of Gebze Inst Tech, 2000-2005 67

Figure 36. Publication profiles overlaid on the map of science of Hacettepe University, 2006-2011 68

Figure 37. Publication profiles overlaid on the map of science of METU, 2006-2011 69

Figure 38. Publication profiles overlaid on the map of science of Gazi University, 2006-2011 70

Figure 39. Publication profiles overlaid on the map of science of ITU, 2006-2011 71

Figure 40. Publication profiles overlaid on the map of science of Ankara University, 2006-2011 72

Figure 41. Publication profiles overlaid on the map of science of Ondokuz Mayıs University, 2006-2011 73

Figure 42. Publication profiles overlaid on the map of science of Ege University, 2006-2011 
Figure 43. Publication profiles overlaid on the map of science of Istanbul University, 2006-2011 75

Figure 44. Publication profiles overlaid on the map of science of Erciyes University, $2006-2011$

Figure 45. Publication profiles overlaid on the map of science of Dokuz Eylül

University, 2006-2011 77

Figure 46. Publication profiles overlaid on the map of science of Anadolu University, 2006-2011 78

Figure 47. Publication profiles overlaid on the map of science of Atatürk University, $2006-2011$ 79

Figure 48. Publication profiles overlaid on the map of science of Frrat University,

2006-2011 80

Figure 49. Co-authorship network of scientists working on nano-related technology: 2000-2005 82

Figure 50. Co-authorship network of scientists working on nano-related technology: 2006-2011 82

Figure 51. Co-authorship map of scientists between 2000 and 2005 85

Figure 52. Co-authorship map of scientists between 2006 and 2011 ............................. 86

Figure 53. Document co-citation map of nano-related technology from 2000 to $2005 \ldots . . . .90$

Figure 54. Document co-citation map of nano-related technology from 2006 to $2011 \ldots . . . .92$

Figure 55. Journal co-citation in nano-related technology articles in Turkey between 2000-2005 
Figure 56. Journal co-citation in nano-related technology articles in Turkey between 2006-2011 93

Figure 57. Nodes are colored according to factor solution of this network: 2000-2005 ..... 95

Figure 58. Nodes are colored according to factor solution of this network: 2006-2011 _.... 97

Figure 59. Geographical distribution of nano-related research activities of cities in

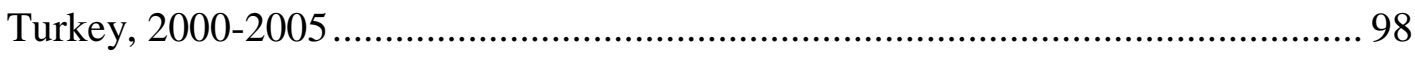

Figure 60. Geographical distribution of nano-related research activities of cities in Turkey, 2006-2011 98

Figure 61.The network of co-authors of international and Turkish scientists working on nano-related technologies, 2000-2005 99

Figure 62.The network of co-authors of international and Turkish scientists working on nano-related technologies. .99 


\section{CHAPTER 1}

\section{INTRODUCTION}

\subsection{RATIONALE OF THE STUDY}

Nano-science is about the creation and manipulation of information, and nanotechnology is the set of applications, which are based on Nanoscience principles (Mehta, 2002). Nanotechnology is the study of materials at atomic levels within the 1 to $100 \mathrm{~nm}$ range. Simply, "nano" means "molecular sized" (i.e., at a magnitude of $10^{-9}$ of a meter) ${ }^{1}$

Nanoscience and nanotechnology have implications in other scientific fields such as physics, chemistry, medicine, biomedicine, manufacturing, and the food industry, to name a few. Therefore, research in nanotechnology promises a great deal of innovation for, and benefit to, society as a whole. According to the United Nations, nanotechnology is one of the emerging research fields, which will have positive impact on both developing and developed countries. For example, while nanotechnology is used for water purification in poor countries, it is used for manufacturing better chips for computers in developed countries. In this respect, countries are investing in research and development of nanotechnology. The European Union (EU) has invested heavily in nanotechnology through its framework programs (FPs) since 2000. The Turkish government has also adopted a new approach by becoming the part of the EU's FPs and has invested heavily in research and development. The Supreme Council for Science and Technology

\footnotetext{
${ }^{1}$ Although the term "nano" is used and applied in nanotechnology related research, not every nano-related term actually is applicable to scientific research in nanotechnology. For example, the terms "nanoscale", "nanogram" or "nanoleakage" are irrelevant to nanotechnology-related research and therefore will not be used in this dissertation.
} 
BTYK / SCST) is the highest-ranking Science, Technology and Innovation (STI) policy and decision-making body in Turkey.

Research and funding have significant roles in implementing scientific research in universities and private research centers in Turkey. The number of nano-related publications has increased since 2005. Recently, Aydoğan-Duda and Şener (2010) conducted research regarding the state of nano-related technologies in Turkey. They found out that there are 10 nanotechnology centers equipped with state-of-the-art technology, employing researchers with PhD degrees from the USA. According to their findings, there are 14 companies manufacturing nanotechnology-related materials in Turkey, whereas there are 41 nanotechnology companies in China, 17 in India and 195 in Germany. Aydoğan-Duda and Şener concluded that by establishing similar institutes participating in the production of joint nano-related technologies and in patenting them, the commercialization of nano-related technology will be enabled in Turkey. This dissertation aims to map the social structure of well-established institutes in Turkish universities to investigate the diffusion of nanoscience and nanotechnology at the micro level.

\subsection{RESEARCH PROBLEM}

Although scientometricians use citation analysis to forecast diffusion of knowledge in scientific fields, citation analysis solely does not depict the true domain of knowledge in scientific fields. Bibliometric methods alone do not expose the social structure of the invisible college among scientists (Crane, 1972). Social network analysis was used by scientists to study people from different scientific fields such as anthropologists, psychologists, sociologists and recently physicists and mathematicians in order to measure the communication or diffusion of knowledge in groups, organizations or even countries. Bibliometrics is defined as "the application of mathematical and statistical methods to books and other media of communication" (Pritchard, 1969, pp. 348-349). Citation analysis and co-authorship analysis of diffusion are two methods used by bibliometricians to track temporal and topological diffusion of scientific publications. Moreover, Crane emphasized the social structure of scientists and concluded that 
The existence of social organization could be inferred (a) if scientists who had published in a particular research area had more social ties with one another than with scientists who had not published in the area, and (b) if scientists who had published in the area could be different in terms of degree of social participation within the area, suggesting the existence of leadership in the field (Crane, 1972, p. 335).

Crane argued that the social structure of a group of scientists who work on research activity is instrumental for the diffusion of knowledge. By utilizing diffusion theory and applying the Social Network Analysis (SNA) technique, we will analyze and map the social and cognitive structure of diffusion of nanotechnology in Turkey. We will elaborate in the next section that a mixture of Rogers' theory and formal usage of Social Network Analysis with which we create a compound framework illustrates a sound picture of diffusion of nanotechnology knowledge in Turkey.

In the coming years, nanotechnology will have potentially changed everyone's lives. This will be seen in fields such as biotechnology, ceramics, drugs, polymers and materials technology, all of which are important in our daily lives. Nanotechnology will have a positive impact on the formation and development of these fields.

In the past two decades, many countries have invested heavily in nano-related technologies. The number of scholarly publications in nano-related technologies in North America and in Europe and, more recently in Far Eastern countries has increased. The US government has allocated $\$ 1.74$ billion dollars to nano-related technologies in $2011 .^{2}$ Closer to home, European countries under the $7^{\text {th }}$ Framework Program have also heavily invested in joint projects among its members. Turkey as a developed country has established its strategic plan regarding nano-related research and development. In this respect, universities (research centers), funders and industries play an important role in this evolution. The Triple Helix model proposed by Leydesdorff and Etzkowitz (1998) is a collaborative model between universities, government and industry.

\footnotetext{
${ }^{2}$ http://www.fas.org/sgp/crs/misc/RL34511.pdf
} 
This dissertation investigates the evolution of nano-related technologies as a research field in terms of the social aspects of knowledge diffusion of nanotechnologies between 2000 and 2011 in Turkey. It utilizes bibliometrics, social network methods and co-word analysis to shed light on knowledge production and its diffusion in academia and industry. We used the above-mentioned methods to ascertain whether or not quantitative data responds formally to the diffusion of nano-related technologies in Turkey.

\subsection{CONCEPTUAL MODEL FOR RESEARCH PROBLEM: DIFFUSION OF AN INNOVATION}

In this thesis, we accept nano-related technologies as a wide-ranging area of knowledge. Literature defines "knowledge" as refined and meaningful information or fact to provide answers to specific problems. The diffusion of knowledge may follow different routes. Scientists have investigated the diffusion of knowledge in societies from different perspectives. To explain diffusion of knowledge, Rogers (2003) pioneered and studied the diffusion of innovation in several fields. He argued explicitly that the social interactions between scientific domains and practitioners are instrumental to the diffusion of knowledge. An innovation can manifest itself in different forms or shapes. For example, an innovation may be a new drug, new computer technology, a new mechanical device or even a new fashion style.

Rogers (2003, p.5) defines the diffusion of an innovation as "the process by which an innovation is communicated through certain channels over time among the members of a social system." According to Rogers, the key elements in the diffusion process are: innovation, communication channels, time and social systems. Rogers (2003, p. 7) defined these terms as follows:

An innovation as an idea, practice, or object that is perceived as new by an individual or other unit of adoption... A communication channel is "the means by which messages get from one individual to another"...Time of the innovation-decision period is the length of time required to pass through the innovation-decision process... Rate of adoption is the relative speed with which an innovation is adopted 
by members of a social system... A social system is defined as a set of interrelated units that are engaged in joint problem solving to accomplish a common goal.

Moreover, he concluded that the time and channels, which people use to spread an innovation, are the main factors in its spreading. Rogers categorized the adopter of an innovation as innovators (2.5\%), early adopters (13.5\%), early majority (34\%), late majority (34\%) and laggards (16\%), based on the mathematically based bell curve. Fig. 1 shows a Rogers' diffusion process model.

\section{Rogers Adoption / Innovation Curve}

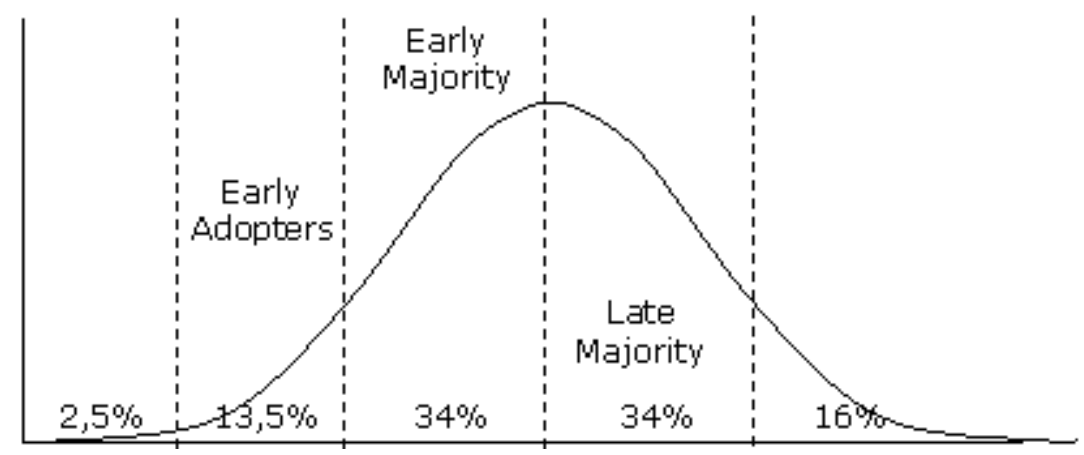

Figure 1. The diffusion of innovations by time according to Rogers Source: http://www.mbaskool.com/business-concepts/marketing-and-strategy-terms/ 1889-innovation-adoption-curve-rogers.html

An innovation starts with a few people and has a few adopters, but eventually it gains the momentum until it reaches its peak. For example, nanotechnology in the mid-1990s was discovered as a research field and it quickly became an important research activity for scientists in a broad scientific field. Rogers' framework enables this dissertation to map the diffusion of nano-related technologies.

From the sociological point of view, Wellman and Berkowitz (1997) argued that the Social Network Analysis is a paradigm in which relational interaction among members signifies the role of people in a network structure. By investigating the social structure (people), especially social relations among members of a group, one can practically expose relations in terms of certain variables (i.e., density, centrality, transitivity, and cluster coefficient). 
Moreover, Emirbayer and Goodwin (1994) stated that network analysis is derived from social theory by which manifests not only its members but also their relational structure. Therefore, by measuring these variables, this dissertation assesses the diffusion of nanorelated technology in Turkey.

So, why is studying a social system so important? People tend to live in a social structure. Scientists work and collaborate in a social system. Assessing social relations among scientists reveals how collaborative they are. Moreover, bibliometric methods have been used as tools to track scientific research. In spite of this, it is difficult for analysts to predict a scientific breakthrough. Conventionally, Derek de Solla Price (1965) studied the scholarly communication process between scientists, thereby opening the door to the quantitative study of science. Indeed, scientific discovery and its evolution has been a challenge for analysts. For example, Chen, Chen, Horowitz, Hou, Liu and Pellegrino (2009) discussed several distinct scientific perspectives: Social Network Analysis, citation analysis, sociological methods, information science and complex network analysis. Furthermore, they argued that scientific discovery comes with a group of specialty, who "attend, read and cite the same body of literature and attend the same conferences" (Chen et al., 2009, p. 192). Furthermore, they argued that co-authorship stimulates the knowledge diffusion in scientific communities.

Crane (1972) studied these groups from the co-citation perspective while Girvan and Newman (2002) examined the network from the co-author perspective. Burt (1992) argued that structural holes in social networks are crucial for connecting clusters in a network structure, resulting in a diffusion of knowledge in the network. According to Burt, structural holes in a social network are disconnected, or poorly connected, areas between tightly and densely connected groups of people. The presence of such structural holes may influence the importance of the positions in a social network. The value of a person in a social network is therefore linked to the potential that person/individual has to establish connections between groups that are separated by structural holes. 
The conceptual model of this thesis is threefold. The model makes use of Rogers' conventional theory of diffusion process as a paradigm. More specifically, it (I) utilizes Social Network Analysis methods in order to map the cognitive structure of nano-related technologies within a social network structure; (II) applies content analysis (co-word) techniques in order to track the structural development of nano-related scientific literature illustrating new research fronts in the network; and (III) further elaborates the process by interviewing nanotechnology scientists as a control unit in the co-authorship network structure. The framework enables us to assess the diffusion of nanotechnology in Turkey between 2000 and 2011.

Social network analysis proposes that relations among its members (Wellman \& Berkowitz, 1997) create social life. According to Freeman (1996), "social networks are formally defined as a set of nodes (or network members) that are tied by one or more types of relations". According to the outcome of the dissertation, the social network of scientists includes properties of the (so-called) "small-world". The term "small-world" was derived from the result(s) of an experiment, which was conducted by Milgram (1967). Milgram proved that an envelope is reached from point A to point B in a well-populated area in 6 steps through acquaintance. Therefore, the "small world" reveals the dynamic structure and cohesion of the network over time. Furthermore Watts (1999) stated that the small world phenomenon should have properties: (1) the network must have more than one member -in real it could be billions; (2) the network is disseminated, that is to say each person is associated to an average of only $\mathrm{k}$ other persons in the network; (3) the network is decentralized, that is to say there are not well connected vertices - a member of the network should be in the network; and (4) the network is made of well-connected clusters. He stated that the above criteria are critical for a network for presence of a small world phenomenon.

Ethnographic method is a qualitative research method in which the ethnographer captures the meaning of social life and presents it graphically or in writing. One can apply one of the ethnographic data gathering techniques to elaborate the social concept of collaboration 
within a structure. Ethnographic method unravels the hidden agenda of interviewees may feel regarding the subject; however, interviewees' responses may not reveal their true feelings about the subject. Therefore, the interviewing responses can be subjective which make it difficult for the researcher to draw specific conclusion. Saville-Troike (2003), states that the ethnographer should apply some sort of quantitative method to generalize his/her qualitative research results. Knowledge in scientific communities is shared through communication (i.e., physical behavior, verbal responses, and communicative speech) which ethnographer should capture. The ethnographer may conduct open-ended or closeended interview by asking questions or collecting data in written formats- in case of nonverbal communication, the ethnographer may elaborate on informants' facial expressions such as raising eyebrows or using body's language (Saville-Troike, 2003).

\subsection{RESEARCH QUESTIONS AND HYPOTHESES}

The aim of this research is to answer the following research questions:

1) What are the key areas of nanotechnology in Turkey? For example, metallurgical, pharmaceuticals, medical devices, high technical industry, and so on.

2) Do co-authorship network structures exhibit a "small world" network structure?

3) How significant is the rate of diffusion of nano-related technology, according to network properties results in two periods: 2000-2005 and 2006-2011?

4) To what extent do scientists share a common vision (behavior) on nanotechnology?

By answering the above questions and by utilizing the diffusion theory framework conceptually, we examine the dissemination of nanoscience and nanotechnology in academia.

This dissertation postulates the following:

- The diffusion of knowledge appears to occur more quickly where scientists have strong positions in the network. 
- The diffusion of innovation occurs stronger within sub-components than that of the whole network.

- Taxonomy identified by co-word analysis in the research process matches the findings at the global level.

Answering the above questions constructs a road map, which depicts not only the diffusion of nano-related technology by means of scientific collaborations but also to some extent assesses the impact of scientific collaborations on scientific outputs in terms of publications in Turkey. We described nanotechnologies and their importance in recent years as an innovation breakthrough and discussed its importance in developed and developing countries. Moreover, we explained the framework of Rogers' theory of diffusion. Rogers's theory expresses that the diffusion of an innovation takes place through a channel of communication. In this thesis, the channel of communication is described as "invisible college" where scientists collaborate on scientific activities.

We studied the diffusion of nanotechnology in Turkey and the collaboration of nanotechnologists by using social network analysis, co-word analysis and interviews. In addition, we compared the similarity of some selected discourses, which were collected from ethnographic interviews by a quantitative method using Latent Semantic Analysis as a text-processing tool.

Rogers' theory of knowledge diffusion was used as a structure by which the conceptual framework of this study is further explained in the next chapter along with literature and the development of nanotechnology in Turkey. 


\section{CHAPTER 2}

\section{LITERATURE REVIEW}

An overview of the methods used in this study is covered and the findings of the related literature are discussed in this chapter along with the related topics. We start with the theoretical foundations of Social Network Analysis and other techniques, followed by mathematical formulas. We discuss the importance of mapping. Finally, ethnographic method and its advantages are covered along with the Latent Semantic Analysis used to analyze research data.

\subsection{SOCIAL NETWORK ANALYSIS AND ITS THEORETICAL BASICS}

Information scientists have studied the growth of science and communication using bibliometrics and Social Network Analysis (SNA) methods. While the former deals mainly with the effects of scientific productivity using citation analysis, the latter mainly focuses on the pattern of relationships among scientists. The network composed of co-authorship among scientists is a true indication of their cooperation in research activity.

According to Wellman and Berkowitz (1997), SNA is a paradigm. Theoretically, it is a premise based on a structured study of human relations. Gestalt theory was instrumental in shaping SNA by sociologists in the early 1920s. Jacob Moreno and Kurt Lewin were the first scientists using SNA in the social sciences. Lewin (1951), who worked on group behavior, argued that a person's attitude or behavior is influenced by his/her position in the social group. In addition, they integrated mathematical formulas from graph theory into SNA. Moreno (1934) used network analysis to show social configurations among school children. Moreover, Milgram (1967) proved that no matter how complex the network structure is, it takes a maximum of six steps from one node 
(person) in a social network structure for a message to be passed along to another node. Combining social theory and mathematics (graph theory), SNA has become a potentially promising tool for psychologists, and anthropologists, among others, to study organizational settings. Their work stimulated other scientists to follow up, incorporating application of SNA in their research (Cartwright \& Harary, 1977). Watts and Strogatz (1998) in their seminal paper proved formally that the six degree separation exists between each node in a complex network. A network consists of nodes and ties, or links connecting nodes. By analyzing the relationships between set(s) of nodes or a subgroup of nodes and their ties in the social group, information scientists measure the social structure of scientists. According to Freeman (2004), SNA can be viewed as:

- Being motivated by a structural intuition based on ties linking social actors;

- Being grounded in systematic empirical data;

- Drawing heavily on graphic imagery; and

- Relying on the use of mathematical and/or computational methods.

\subsection{THE "SMALL WORLD" PHENOMENON}

The "small world" phenomenon conjectures that each member in a society is linked through friends. Literally, every node in a small world is connected through an acquaintance. Why is the small world effect so important?

According to Newman (2000), the spread of news, rumors, jokes from one place to other places over a social network in which the average degree of separation is six. The spread of disease also occurs by person-to-person contact; therefore, the structure of networks of such contacts has a huge impact on the nature of epidemics, for example, the spread of HIV or flu in social structure. Hence, we can say that the small world phenomenon emulates the diffusion of news, an innovation or knowledge. The small world should have four properties: sparseness, clustered, traversable and egocentrics (i.e., star network). He 
studied and found out that average distance from one person to another person by an acquaintance is proportional to size of the community logarithmically which implies one of the small world properties. Moreover, he found out that to traverse between two randomly selected nodes takes an average of six steps. The longest line between two nodes is called radius of the network. The small world effect is a phenomenon that has been studied by scientists in different fields.

In social contexts, Moody (2004) analyzed the structure of a social science collaboration network over a period. He discovered that collaboration between graduate students in a specific topic creates a small world of scientists, which remove restrictions between them. Small world networks may manifest themselves in several shapes and models. Therefore, a good understanding of small world models helps us understand network characteristics. For example, according to Watts (2003) a social network can be categorized as active or passive. Granovetter (1974) studied former one in the perspective of finding a job, and by Burt (1992) as social capital, which preludes the "rich get richer" phenomenon. In this study, co-authorship network of structure is represented in a passive sense where the nodes and the edges connecting them are treated as actors and their relationships.

One can model the small world as a random graph. A random graph may be defined as $N$ people in the world, and on average, they each have $z$ acquaintances. This means that there are connections between people in the entire population. The number $z$ is called the coordination number of the network. We can make a very simple model of a social network by taking $N$ dots ("nodes" or "vertices") and drawing $N \times z$ lines ("edges") between them by randomly choosing pairs to represent these connections. Such a network is called a random graph (Newman, 2000, p. 407). On the other hand, in a scale-free model, each actor (node) with a high degree (i.e., star node) in the network is connected to another node which does not necessarily have a high degree. This approach leads to the star network. Moreover, the degree distribution of a node in a co-operative scientific network adheres to the power law (Fig. 2). 


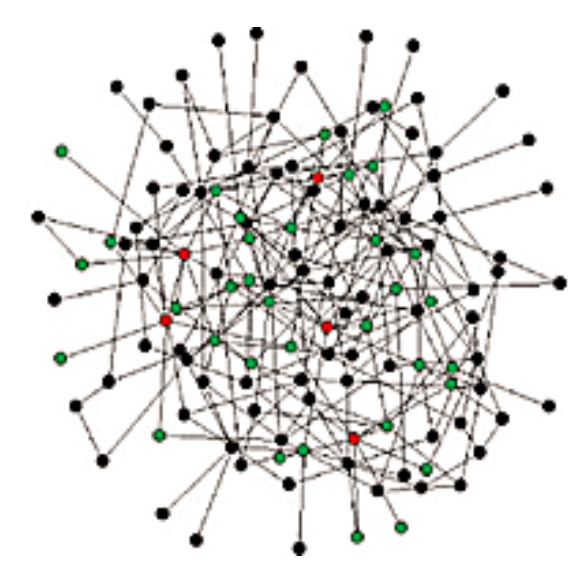

Figure 2. (a) Random graph network,

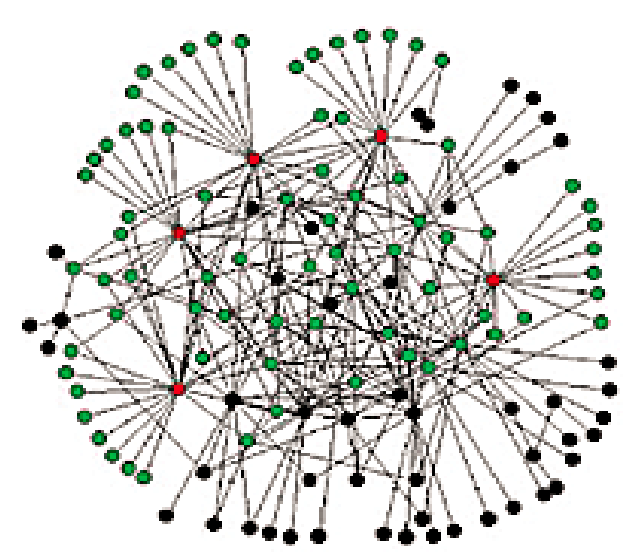

(b) Scale-free network

Moreover, degree centrality can be defined in two ways: in-degree, out-degree centrality. Whereas in-degree means the number of links a node can have coming to it, out-degree means the number of links going out of the node. The former is known as an influential node in the network, but the latter is interpreted as a popular node. Small-world models are comprised of clusters or components. Clusters embedded in a network structure reveal a property that scientists have defined as a clustering coefficient. According to Watts and Strogatz (1998), one can define a clustering coefficient $C$, which is the average fraction of pairs of neighbors of a node which are also neighbors. Meaning, if node $A$ neighbors with node $B$ and $B$ is a neighbor to node $C$, there is a probability that node $A$ is a neighbor to node $C$. The clustering coefficient is calculated by:

$$
\mathrm{C}=\text { (number of triangles connected in the graph }) \div(\text { number of triples center in the graph) }
$$

Wasserman and Faust (1994, p. 243) call the above method transitivity. Centrality of a network is another important property of social structures. The degree of a node (vertex) in the network is the total number of other nodes to which it is connected (Girvan \& Newman, 2002). Otte and Rousseau (2002, p. 443) define centrality, closeness and betweenness thus: 
(1) Degree centrality is equal to the number of connections that an actor (i.e., a node) has with other actors; (2) Closeness takes the structural position of the actors in the whole network into account. A high closeness for an actor means that he or she is related to all others through a small number of paths; (3) Betweenness measures the number of shortest paths passing through an actor.

Betweenness centrality plays an important role in the structures of the social network. One can describe betweenness centrality as a pivotal point in the network structure. According to Freeman (2004), the discovery of the structural properties of scientific papers is measured by the betweenness centrality. Actors with a high level of betweenness centrality play pivotal role in connecting different groups. One can say that betweenness centrality characterizes preferential attachment, cliques, or brokers. As Barabasi and Albert (1999, p. 509) state, "preferential attachment play an important role in network development." In other words, people in social networks tend to work with well-known people that lead to the concept of "strong and weak ties", meaning the group of people who are attached to one node with high centrality. According to Moody (2004) and Scott (2000), such a network model is a star network.

Newman (2000) stated that collaboration among scientists in networks is a good example of showing preferential attachment. As mentioned earlier, if a node has a higher degree, there is a higher probability of being acquainted if they share a mutual friend. The former conjecture may precisely result in the power square law such as Lotka's law, where only $20 \%$ of people in the social network are well connected and the remaining $80 \%$ people in a social network are loosely connected. Martin, Ball, Karrer, Newman ${ }^{3}$ reiterated the authorship productivity resembles Lotka's square law in the network. Mathematically, the Lotka's square law is defined as:

$$
f(x)=a x^{k}
$$

where $a$ is constant and $k$ is 1 or 2 .

\footnotetext{
${ }^{3}$ Retrieved from http://arxiv.org/abs/1304.0473
} 
Each group creates a community in which a node with a high degree of centrality is the central node. Therefore, collaboration networks consist of separate clusters representing different scientific fields where they may connect through lower degree connectors. Newman (2000) referred to clustering as "community structure". Each community comprises several star networks and these clusters may be connected by a node of lesser degree. Moreover, PageRank is a metric that was introduced first by Page and Brin (1989) which measures the popularity of web page. In the thesis, it reflects the prestige of a scientist in network structure.

\subsection{THE DIFFUSION OF INNOVATIONS}

Rogers studied the diffusion of new agricultural methods of farmers in Ohio, USA, in 1960. For example, he discussed the diffusion of hybrid corn seed in order to find a solution to the famine in Ohio in 1936 in his seminal book The Diffusion of Innovations (2003) which was the most-cited book in the social sciences. As mentioned in Chapter 1, according to Rogers' model, the innovation process passes through several levels: innovators, communication channels (i.e., early adopters, late adopters), time, and social system(s).

Valente $(1995,1996)$ described several network models for the diffusion of innovations. He argued that each of the thresholds formed by clusters within a network as a (set of) focal points which are instrumental to the diffusion of innovations. According to Valente (1996), a/the social network thresholds coefficient indicates the diffusion of innovation in a knowledge domain. He was (particularly) concerned about the behavioral aspect of the diffusion of innovation between social networks, especially in health oriented organizations. He argued that the diffusion of innovation is based on some early adopters with a higher threshold in the network structure; that is to say, some proportions of the social system facilitate the early adopters in the diffusion of innovation. 
Many articles on the diffusion of information (knowledge) have focused on the social context(s) of organizational settings. For example, Özel (2010) assessed the diffusion of knowledge in business management among academia in Turkey. He calculated the coauthorship relationships of those members of academia in business management from 1928 to 2010. Milojević (2009) studied the diffusion of nano-related technologies using SNA techniques and mapped the evolution and socio-cognitive structure of nanoscience/nanotechnology in the United States. Lievrouw, Rogers, Lowe and Nadel (1987) studied the "invisible college" of health system using triangulation methods: network analysis, citation analysis and survey. Zuccala (2004) applied same methods to study the "invisible college" in the Singularity Theory community in Mathematics. Our aim is to map the diffusion of nano-related technologies from social network perspectives.

\subsection{THE GRAPH THEORY}

Information scientists employ graph theory to investigate network structure quantitatively and to model its organization. As pointed out earlier, Social Network Analysis (SNA) is based on graph theory. In SNA, nodes can be represented as a set and each set may contain subsets. Symbolically, the notation for a graph can be written $G(V, E) . G(V)$ describes the number of nodes or vertices in the graph, whereas $G(E)$ illustrates the number of links (e.g., edges or arcs) in the graph. A graph may be directed (Fig. 3a) or undirected (Fig. 3b). In an undirected graph, the link direction between the two nodes is not necessarily important whereas in a directed graph there are reciprocal relationships between nodes. According to Wasserman and Faust (1994), the most fundamental type of relationship between nodes is the dyadic relationship. More complex relationships include triads, cliques, subgroups, groups, positions, and clusters. Relations are generally plotted according to three parameters: direction, strength, and content. 


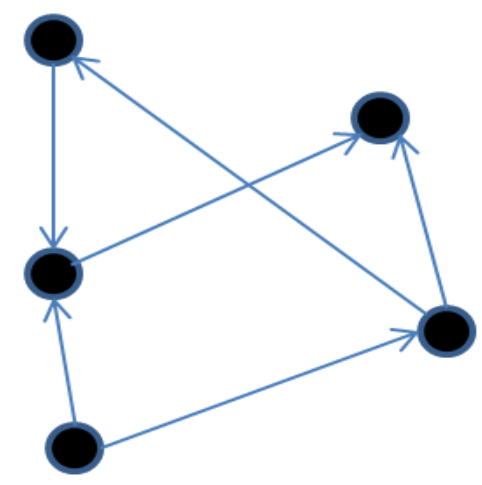

(a)

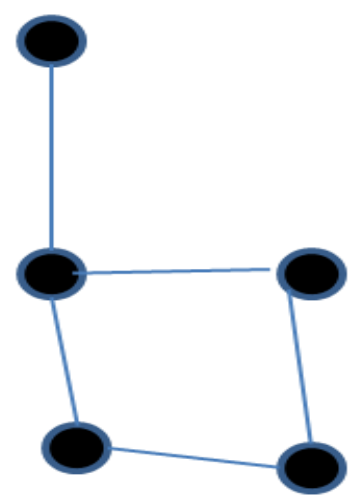

(b)

Figure 3. (a) Directed Graph,

(b) Undirected graph

A node may have a relation tie with another node or be null; a node may have a directed relation or undirected relation with another node. Co-author relationship is an example of undirected graph. For example, Figure 4 below depicts a graph with 6 vertices and 6 edges. Its structural properties are defined as vertices and edges where vertex set $V=\{a, b, c, d, e, f\}$ and edge set $E=\{(a, b),(b, c),(c, d),(c, e),(d, e),(e, f)\}$. We can draw the Fig. 4 graph as $\mathrm{n}$ x $\mathrm{n}$ matrix, as shown below:

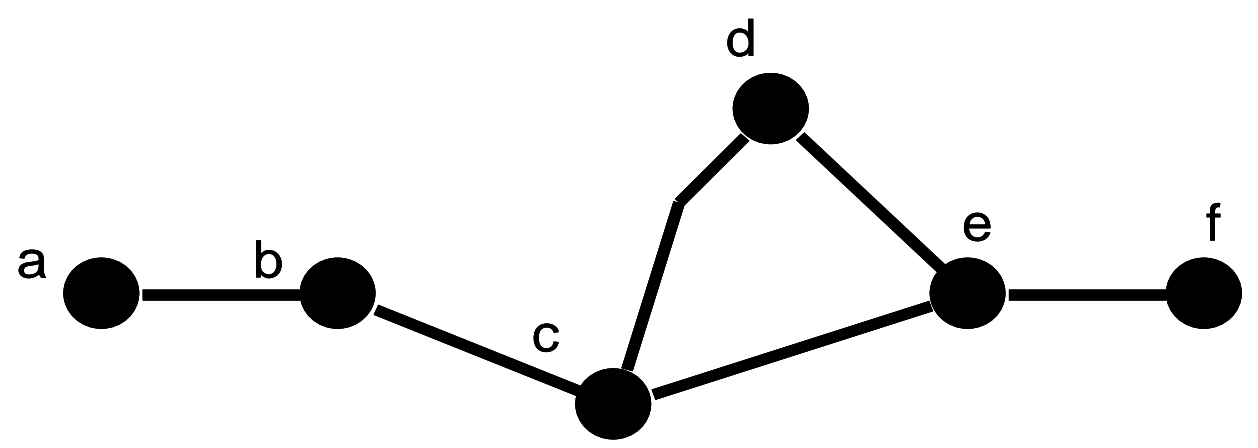

Figure 4. Illustration of an incomplete graph 
Table 1. Matrix presentation of the incomplete graph depicted in Figure 4

\begin{tabular}{lllllll}
\hline & $\mathrm{a}$ & $\mathrm{b}$ & $\mathrm{c}$ & $\mathrm{d}$ & $\mathrm{e}$ & $\mathrm{f}$ \\
\hline $\mathrm{a}$ & 0 & 1 & 0 & 0 & 0 & 0 \\
$\mathrm{~b}$ & 1 & 0 & 1 & 0 & 0 & 0 \\
$\mathrm{c}$ & 0 & 1 & 0 & 1 & 1 & 0 \\
$\mathrm{~d}$ & 0 & 0 & 1 & 0 & 1 & 0 \\
$\mathrm{e}$ & 0 & 0 & 1 & 1 & 0 & 1 \\
$\mathrm{f}$ & 0 & 0 & 0 & 0 & 1 & 0 \\
\hline
\end{tabular}

Node $a$ is adjacent to node $b$, and node $b$ to node $c$. Not all nodes are adjacent to each other. If a graph contains nodes that all vertices are adjacent to each other, then it is a complete graph (Table 1).

Fig. 4 is not a complete graph since not all nodes are connected to each other. The density of the graph in Fig. 4 is calculated with 6 nodes the density of the graph is $6 / 15=0.40$. A clique is a subset of individuals in which every person is connected to every other person. For example, nodes $d, c$, and $e$ are all connected to each other. A clique is a maximal complete sub graph. A complete sub graph of $G$ is a section of $G$ that is complete (i.e., density = 1). Cliques have been seen as a means to represent what social scientists have called primary groups or ego centric groups. Prestige measures the reputations within social networks and applies only to the networks comprising directed graphs. While not every vertex in the graph in Fig. 4 is adjacent to each other, one can construct a sequence of adjacent vertices from any vertex to any other. Graphs with this property are designated completely connected. Similarly, any pair of vertices between which one vertex can reach the other via a sequence of adjacent vertices is called reachable. 


\subsection{CO-WORD ANALYSIS: MAPPING THE COGNITIVE STRUCTURE OF NANO-RELATED TECHNOLOGIES}

In the last two decades, the number of publications in many scientific fields has grown dramatically. In recent years, due to the advancement in computer technologies, the amount of information generated in multi- or interdisciplinary research fields has likewise increased. In order to study the scientific trends in a broad variety of multidisciplinary fields, information scientists have created new techniques such as co-word analysis. Coword analysis of texts helps map scientific fields and reveals the cognitive structure of the scientific domain (Chen, 2004). Callon, Courtial, Turner, and Bauin (1983) applied the coword analysis onto literature over time by analyzing the frequencies or co-occurrences of words in titles, abstracts, or generally in text.

\subsection{NANOTECHNOLOGY DEVELOPMENT IN TURKEY}

Assessing the productivity of science is a major and difficult task for policy-makers. Measuring scientific output is an important issue for governments around the world due to the fact of the necessity for governments to allocate funds properly. Bibliometrics is used to analyze the productivity of science and technology quantitatively. Although Turkey has a national plan promoting nano-related technologies through university funding and the private sector, the outcome of this plan has yet to be assessed. For example, AydoğanDuda (2012b) has edited a book in which there are examples of developing countries' investment in nano- related technology. She discusses that Turkey intended to approach nanotechnology development in context of management in developing countries (Aydoğan-Duda, 2012a; 2012b).

One can measure scientific output merely by calculating the number of researchers and scientific outputs in terms of the number of publications. However, it is not clear whether scientific output has had any impact on economic growth in the country. Furthermore, Motoyama and Eisler (2011) argued that by calculating the number of publications divided 
by the number of researchers and resources invested on nanotechnology shows more accurate results in terms of scientific output. In addition, one may even use non-parametric (percentile) statistics to measure citations of journal publications of nano-related technologies (Leydesdorff \& Welbers 2011).

The first detailed "Turkish Science Policy: 1983-2003" was published in 1983 -the first report that created the groundwork that led to the "Vision 2013 Project". The Supreme Council of Science and Technology (SCST) has been vigorously supervising scientific activities in Turkey since the mid-1990s, thus shifting Turkey's science policy from "building a national R\&D infrastructure" to "innovation-oriented national policies" (Uzun, 2006). Moreover, the Ministry of Science, Industry and Technology oversees the scientific development in Turkey. TÜBİTAK systematically supports research and development in universities especially for institutes which take part in research and innovation. It was stated previously that the United Nations has declared nanotechnology as the biggest breakthrough in science in years to come. So, what is so significant about nanotechnology and nanoscience which has gained the attention of scientific communities and industries?

Nanotechnology is not a new idea. It was first introduced by Feynman (1960), who started a road map for nanotechnology/nanoscience research activity. According to Thompson Reuters' Web of Science (WoS), the first article containing the phrase "nano" in its title was published in 1988 in Turkey. Since then, the number of scientific articles increased tremendously. Some 500 scientific papers were published alone in 2009, generating a total of 4500 citations. It is clear that nanotechnology has become a major field of research in Turkey. As Özbay, a scientist at the Nanotechnology Research Center (NANOTAM) at Bilkent University, Ankara, Turkey, has authored several nanotechnology related papers. In addition, he is the guest editor of the Science Magazine. Along with TÜBITTAK, the Ministry of Development is one of the governmental bodies which financially support nanotechnology projects. For example, the Ministry of Development has established The National Research Center for Nanotechnology on the Bilkent University campus. As of 2008, the Ministry of Development has invested a total of 58 million TL in two phases to 
improve the infrastructure of the research facility. The center will act as a hub promoting nanotechnology in Turkey. NANOTAM is another research center at Bilkent University (not supported by the Ministry of Development directly) that collaborates with the industry. Both institutes have published a substantial quantity of scientific papers. There are 178 nanotechnology related files with patents pending at the Turkish Patent Institute (TPE) and a few patents are filed at the US Patents Office which has been filed by research associates from both research centers. Since 2000, Turkey's road map for nanotechnology has been set by combining two important elements: research and finance. Nanotechnology is one of the strategic fields of research and technology mentioned in the new vision 2023 for science and technology for Turkey prepared by the Supreme Council of Science and Technology. According to SCST, only $0.80 \%$ of the gross national product (GNP) was allocated for research and development. In their annual plans (2007-2010), the Ministry of Development supported several nanotechnology-related projects carried out by research institutes such as Marmara Research Center and Gebze Institute of Technology and several universities.

\subsection{GROWTH AND DIFFUSION OF NANOTECHNOLOGY AT THE GLOBAL LEVEL}

Robert Solow, a Nobel Prize winning economist, formulated a theory that postulated the impact of technological development on innovation back in 1950 (Garfield, 1988). Recently, however, economists argue that a greater number of factors influence economic growth, other than technology. For example, funding and the quality of researchers are considered to be two of the more important elements providing an economic impact. Another theory that endorses direct manipulation of research and development by government is Endogenous Theory. The policies of governments directly shape research activities by investing in research and development that result in (material) goods and products or scientific publications.

In a global perspective, Kostoff, Stump, Johnson, Murday, Lau and Tolls (2006) investigated the development and infrastructure of the nano-related technology in the 
world by studying the global literature. China, Far Eastern countries and USA, Germany, and France were selected the most productive countries in terms of number of publications. Nano-related literature, prolific authors, journals, institutions and most cited authors/papers/journals were analyzed by Kostoff et al. (2006) to measure the development of nanotechnology in the world globally. In addition, a text mining was done on records to properly retrieve records from Science Citation Index (SCI) and Social Science Citation Index (SSCI). For example, most nano-related technology papers were appeared in Science: Physics, Chemistry and Material and Surface. A literature research overview was done by Kostoff, Koytcheff and Lau (2007) using a text query. It was found that Turkey's appearances become evident in nanotechnology development at the global level since 2002.

\subsection{MAPPING THE DIFFUSION OF THE KNOWLEDGE}

Derek de Solla Price paved the way for scientific visualization in his seminal work entitled "Networks of Scientific Papers" by utilizing the bibliographic data of journals (Price, 1965). Later, White and McCain (1998) studied and mapped the scientific domain through conventional methods. However, refining an immense set of bibliographic data manually was a cumbersome task. Börner, Chen and Boyack (2003) explained the mapping techniques thoroughly from historical, developmental and mathematical perspectives. Mapping of science has been a method for discoveries of new trends or cognitive development of scientific endeavors. According to Leydesdorff and Persson (2010), one way to investigate the diffusion of an innovation and to study the spatial dynamics of science discoveries is the geographical mapping of cities. Geographical mapping of cities shows scientists working on nano-related technology, depicting a better picture of collaboration on both national and international levels. Using Google Maps, Leydesdorff and Persson (2010) mapped the cities in which information science (IS) journals were published. The co-authorship network of cities is a testimonial of social network properties such as the "small world" effects in science. 
From a geographical perspective, the well-known institutes (centers) will tend to work with other leading institutes (Leydesdorff \& Rafols, 2009). In terms of social and organizational distances, the map shows the diffusion of nano-related technology between centers in each country. The co-authorship networks between cities provide us with consecutive matrices for each year. These networks can be compared in terms of density, largest components, degree distribution, and clustering coefficient using standard software for Social Network Analysis such as Pajek ${ }^{4}$ and Gephi. ${ }^{5}$ Our main questions (in this geographical dimension) are: do patterns of diffusion change and how does this show in the development of various network parameters? What types of networks emerge? When does a network stabilize, and how?

Hence, the geographical diffusion of nano-related technologies by Turkish scientists locally and internationally and by their counterparts defines the globalization of the scientific field using Social Network Analysis.

\subsection{OVERLAY MAPS}

Scientometricians use visualizations in addition to other indicators to track or investigate new scientific developments over time. However, sometimes it is difficult to track scientific research fields within a map of science. Rafols, Porter and Leydesdorff (2010) introduced a novel approach to illustrate bodies of research precisely surrounded by global scientific domains. They stated that

maps position units in a network instead of ranking them on a list. Maps allow for the representation of diverse and large sets of data in a succinct manner. They make it possible to combine different types of data... (Rafols et al., 2010).

Science overlay maps "help benchmark, explore collaborations, and track temporal changes" (Rafols et al., 2010, p. 1871).

\footnotetext{
${ }^{4}$ Pajek was developed by Vladimir Batagelj and Andrej Mrvar both in University of Ljubljana in Slovenia. ${ }^{5} \mathrm{Gephi}$ is an open source software, leader in the visualization and analysis of large networks in real time developed by consortium.
} 
Rafols et al. (2010) mapped the scientific fields based on the citation similarities between ISI Subject Categories (SC). For example, Figure 5 below illustrates a global base map based on 224 ISI Subject Categories created by Pajek.

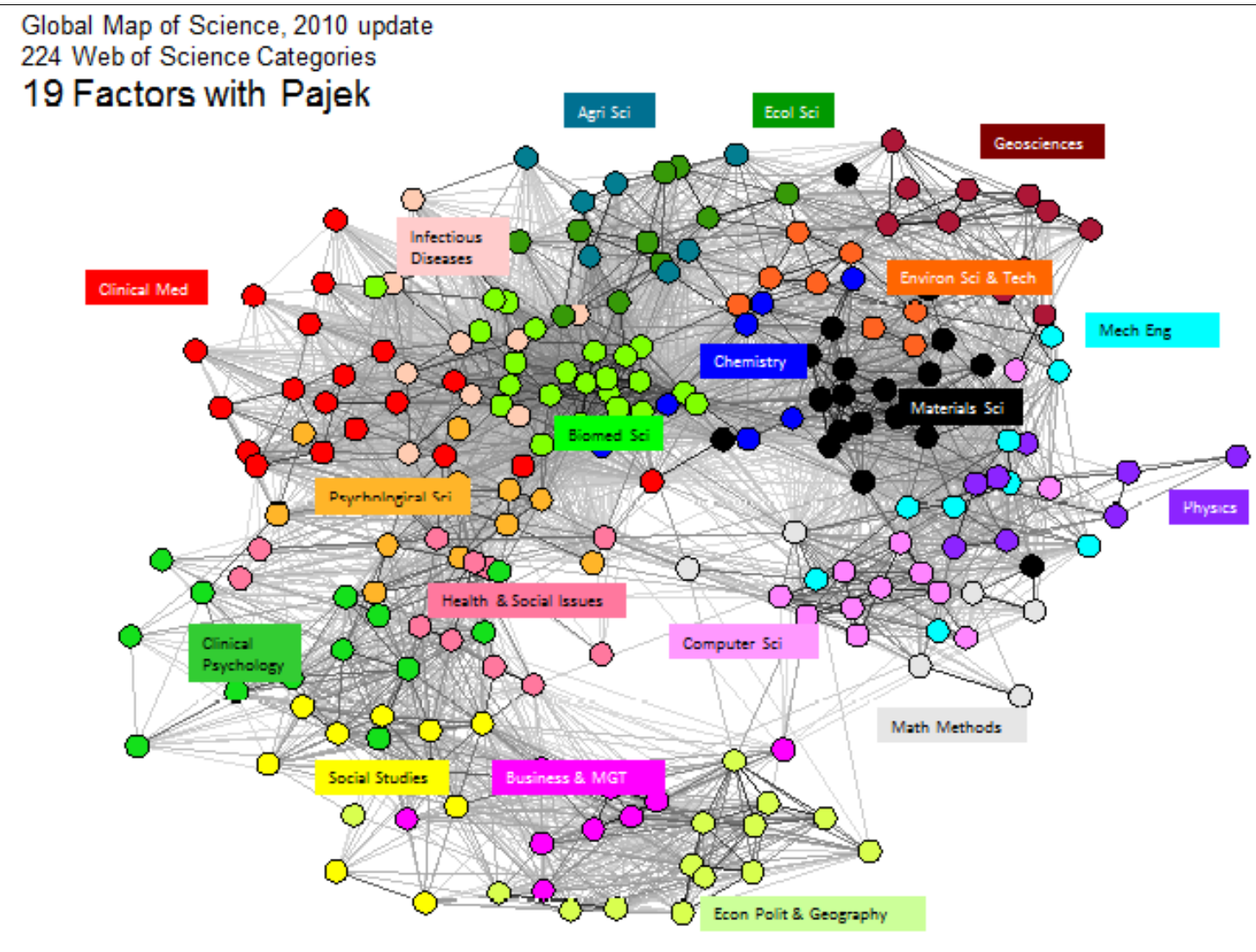

224 Web of Science Categories

Figure 5. Global map of science based on ISI subject categories

Note: Figure is adopted from Rafols, Porter and Leydesdorff (2010)

Overlay maps comprise the elements of a network: authors, publications and scientific topics, to name three. Therefore, one can see the associations between the components in the cluster. As stated in the previous section, the advent of technology, especially in computer science, has assisted scientists to accomplish better maps. 


\subsection{ETHNOGRAPHIC METHOD: LATENT SEMANTIC ANALYSIS APPROACH}

The term "ethnographic" is derived from the Greek roots ethno=folk and grapho to write. Sociologists apply ethnographic methods to justify their quantitative research results. Normally, social scientists and anthropologists employ ethnographic methods such as interviewing or observing the sample data. For example, sample data may be an organization or a tribe in remote areas in a country. An in-depth interview reveals the interest of interviewees in the subject problem.

According to Kuhn, scientific communities create knowledge, the state of which is shaped by a "paradigm". The term "paradigm" is defined as "universally recognized scientific achievements that, for a time, provide model problems and solutions for a community of researchers" (Kuhn, 1970, p.123). Subsequently, Foucault argued that knowledge is power that is represented by a discourse. In simple terms, discourse is a conversation among a group of people in a society (Fulcher, 2005).

As mentioned earlier, a discourse is representation of knowledge in forms of communication. For example, one can consider nanotechnology as the knowledge domain in which scientists discuss or solve particular nano-related issues. Leydesdorff (2001) argued in his book that "world of science" can be described using three dimensions: scientists, texts and cognitions. He also emphasizes language usage coherently in describing our scientific world that is a phenomenon at various levels of aggregation.

According to Leydesdorff and Welbers (2011), semantics measured in two ways: similarity patterns (correlations) and latent variables (factor analysis). One example is latent semantic analysis (LSA), which was invented by Deerwester, Furnas, Harshman, Landauer, Lochbaum, and Streeter. It utilizes the singular value decomposition (SDV) technique to create a mathematical representation of the relationship of words or text in a passage based upon a semantic space (Landauer, Foltz, \& Laham 1998, as cited in Tonta \& Darvish, 2010). 
It is not a traditional natural language processing or artificial intelligence program, as it uses no humanly constructed dictionary, knowledge bases, semantic networks, grammars, syntactic parsers, or morphologies. In other words, SDV is a factorization technique that reduces a matrix to three smaller matrices in which each element in the matrix represents in one's research- contextual meaning of words and their semantic relationships based on large quantities of text ${ }^{6}$ (Fig. 6).

The following relies on Dumais: ${ }^{7}$ consider a rectangular $\mathrm{t} x p$ matrix of terms and passages, $X$. Any rectangular matrix can be decomposed into the product of three other matrices using the singular value decomposition. Thus,

$$
X=W * S * P^{T}
$$

where $\mathrm{W}$ is a $\mathrm{w} \times \mathrm{m}$ matrix with orthonormal columns (i.e., the columns are mutually perpendicular vectors each of which sums to unity), $S$ is an $m \times m$ diagonal matrix with its entries sorted in decreasing order, $\mathrm{P}$ is an $\mathrm{m} \times \mathrm{p}$ matrix with orthonormal columns, $\mathrm{T}$ is a transpose of $\mathrm{P}$.

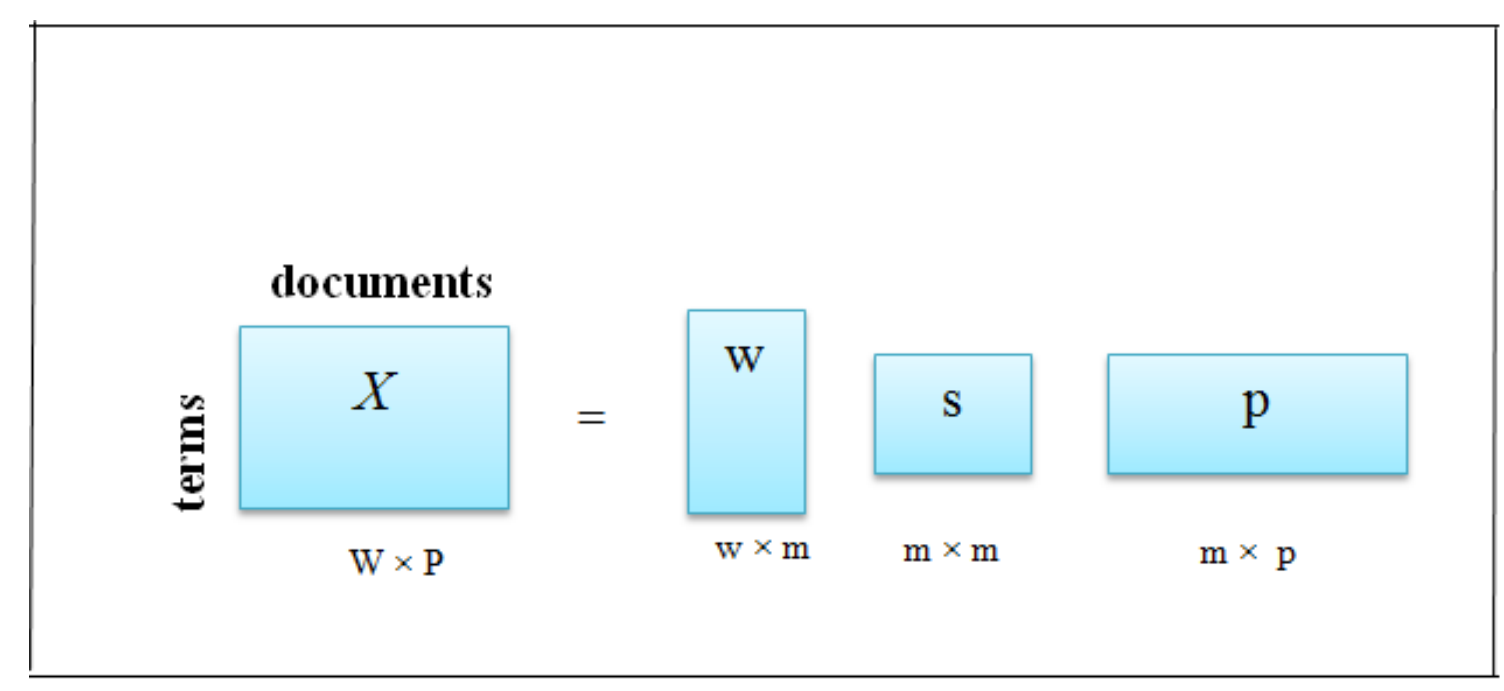

Figure 6. Representation of matrix reduction in using Singular Value Decomposition

\footnotetext{
${ }^{6} \mathrm{http}: / /$ lsa.colorado.edu/papers/dp1.LSAintro.pdf

${ }^{7}$ http://www.scholarpedia.org/article/Latent_semantic_analysis
} 
Moreover, LSA overcomes the problem of synonymy and polysemy problems in information retrieval by capturing the latent semantic relations between terms (Deerwester et al., 1990; Landauer, Foltz, \& Laham, 1998). ${ }^{8}$ LSA compares one script to the other on the same subject even though two scripts may not necessarily have any words in common. For example, William (2012) used LSA to test the reading comprehension of a passage by group of participants using a survey. Moreover, LSA was used as an application to analyze open-ended responses in an epidemiologic survey study (Leleu et al., 2011).

Ethnographic methods were used to gather unstructured data from Turkish nanotechnology scientists through structured interviews and the similarity of what they said was analyzed by using LSA.

\subsection{SUMMARY}

In this chapter, we explained the historical development of Social Network Analysis, followed by a brief introduction of graph theory underpinning SNA and co-word analysis. We described the network structure and its properties; the small-world experience and Rogers' diffusion of innovation, Moreover, we discussed the role of overlay maps and mapping tools in investigating the cognitive structure of institutions. Network centrality was to track and identify most productive countries in terms of bibliographic data which reveals the diffusion of nanotechnology development. We approached ethnographic methods in terms of discourse analysis and briefly introduced Latent Semantic Analysis, and then its usage in scientific researches. To some extent, literature on nanotechnology was reviewed.

\footnotetext{
${ }^{8}$ For more information on LSA, see http://lsa.colorado.edu.
} 


\section{CHAPTER 3}

\section{RESEARCH METHOD AND DATA PROCESSING}

The aim of this research is to assess the diffusion of nano-related technology by mapping of collaborative social structure of scientists in Turkey between 2000 and 2011. Using Rogers' diffusion model as a conceptual model, we attempt to answer the following research questions:

1) What are the key areas of nanotechnology in Turkey? For example, metallurgical, pharmaceuticals, medical devices, high technical industry, and so on.

2) Do co-authorship network structures exhibit a "small world" network structure?

3) How significant is the rate of diffusion of nano-related technology according to network properties results in two periods: 2000-2005 and 2006-2011?

4) To what extent do scientists share a common vision (behavior) on nanotechnology?

In order to answer research questions, we used a compound textual query on nanotechnology modified from Kostoff's ${ }^{9}$ (see Appendix A) and searched the Web of Science (WoS) in two periods: 2000-2005 and 2006-2011. We retrieved a total record of 2664 (articles and reviews) on nanotechnology from 2000 to 2005 and 7398 from 2006 to $2011^{10}$ in which each record contains at least one (1) address of a Turkish university. We calculated and analyzed records in order to assess the diffusion of nano-related technology in Turkey. We illustrated the total number of scientific publications and nano-related technology technologies using column bar graphs. Next paragraphs define a road map describing the thesis' explanatory approach.

\footnotetext{
${ }^{9}$ Personal communication with Prof. Kostoff 20 April 2012.

${ }^{10}$ Data were extracted in November 2013 from WoS.
} 


\subsection{SOCIAL NETWORK ANALYSIS: STATISTICAL RESULTS}

We used overlay maps to capture collaborations in network structures. VOSviewer was used to implement the method of associative strength, which clusters bibliometric data based on their similarities to map network structure. We used the above techniques to overlay the interactions among journals, cities, people or addresses on a geographic map as well.

A geocoder located at "http://www.gpsvisualizer.com/geocoder/" was used to get the geocoordinates for each city whereas Google Maps was used to overlay the relationships among cities on a geographic map.

Bibexcel was used to create a list of related cities' frequency from the records by feeding the list onto the web page mentioned above in order to retrieve the Geo-coordinates of the cities, and to calculate the most frequent collaborators from selected universities in the thesis. Moreover, Bibexcel was utilized to create a co-authorship map based on the most frequent first authors, and all authors from WoS and Scopus, respectively. We take an explanatory approach for universities in terms of the number of nano-related publications using overlay maps. We divided universities based on two periods. The top rank universities were selected based on their degree centralities in terms of scientific collaboration on nano-related technology. Additionally, we acknowledged scholars whose publications accelerate the diffusion process, as prolific authors. Gephi (see https://gephi.org/) was used to calculate the properties of the social network structure, for example, the centrality (betweenness, closeness, degree \& PageRank) of each node in the social network structure, but also Gephi was used to depict the network's features visually. PageRank metric was used to track the significant and prestigious nodes in a network structure. Co-word analysis and factor analysis were used to track the cognitive development in social network analysis through years. ${ }^{11}$

\footnotetext{
${ }^{11}$ The co-word analysis was conducted based on software: http://www.leydesdorff.net/software/fulltext/index.htm
} 


\subsection{ETHNOGRAPHIC INTERVIEWS}

First, we informed the scientists formally to read the purpose of our study and sign the consent form (see Appendix B). We collected and conducted a qualitative research by interviewing the senior and junior scientists. Scientists whose research activities span more than 20 years were considered seniors whereas the rest were considered juniors. During an interview while the junior scientists were asked structured questions (Appendix C) while senior ones were asked semi-structured open-ended questions (see Appendix D). The main reason that senior scientists were presented with semi-structured questions was their positional and relational structure in the social network: we were interested in their opinion on nanotechnology - past and future. Although we constructed questions in a semistructured manner for senior scientists, we also examined the hidden meaning in the discourse collected from junior scientists, which reveals the semantic aspect of the words in the discourse provided by several scientists. Furthermore, in the ethnographic inquiry section, the relationship latency of each scientist's (juniors) written replies has been examined since their positional and relational perspective on the network is in a state of shaping.

In this respect, we collected data from 10 interviewees who are key scientists: five seniors, five juniors and their nano-related research activities through live interviews and an online survey (only junior scientists were surveyed online). Results compiled from juniors incubate a prototype, which may indicate their thoughts regarding co-authorship network structure. In other words, from a linguistic point of view, we analyzed the documented sources collected during the interviewing process from some key scientists in the social network structure. 


\subsection{LATENT SEMANTIC ANALYSIS APPROACH}

We used Latent Semantic Analysis method (http://lsa.colorado.edu) to find the similarity between documents (scripts of interview) compiled from interviewees. For example, junior scientists were asked structured questions regarding the co-authorship graph (Where would you like to see yourself in this social structure map?) or regarding the nanotechnology (When did you hear the term nano in your subject study?).

In addition, we captured and elaborated on the scientists' response (seniors and juniors) to her/his co-authorship map of nano-related technology. Semi-structured interviews were carried out with scientists who are central in their research clusters or had participated in research activities. Then, their verbal reaction was recorded by the researcher regarding the co-authorship map of the social network in their university which was represented to them during personal interviews. Thus, the semantic meaning sometimes hidden in the interviewees' words can be revealed. Studying scientists' reactions to an image facilitated better communication in discourse. The image (snapshot) of the map of co-authorships among scientists elicited specific utterances from each person which we used for further analysis. Seniors' responses were elaborated upon and scripted by the researcher. Their responses were analyzed by one of the latent semantic analysis methods called "one to many" sentences located at "http://lsa.colorado.edu" with a topic space in "Generalreading_up_to_1 ${ }^{\text {st }}$ _year_college (300)" to capture their similarities.

\subsection{SUMMARY}

We utilized a text query to extract the records in nano-related technology from WoS in Turkey. Gephi was used to analyze statistical data; VOSviewer was used to map the cocitation maps and Microsoft Excel to draw figures and Google-Maps to overlay the network structure on the map. We chose to apply a qualitative method by conducting ethnographic interviews with junior and senior scientists. Senior scientists were subjected to semi-structured interviews while junior scientists answered structured questions. Latent semantic analysis method was used to capture the similarity of sentences in vector space 
among junior scientists. In the next chapter, we present the findings of our study and discuss their implications. 


\section{CHAPTER 4}

\section{FINDINGS}

\subsection{GOVERNMENT AGENCIES' SUPPORT}

As pointed out earlier, mainly two governmental bodies, TÜBİTAK and the Ministry of Development (MoD) have been supporting research in Turkey. Since 2005, TÜBİTAK has especially invested heavily in research and development in universities. In other words, TÜBİTAK mostly provides funds for specific nano-related research projects which may lead to scientific publications or patent submissions, whereas (MoD) mostly provides funds for infrastructure development. For example, during the period 2000 to 2005, most funds were spent on buildings and laboratories. Moreover, MoD has conventionally been investing in infrastructural development of institutes in which nanorelated technology research has been carried out. UNAM (National Institute of Material Science \& Nanotechnology) participates in the Clean Room Technology project with the support of MoD. Istanbul Technical University (ITU) and Gebze Institute of Technology have been actively involved in nano-related projects since 2005 .

Turkey's scientific publications in nano-related technologies increased from 215 articles in 2000 to 1748 articles in 2011, more than an eight-fold increase (Fig. 7). 


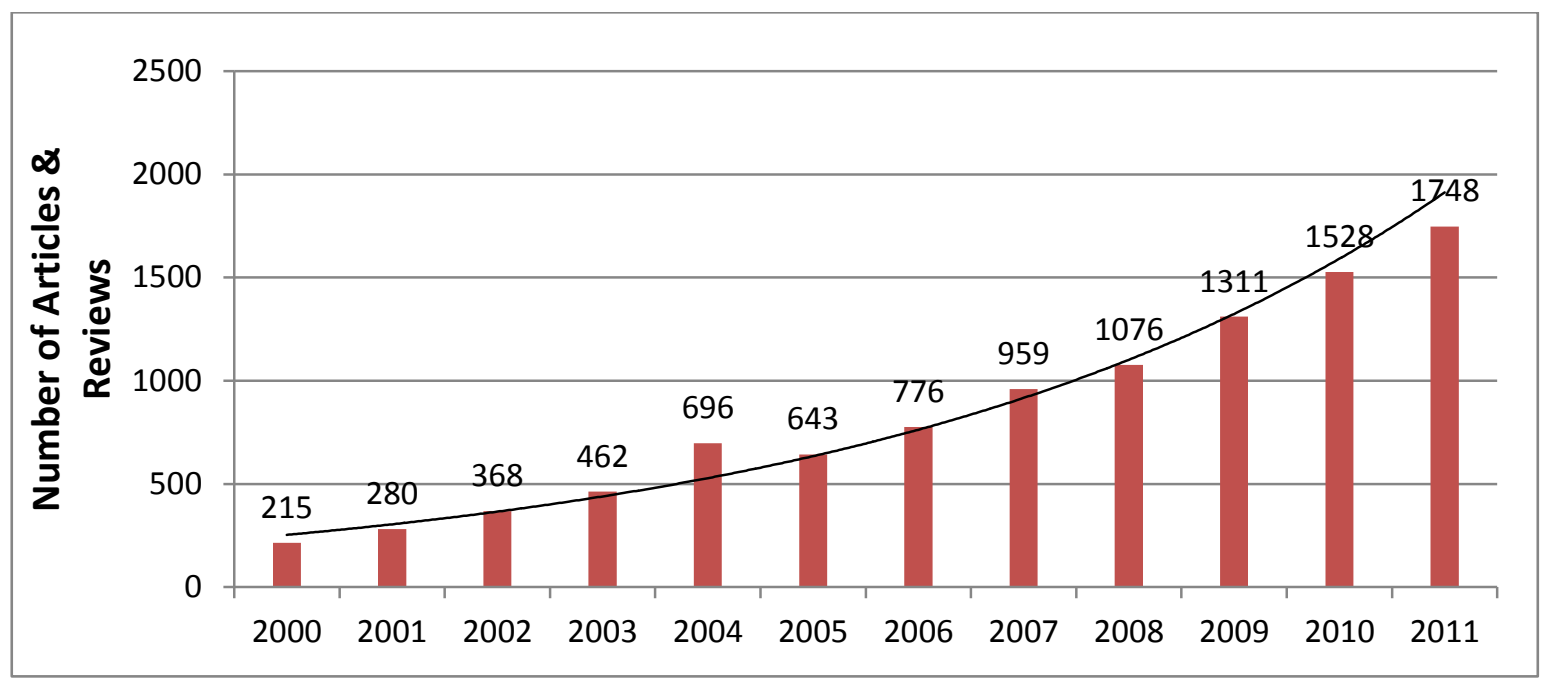

Figure 7. Number of nano-related technologies publications in Turkey: 2000-2011 Source: Thomson's ISI Web of Science as of November 2013

There are about 180 universities in Turkey, two-thirds being state-funded. Fig. 8 shows the number of publications of nano-related technology in some universities in Turkey: the Middle East Technical, Hacettepe, Istanbul Technical, Gazi, Bilkent and Ankara Universities have published more articles than other universities. All but one of them (Bilkent) are state funded universities. As we mentioned earlier, governmental agencies support research institutes located in Bilkent University. Koç, Fatih and Sabanci as three non-state universities have also published 193, 150 and 138 articles, respectively. In general, newly established universities published fewer papers on nanotechnology. 


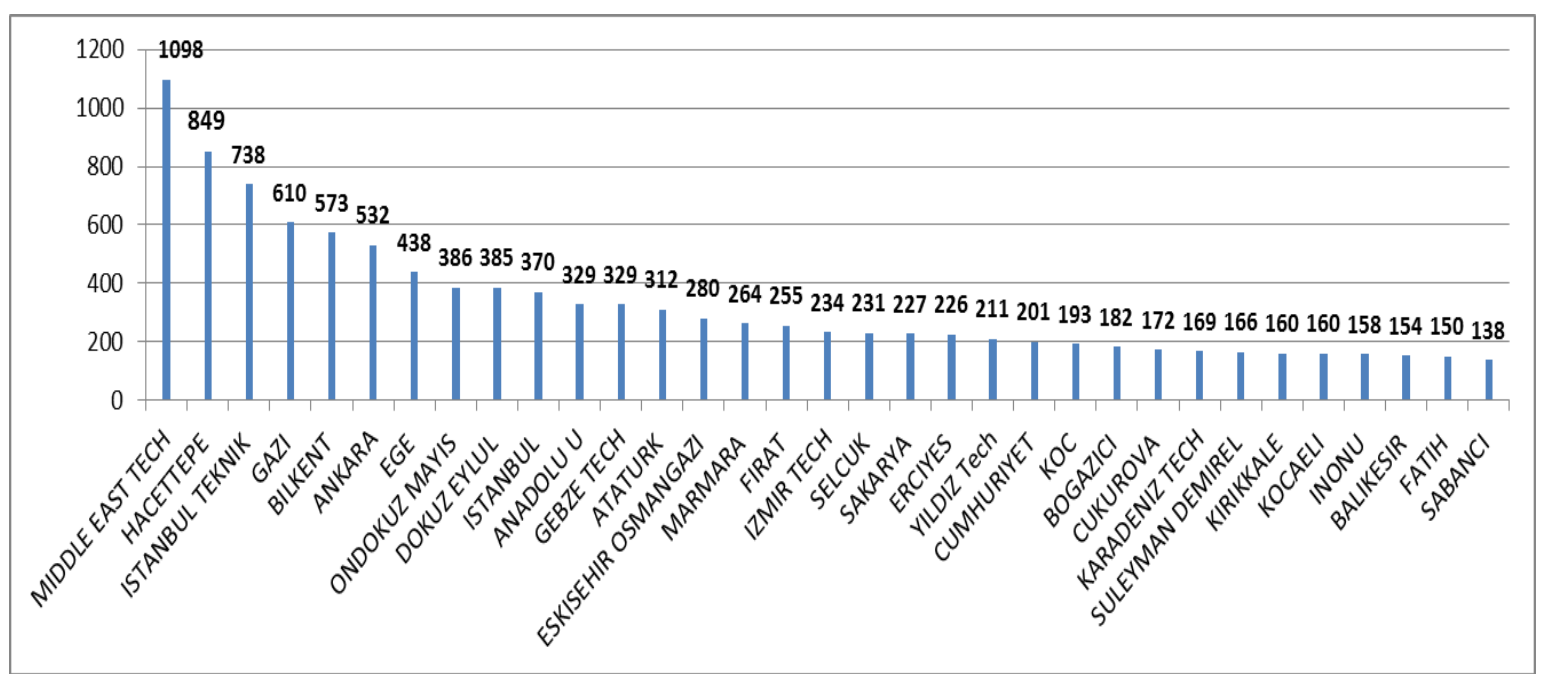

Figure 8. Number of scientific publications of universities in nano-related technologies in Turkey between 2000 and 2011 Source: Web of Science as of November 2013

Universities mostly are funded by governmental agencies and since 2005 Turkish government has increased its support ${ }^{12}$ in terms of funds and academic exchanges among universities (locally, internationally, and post-doctoral programs), to name three. Nanorelated projects at the Middle East Technical University (METU) and Istanbul Technical University (ITU) are distributed to various departments. Gazi and Hacettepe University medical schools are actively involved in nano-related technology and its application in medicine. In addition, scientists working at well-equipped research centers also have shared their knowledge in the joint projects with other universities. For example, scientists at Gebze Institute of Technology, ITU, Sabanc1 and Fatih Universities participate with MAM (Marmara Research Center) research centers' joint projects.

Based on our data collection and investigation, TÜBİTAK and the Ministry of Development (MoD) have supported research activities in several universities in terms of capitals. Table 2 provides data about the number of nano-related articles published and the total funds received. Also, it shows that some universities have not been recipient of funds. For example, Bilkent and Sabanci Universities have not received funds from MoD, yet they both still have published scientific articles. Istanbul Tech, METU and Gazi

\footnotetext{
12 To see a list of all supports from TÜBİTAK: “ http://www.tubitak.gov.tr/tr/destekler/akademik/uluslararasidestek-programlari\#destekler_akademik_ana_sayfa_akordiyon-block_1-1”
} 
Universities benefit most from governmental agencies. We conjecture that funds stimulate the growth in terms of publications in universities.

In this thesis, we elaborate on universities with the highest co-occurrence frequency and scholars who are influential in the network structure. As we mentioned in the previous chapter, we have selected universities from each period: 2000-2005 and 2006-2011 with the highest degree centralities. First, we investigate universities with the highest degree centralities which are mostly instrumental in diffusion of nano-related technology in terms of number of publications. Second, by studying their collaborative network structure, we identified scholars who are instrumental in knowledge diffusion in the network structure. There might be scholars who do not appear in the universities with the highest degree centrality but they may have collaborated with other scholars. Hence, we analyzed the entire network in each period. The next sections contain statistical results for couniversities and co-authorships analysis. 
Table 2. Number of nano-related articles published and total funds received by several universities (as of July 22, 2013)

\begin{tabular}{|c|c|c|c|c|}
\hline University & $\begin{array}{c}\text { \# of } \\
\text { Publications }\end{array}$ & $\begin{array}{l}\text { MoD Funds } \\
(\times 1000 \text { TL })\end{array}$ & $\begin{array}{l}\text { TÜBİTAK Funds } \\
(\times 1000 \mathrm{TL})\end{array}$ & Total Funds \\
\hline METU & 1098 & 719 & 953 & 1672 \\
\hline Istanbul Technical & 738 & 15.705 & 612 & 16.317 \\
\hline Hacettepe & 849 & 359 & 742 & 1101 \\
\hline Gazi & 610 & 13.356 & 512 & 13.868 \\
\hline Gebze Inst Technology & 329 & 15.100 & 271 & 15.371 \\
\hline Bilkent & 573 & -- & 868 & 868 \\
\hline Sabancı & 138 & -- & 176 & 176 \\
\hline Anadolu & 329 & 550 & 271 & 821 \\
\hline Marmara & 264 & 920 & 212 & 1132 \\
\hline İzmir Advanced Tech Institute & 234 & 920 & 205 & 1125 \\
\hline Boğaziçi & 182 & 420 & 160 & 580 \\
\hline Kocaeli & 160 & 192 & 130 & 322 \\
\hline Balıkesir & 154 & -- & 553 & 553 \\
\hline Fatih & 150 & 1230 & 90 & 690 \\
\hline Osmangazi & 280 & 1230 & 90 & 1320 \\
\hline Akdeniz & 106 & 796 & 80 & 876 \\
\hline Dumlupınar & 97 & 608 & 74 & 682 \\
\hline Kahramanmaraş Sütçü İmam & 73 & 392 & 63 & 455 \\
\hline Abant İzzet Baysal & 72 & 1695 & 57 & 1752 \\
\hline
\end{tabular}

Note: Data regarding funds were collected from the Ministry of Development and TÜBİTAK

\subsection{CO-UNIVERSITIES ANALYSIS}

As we mentioned earlier, the top rank universities were selected based on their degree centralities in terms of scientific collaboration on nano-related technology. Fig. 9 and Fig. 10 show the network structure of co-universities in nano-related technologies between 2000-2005 and 2006-2011 in Turkey, respectively. VOSviewer creates clusters based on 
the similarity of two items (nodes) in a vector space (low-dimensional space). Almost 6 different density clusters designated according to their similarity were created by VOSviewer with an overall density of 0.064 . Degree centralities were analyzed using Gephi. Cluster density map reveals that universities with higher weight centrality are mostly positioned in the center of the network whereas the ones with lower degrees are lined towards peripheral: the Middle East Technical, Ankara, Hacettepe, Gazi and Istanbul Technical and Bilkent are the densest sub clusters in the whole network structure. They collaborate with Furat, Yeditepe, Fatih and Çukurova Universities and Gebze Institute of Technology, respectively. Bilkent University has collaborated with National Institute of Standard \& Technology in the United States of America, which indicates that Bilkent University has collaborated internationally more than other universities in 2000-2005.

Furthermore, in the right side of the graph Anadolu and Osmangazi, at the top of the graph Atatürk and Balıkesir, in the left corner Karadeniz Technical, Erciyes and Ondokuz Mayıs, and in the right lower corner Cumhuriyet and Dokuz Eylül Universities have collaborated during 2000-2005 in Turkey.

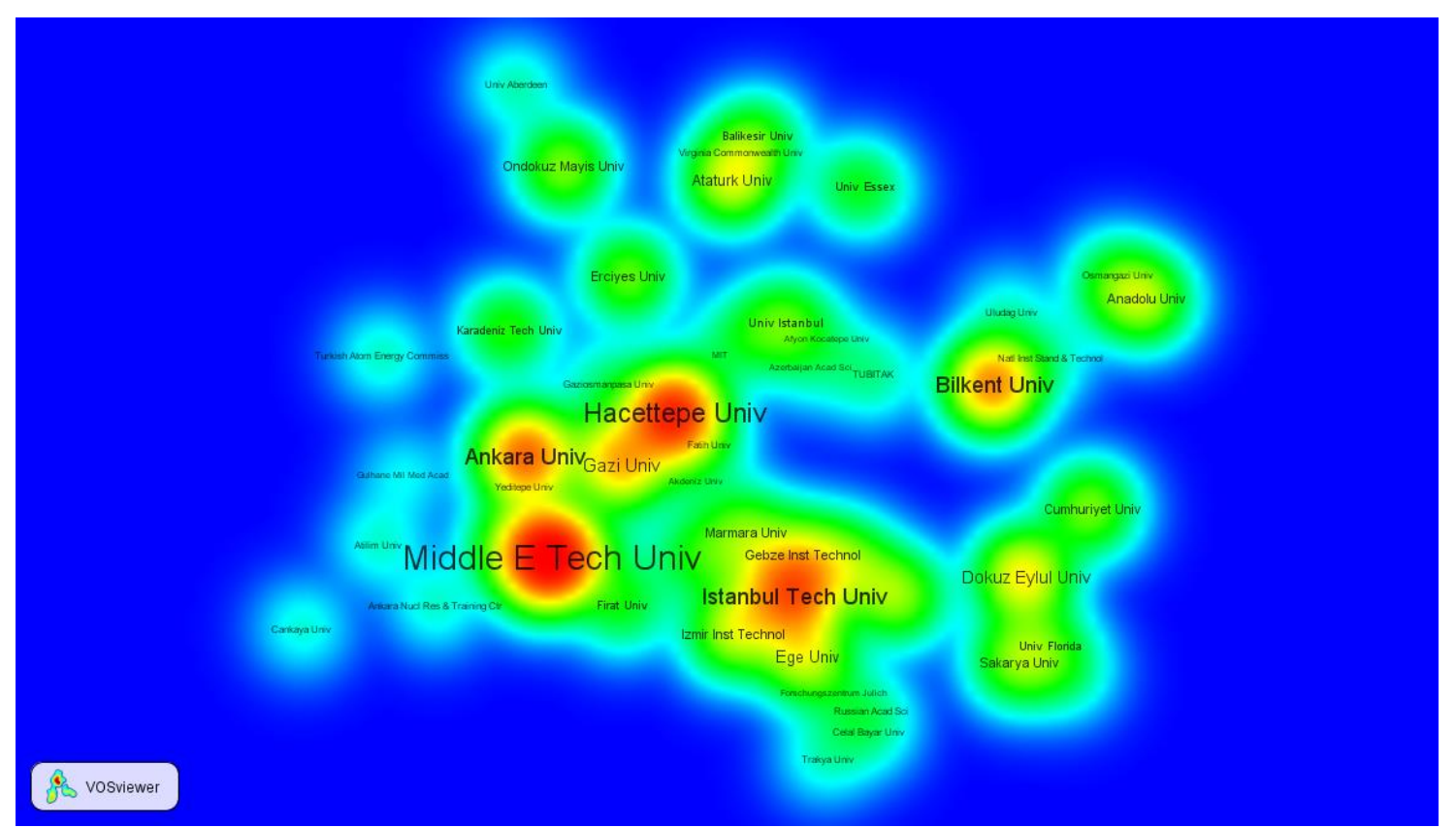

Figure 9. Density map of collaboration on nano-related technology among universities in Turkey: 2000-2005 
New universities have emerged in the network structure in 2006-2011. Hacettepe, METU and Gazi Universities have maintained their central status. Ege, Ondokuz Mayis, Karadeniz Technical, Akdeniz, İnönü, Sakarya and Çanakkale Onsekiz Mart Universities were added to the network structure in 2006-2011. Bilkent University asserts its international collaboration (Fig. 10).

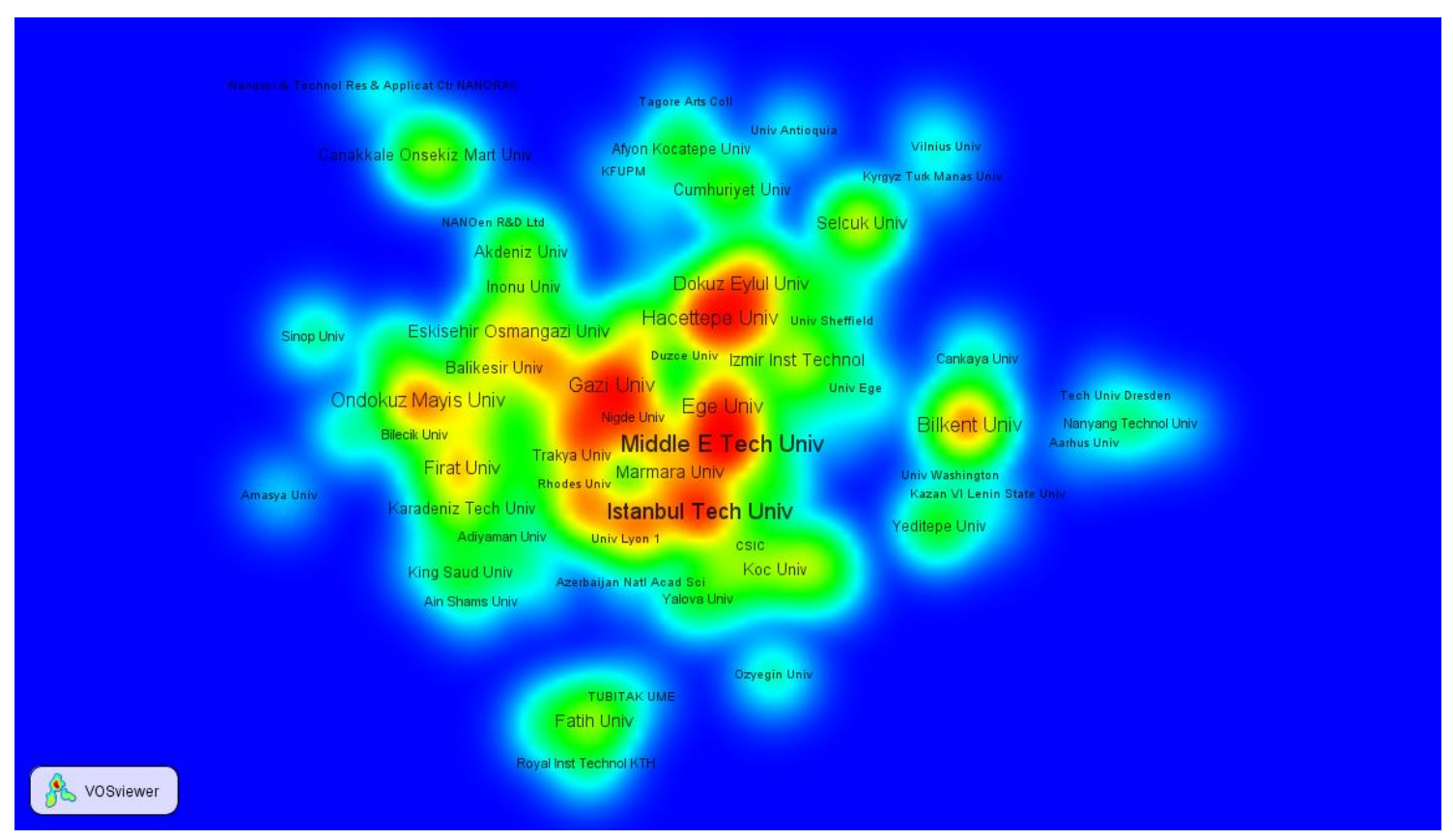

Figure 10. Cluster density map of collaboration on nano-related technology within universities in Turkey: 2006-2011

All universities that published in nano-related technology field were incorporated into the social network structure yielding a clustering coefficient of 0.364 , and with a density of 0.128 , which indicates that 36 percent of the nodes (universities) are well embedded (collaborative) in nano-related technology development. METU, Hacettepe and Gazi Universities are located in the Ankara Province. We can observe that universities in different regions collaborate with each other. In order to see a better picture of each university in the network structure and their collaboration, we constructed a map of all universities working on nano-related technologies based on their degree centrality coefficients from 2000 to 2005 (Fig. 11). 
The number of nodes has increased from 69 in 2000-2005 to 169 in 2006-2011 with a density of 0.075 and clustering coefficient of 0.456 , which indicates that $46 \%$ of clusters are well-embedded within the network structure (Fig. 12). Although the density has decreased slightly, clustering coefficient has increased in a higher rate. In other words, the network structure is quite loose in both periods; however, sub-clusters within the whole network are well-connected, which is an indication of the small-world phenomenon.

Fig. 12 illustrates the collaboration of Turkish Universities working on nano-related technologies conferring to their co-occurrence frequency. As mentioned earlier, the number of publications has increased since 2005 in Turkey. Growth in number of universities and their collaboration in research on nano-related technologies from 20002005 to 2006-2011 are two indications of diffusion of scientific knowledge in Turkey. 


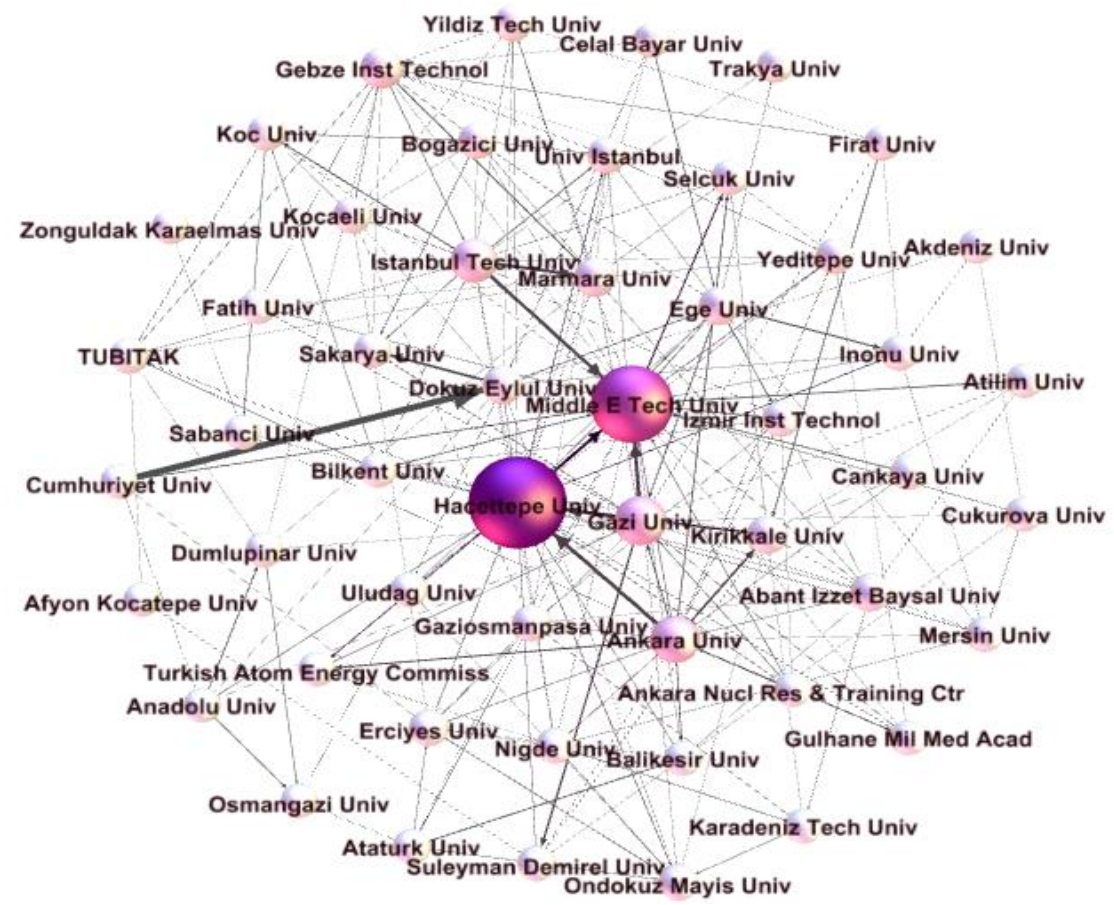

Figure 11. Collaboration of universities based on their co-occurrences frequency in Turkey: 2000-2005

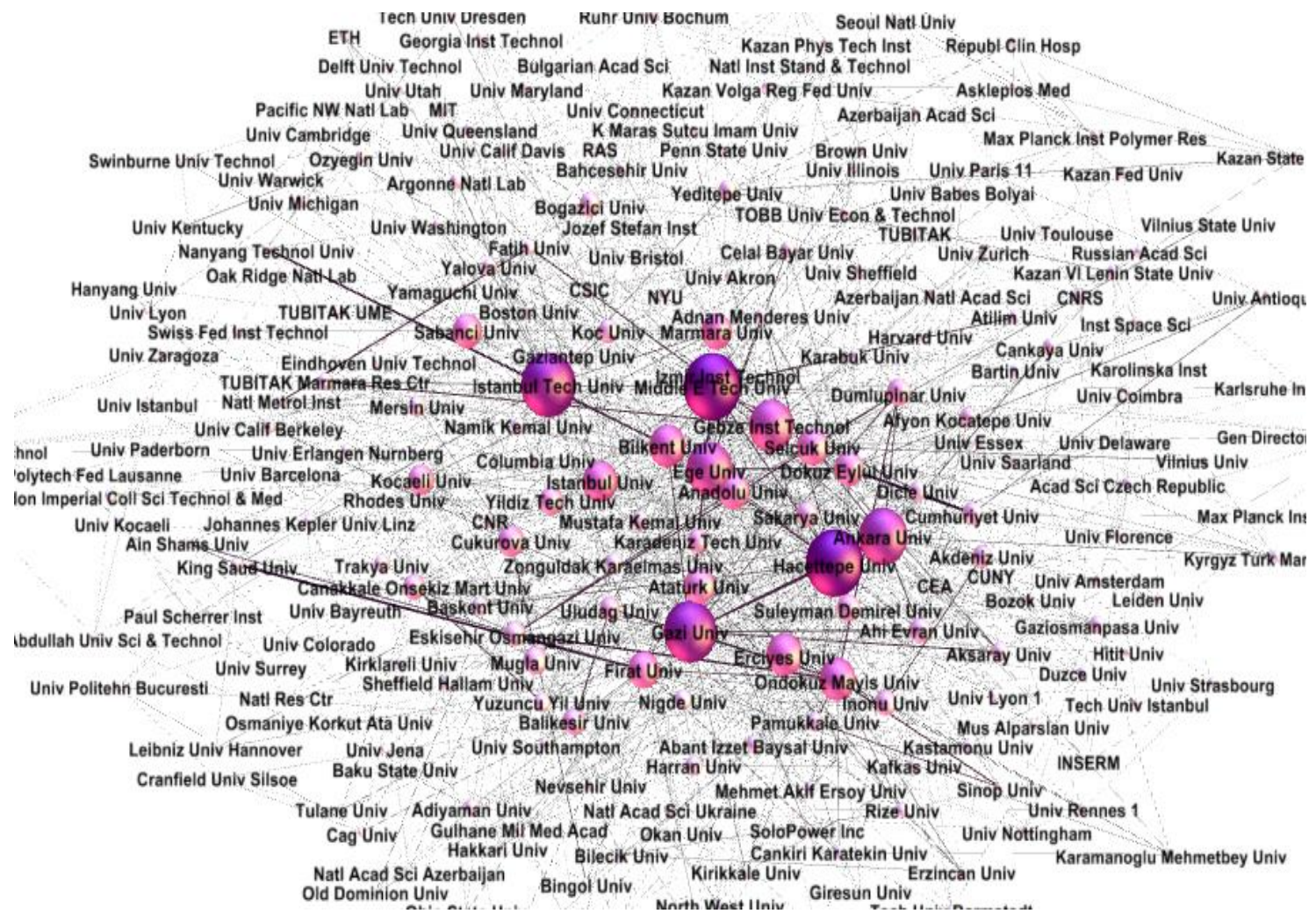

Figure 12. Collaboration of universities based on their co-occurrence frequency in Turkey: 2006-2011 
In order to see the contribution of each university, we selected 15 universities with the highest co-occurrence frequency collaborating in nano-related technologies development in network structure in two periods (Table 3 ).

Table 3. Top 15 universities with highest co-occurrence in Turkey

\begin{tabular}{lrlr}
\hline \multicolumn{1}{c}{ 2000-2005 } & & \multicolumn{2}{c}{ 2006-2011 } \\
\hline University & Freq & University & Freq \\
\hline Hacettepe & 29 & Hacettepe & 63 \\
Middle E Tech & 21 & Mazi & 63 \\
Ankara & 20 & Istanbul Tech & 57 \\
Gazi & 18 & Ankara & 53 \\
Istanbul Tech & 17 & Gebze Inst Tech & 47 \\
Gebze Inst Tech & 15 & Ondokuz Mayıs & 42 \\
Dokuz Eylül & 14 & Ege & 41 \\
Marmara & 14 & Istanbul & 41 \\
Bilkent & 13 & Erciyes & 40 \\
Abant İzzet Baysal & 12 & Bilkent & 38 \\
Kirıkkale & 12 & Dokuz Eylül & 34 \\
Ege & 11 & Anadolu & 34 \\
Ondokuz Mayıs & 11 & Atatürk & 33 \\
Erciyes & 11 & Firat & 31 \\
Kocaeli & $\mathbf{1 7}$ & Average & $\mathbf{4 6}$ \\
Average & & &
\end{tabular}

Average co-occurrence frequency of the selected universities working on nano-related technologies rose from 17 in 2000-2005 to 46 in 2006-2011, which indicates greater collaboration of selected universities in the network structure (see Appendix G for a list of universities). The growth of co-occurrence frequency in universities is almost threefold, an indication of universities' participation in nano-related technology in Turkey in a relatively short period. Each node represents the total number of collaborations that the selected university has with other university in each period.

Although top 5 universities have maintained their status in different order in the second period, Kırıkkale, Marmara, Kocaeli and Abant İzzet Baysal Universities have lost their place to new universities: F1rat, Anadolu, and Atatürk. Interestingly, Ondokuz Mayıs University has moved up from $13^{\text {th }}$ place in $2000-2005$ to $7^{\text {th }}$ place in $2006-2011$ (Fig. 13). 
High degree of closeness centrality indicates the cohesiveness of subclusters within network structure. We conjecture that selected nodes are in close (i.e., shortest path) distance from each other.

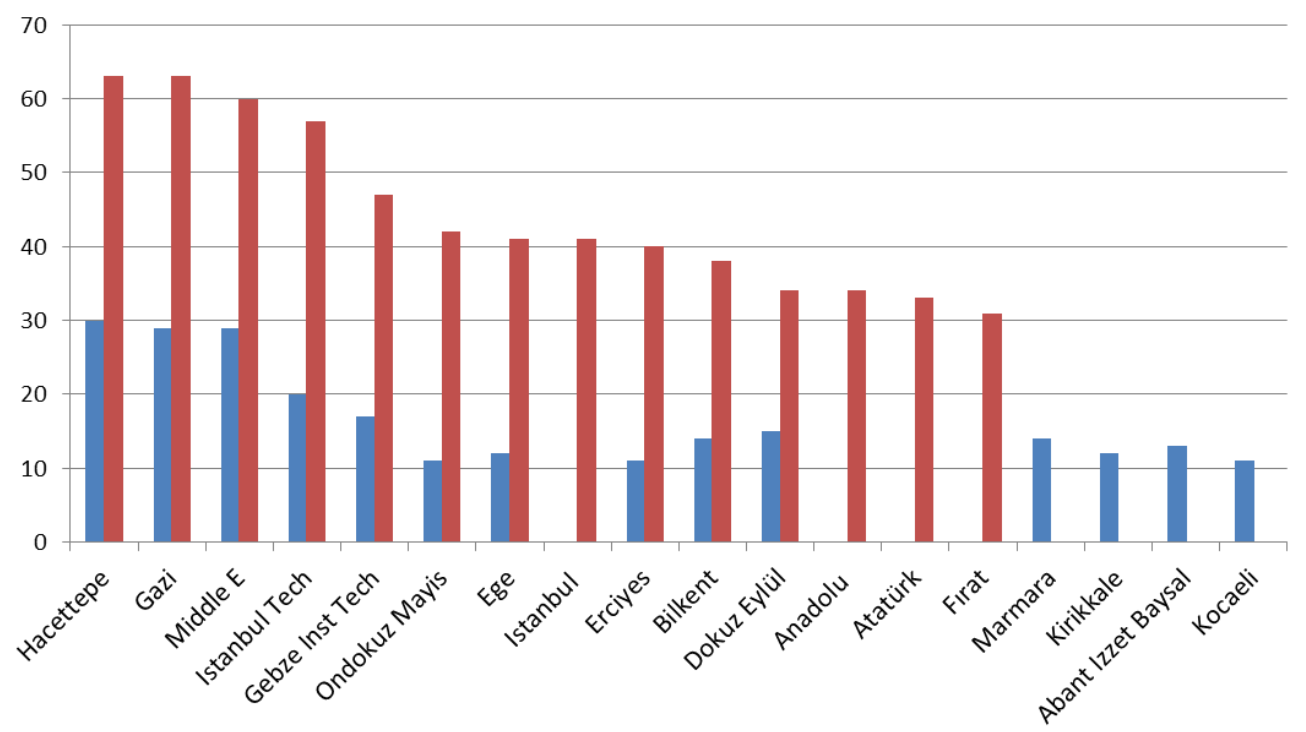

Figure 13. Comparison of co-occurrence frequency of selected universities in two periods

Moreover, Table 4 summarizes the coefficient centralities (betweenness, closeness) of universities working on nano-related technologies between 2000-2005 and 2006-2011, respectively. 
Table 4. Centrality coefficients of the network structure: 2000-2005 and 2006-2011

\begin{tabular}{lrrrrr}
\hline & $2000-2005$ & & & $2006-2011$ & \\
\cline { 2 - 4 } University & Betweenness & Closeness & University & Betweenness & Closeness \\
\hline Hacettepe & 0.192 & 0.652 & Hacettepe & 0.086 & 0.602 \\
Middle E Tech & 0.151 & 0.626 & Gazi & 0.098 & 0.598 \\
Ankara & 0.073 & 0.574 & Middle E Tech & 0.107 & 0.596 \\
Gazi & 0.075 & 0.574 & Istanbul Tech & 0.105 & 0.596 \\
Istanbul Tech & 0.051 & 0.539 & Ankara & 0.054 & 0.583 \\
Gebze Inst Tech & 0.050 & 0.500 & Gebze Inst Tech & 0.054 & 0.556 \\
Dokuz Eylül & 0.044 & 0.521 & Ondokuz Mayls & 0.028 & 0.549 \\
Marmara & 0.024 & 0.512 & Ege & 0.044 & 0.564 \\
Bilkent & 0.061 & 0.504 & Istanbul & 0.044 & 0.547 \\
Abant İzzet Baysal & 0.022 & 0.521 & Erciyes & 0.033 & 0.540 \\
Kirıkkale & 0.024 & 0.500 & Bilkent & 0.080 & 0.551 \\
Ege & 0.026 & 0.508 & Dokuz Eylül & 0.033 & 0.537 \\
Ondokuz Mayis & 0.045 & 0.512 & Anadolu & 0.025 & 0.542 \\
Erciyes & 0.043 & 0.521 & Atatürk & 0.023 & 0.535 \\
Kocaeli & 0.018 & 0.470 & Firat & 0.036 & 0.505 \\
Average & $\mathbf{0 . 0 6 0}$ & $\mathbf{0 . 5 3 6}$ & Average & $\mathbf{0 . 0 5 7}$ & $\mathbf{0 . 5 6 0}$ \\
\hline
\end{tabular}

The average degree of closeness centrality slightly rose from 0.536 in 2000-2005 to 0.560 in 2006-2011. Betweenness centrality, on the other hand, decreased from 0.060 in 20002005 to 0.057 in $2006-2011$, respectively.

Low betweenness centrality supports the notion that clusters in the network are not wellconnected. The network structures for both periods are loose. On the other hand, the high closeness degree yields that sub-clusters within the network structure is wellconnected. For example, the network structure of Hacettepe University was more connected in 2000-2005 than in 2006-2011. 


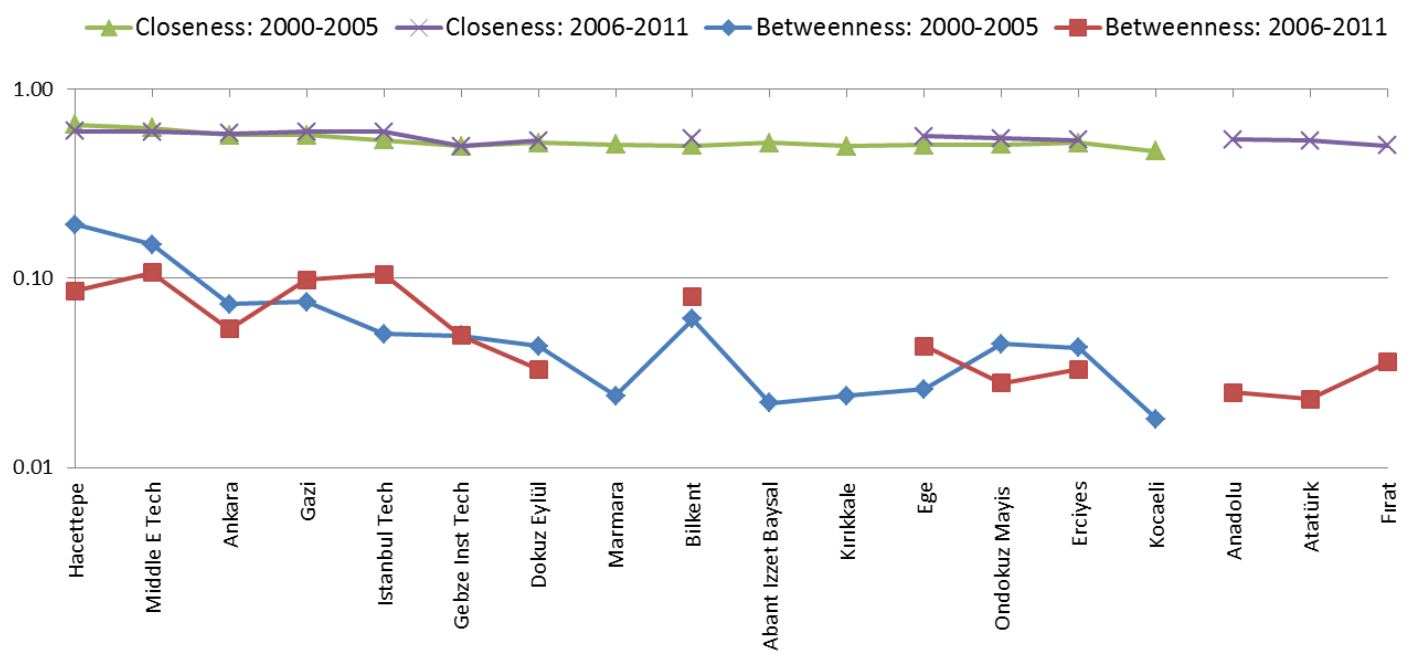

Figure 14. Betweenness and closeness centrality of selected universities in two periods: 2000-2005 and 2006-2011

In the next section, we investigate the rate of diffusion in terms of the number of collaborators in the network between 2000 and 2011.

\subsection{THE RATE OF DIFFUSION: 2000-2011}

Network structures started in 2000 with 214 authors collaborating and continued with 2989 new adopters collaborated in 2011 (Fig 15). The number of adopters increased in 20002005 period with some fluctuation in 2003. However, we see a tipping point of authors collaborating in 2006 in which scientific publications in nano-related technology started to increase in a much greater rate, which may be due to the fact that nanotechnology became one of the top research fields supported by government funds. Table 5 and Fig. 15 show the number of new and cumulative adopters working on nano-related technology in Turkey. 
Table 5. Number of new and cumulative adopters between 2000 and 2011

\begin{tabular}{rrr}
\hline Year & New adopters & Cumulative adopters \\
\hline 2000 & 214 & 214 \\
2001 & 177 & 391 \\
2002 & 193 & 584 \\
2003 & 381 & 965 \\
2004 & 115 & 1080 \\
2005 & 282 & 1362 \\
2006 & 1622 & 2948 \\
2007 & 1668 & 4652 \\
2008 & 1907 & 6559 \\
2009 & 1919 & 8478 \\
2010 & 2225 & 10703 \\
2011 & 2989 & 13692 \\
\hline
\end{tabular}

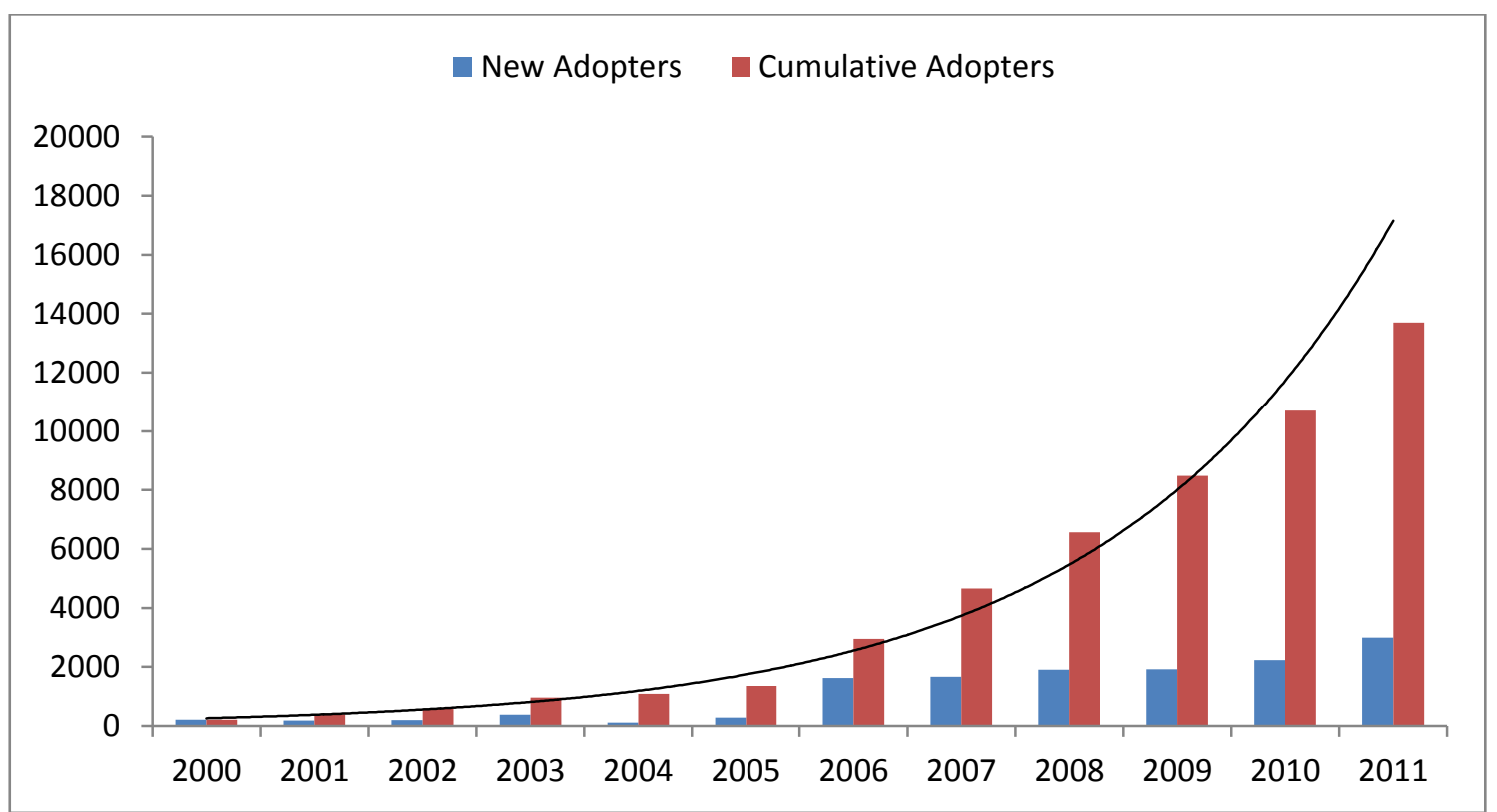

Figure 15. Adoption rate of collaborations between 2000-2011

In the following sections, we overlay research activities based on WoS 224 Subject Categories for selected universities on science map and their coefficient centralities from 2000-2005 to 2006-2011 in Turkey. 


\subsection{NETWORK OF NANO-RELATED TECHNOLOGY IN TURKEY: 2000-2005} AND 2006-2011

An overlaid map of nano-related scientific activities on the map of science from records based on WoS Categories was created (Fig. 16). Clearly, each color located in the map represents a factor, which represents a subject category on the map. Node size in the graph is proportional to its co-occurrences with other nodes.

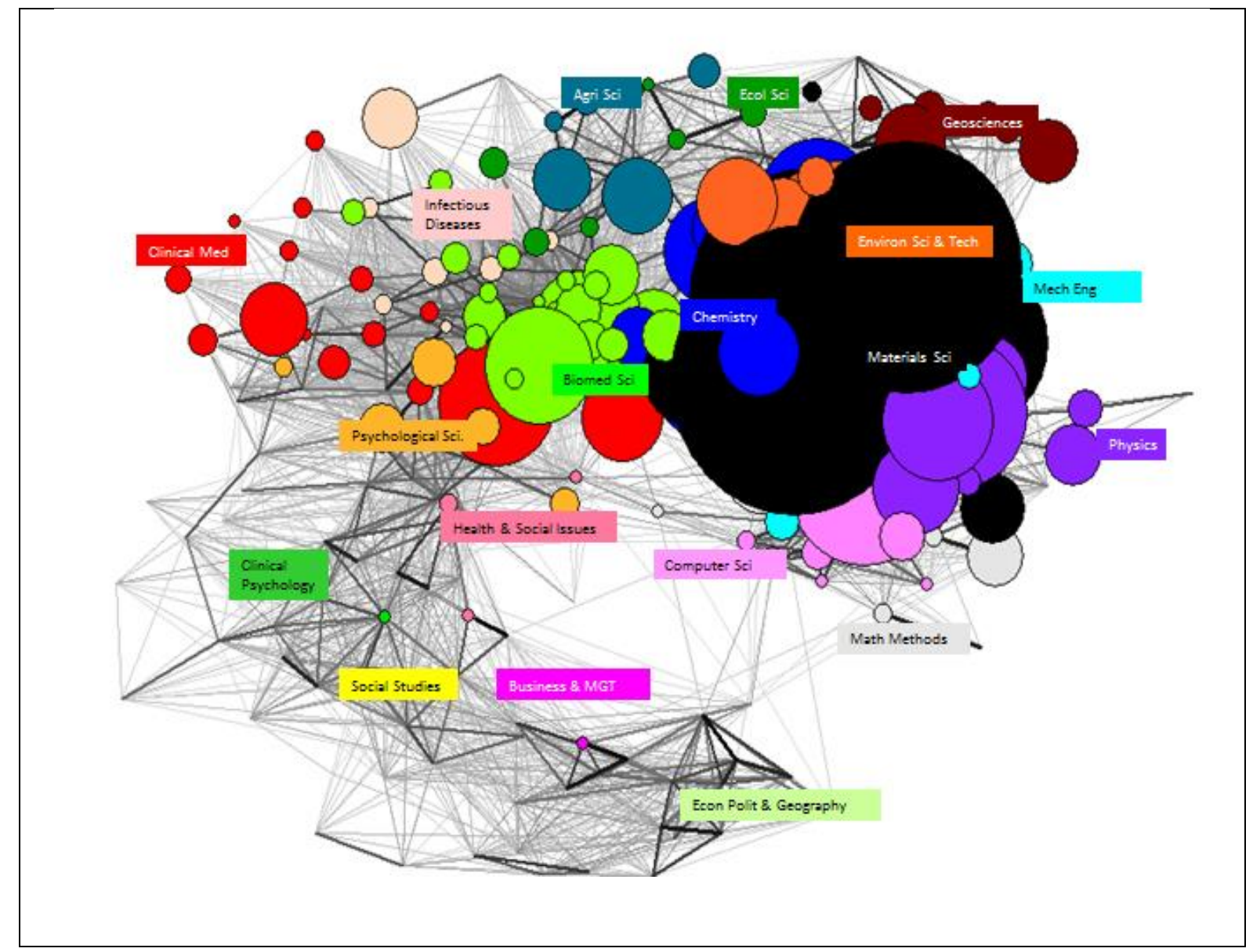

Figure 16. Profile of universities based on subject category in nano-related technology overlaid on map of science in Turkey: 2000-2005

Material Science, Chemistry, Physics followed by Clinical Medicine and Psychological Science are scientific fields that have precedence over other scientific activities by Turkish scientists. Ecological Science, Geosciences, Environmental Science \& Technology, 
Computer Science and Agricultural Science were also noticeable. To a lesser extent, Mechanical Engineering, and Clinical Psychology Issues were investigated by Turkish scientists between 2000 and 2005. The statistical results for the overlaid map based on Subject Categories for all universities are following: betweenness centrality of 0.079, degree centrality of 0.550 and closeness centrality of 0.477 (Table 6). We can deduce that Material Sciences lead scientific field in which many applications of nano-related technologies are utilized in 2000-2005.

Next figure (Fig. 17) illustrates an overlaid map of WoS Categories on the map of science from 2006 to 2011 with degree centralities: betweenness centrality of 0.027, degree centrality of 0.640 and, finally, closeness centrality of 0.625 (Table 6). In contrast with 2000-2005 network structure, degree and closeness coefficients centrality rose from 0.550 to 0.640 for the former and 0.477 to 0.625 for the latter while betweenness centrality decreased to a lower degree. Betweenness centrality indicates that flow of information among sub-clusters was reduced to some extent. We can interpret the increase in degree centrality as an increase in the number of edges connected to each node.

Table 6. Degree centralities of network structure based on WoS subject categories

\begin{tabular}{cccc}
\hline Years & Betweenness & Degree & Closeness \\
\hline $2000-2005$ & 0.079 & 0.550 & 0.477 \\
$2006-2011$ & 0.027 & 0.640 & 0.625 \\
\hline
\end{tabular}




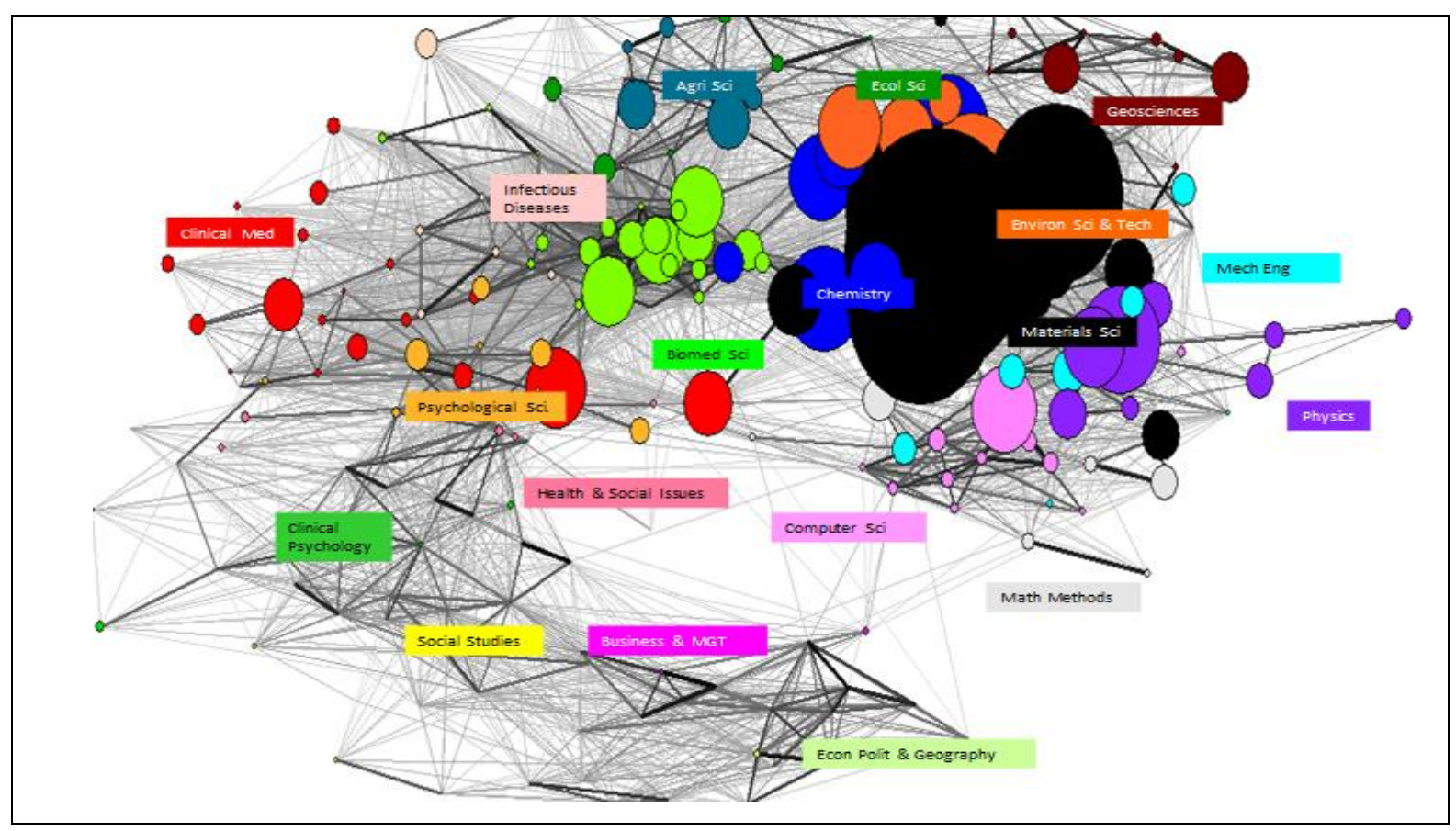

Figure 17. Profile of universities based on subject category in nano-related technology overlaid on map of science in Turkey: 2006-2011

We conjecture that the diffusion of nano-related technology has increased due to a higher closeness degree in the network structure. However, there is a slight decrease of collaboration among research fields in the network structure.

In the next sections, we present the statistical results for 15 selected universities in details in each period: 2000-2005 and 2006-2011. Then, we compare and contrast their coefficient centralities following by overlaid maps of each selected university. 


\subsection{NETWORK OF PUBLICATIONS IN NANO-RELATED TECHNOLOGY IN TURKEY: 2000-2005 AND 2006-2011}

Table 7 shows the top 15 universities and their publications' centrality coefficients in nano-related technology of the network structure.

Table 7. Centralities coefficients of the top 15 universities' publications on nano-related technology, 2000-2005 and 2006-2011

\begin{tabular}{|c|c|c|c|c|c|c|c|}
\hline \multicolumn{4}{|c|}{$2000-2005$} & \multicolumn{4}{|c|}{ 2006-2011 } \\
\hline University & Degree & Closeness & Betweenness & University & Degree & Closeness & Betweenness \\
\hline Middle E Tech & 0.523 & 0.467 & 0.113 & Bilkent & 0.620 & 0.588 & 0.069 \\
\hline Bilkent & 0.515 & 0.495 & 0.124 & Gebze Inst & 0.603 & 0.541 & 0.068 \\
\hline Hacettepe & 0.401 & 0.495 & 0.072 & Hacettepe & 0.574 & 0.524 & 0.022 \\
\hline Ondokuz Mayis & 0.357 & 0.359 & 0.106 & Middle E Tech & 0.562 & 0.511 & 0.054 \\
\hline Dokuz Eylül & 0.323 & 0.322 & 0.060 & Istanbul Tech & 0.534 & 0.468 & 0.031 \\
\hline Gebze Inst Tech & 0.314 & 0.499 & 0.110 & Anadolu & 0.470 & 0.379 & 0.042 \\
\hline Kirikkale & 0.288 & 0.457 & 0.119 & Gazi & 0.457 & 0.373 & 0.070 \\
\hline Ege & 0.276 & 0.359 & 0.126 & Ondokuz Mayis & 0.455 & 0.415 & 0.067 \\
\hline Abant İzzet Baysal & 0.252 & 0.612 & 0.184 & Istanbul & 0.445 & 0.415 & 0.067 \\
\hline Gazi & 0.244 & 0.373 & 0.156 & Ege & 0.431 & 0.382 & 0.035 \\
\hline Marmara & 0.225 & 0.336 & 0.215 & Ankara & 0.418 & 0.363 & 0.071 \\
\hline Ankara & 0.224 & 0.373 & 0.072 & Dokuz Eylül & 0.323 & 0.322 & 0.060 \\
\hline Kocaeli & 0.218 & 0.325 & 0.425 & Firat & 0.317 & 0.452 & 0.051 \\
\hline Erciyes & 0.162 & 0.466 & 0.098 & Erciyes & 0.256 & 0.452 & 0.049 \\
\hline Istanbul Tech & 0.109 & 0.363 & 0.151 & Atatürk & 0.230 & 0.316 & 0.091 \\
\hline Avg & 0.295 & 0.420 & 0.142 & Avg & 0.446 & 0.433 & 0.056 \\
\hline
\end{tabular}

The average degree and closeness centrality coefficients rose from 0.295 to 0.466 for the former and from 0.420 to 0.433 for the latter; however, betweenness centrality decreased from 0.142 to 0.056 indicating that there is less connectivity within sub-clusters in the network structure. METU, Bilkent and Hacettepe Universities are at the pinnacle of the list 
while Istanbul Technical, Erciyes and Kocaeli Universities are at the bottom with the lowest degree centrality coefficients in the 2000-2005 period.

Dokuz Eylül, Hacettepe and Ankara Universities have the lowest betweenness centrality coefficients indicating that sub-clusters within the whole network structure are not wellconnected. However, their higher closeness centrality coefficients indicate a higher propensity for well-connected clusters during 2000-2005 in Turkey. High betweenness centrality of Kocaeli University yields the flow of knowledge among its three subject fields: Clinical Medicine, Materials Science and Ecological Science.

Moreover, the higher degree centrality yields more participation of a node in the network than that a node with a lower degree centrality. For example, Bilkent, METU and Hacettepe Universities have the highest degree centrality coefficients in the network, which is an indication of their greater contribution to the network structure in terms of number of publications. Therefore, we conjecture that network structure adheres to the small-world phenomenon.

Kırıkkale, Abant İzzet Baysal, Marmara and Kocaeli Universities are no longer in the top 15 universities in the 2006-2011 period in terms of their production of nanotechnology papers. Instead, Anadolu, İstanbul, Firat and Atatürk Universities rose to the first 15 universities.

Bilkent is at the top of the 2006-2011 list with the highest betweenness and closeness centralities followed by Gebze Institute of Technology (Gebze was in the $6^{\text {th }}$ place in 20002005). Hacettepe University and METU are also at the top of the 2006-2011 lists (Fig. 18). These four universities form a cohesive network structure in 2006-2011. In general, betweenness centrality coefficients are much lower for all universities except Bilkent University and Gebze Institute of Technology. Atatürk, Erciyes and Firat Universities are at the bottom of the list with the lowest coefficients of degree and closeness. 


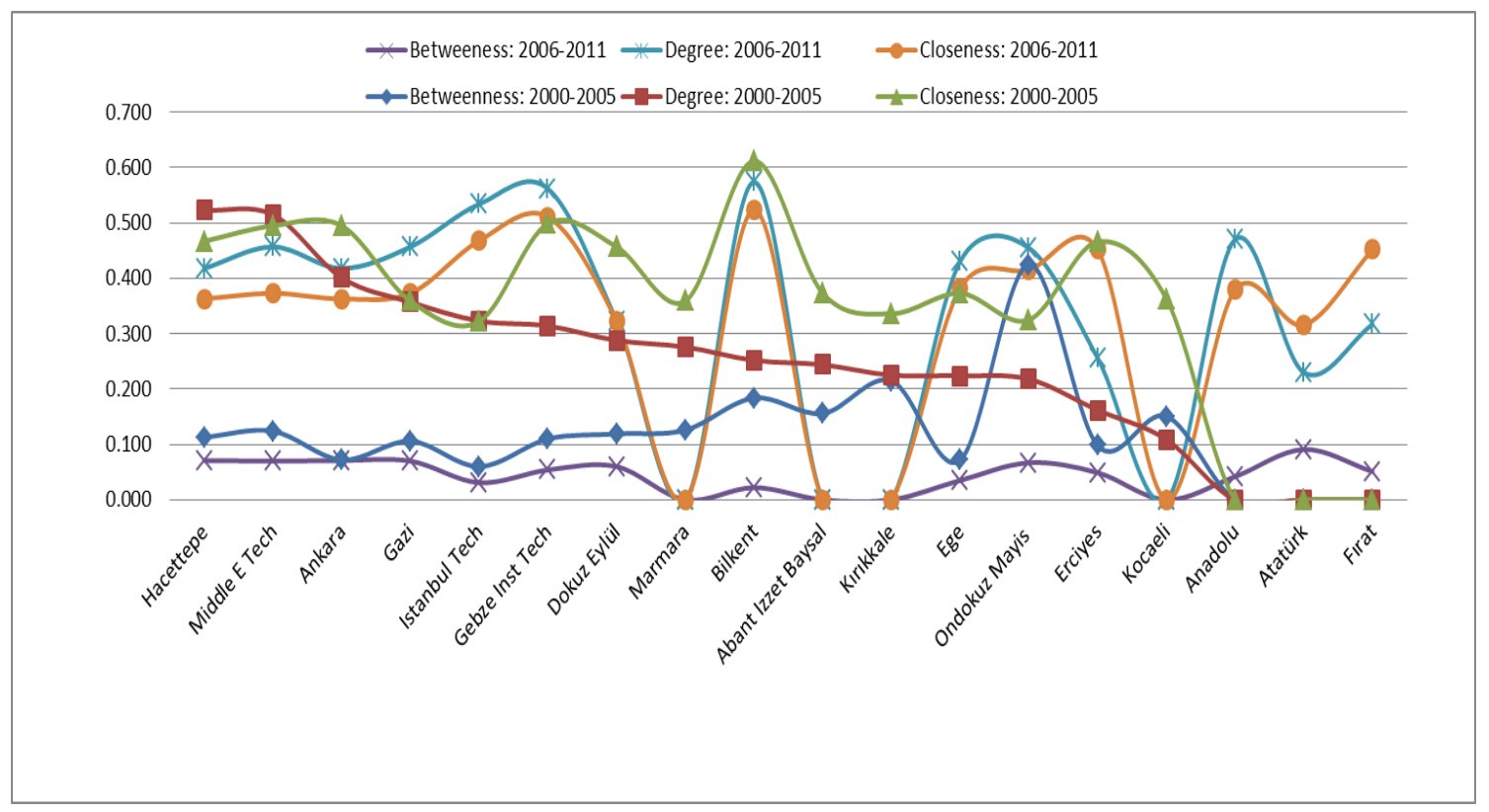

Figure 18. Degree centralities of selected universities in two periods: 2000-2005 and 2006-2011

What follows are the network centrality of 15 universities in 2006-2011. The order of universities does not strictly follow the order in Table 7 . We present 15 overlay maps of selected universities mentioned above in details in each period: 2000-2005 and 2006-2011. Overlay maps generated for each university illustrates each university's publication, which signifies nano-related technology in terms of WoS Subject Categories, and then, by analyzing and comparing their statistical results in each period, we explored the diffusion of nano-related technologies in Turkey 


\subsection{NETWORK OF NANO-RELATED TECHNOLOGY IN SELECTED UNIVERSITIES: 2000-2005}

The Middle East Technical University (METU) is a leader in nano-related technologies in terms of number of publications. METU participates mostly in science subjects: Material Sciences, Chemistry, Environmental Science and Technology (Fig. 19), followed by the Biomedical Science in the center, Geosciences in the upper right corner, Computer Science and Mathematics in the lower right part of the map. Social Studies are noticeable in lower left part of the graph. We can say that there is collaboration between Engineering Science and Medicine at both universities. The statistical results for the overlaid map based on Subject Categories for METU are following: betweenness of 0.113, degree centrality of 0.523 , and closeness of 0.467 . Results indicate that flow of knowledge between subclusters is higher than that of base map. Similarly, flow of information within sub-clusters is high, too. METU plays an important role in the diffusion of nano-related technology in the whole network structure.

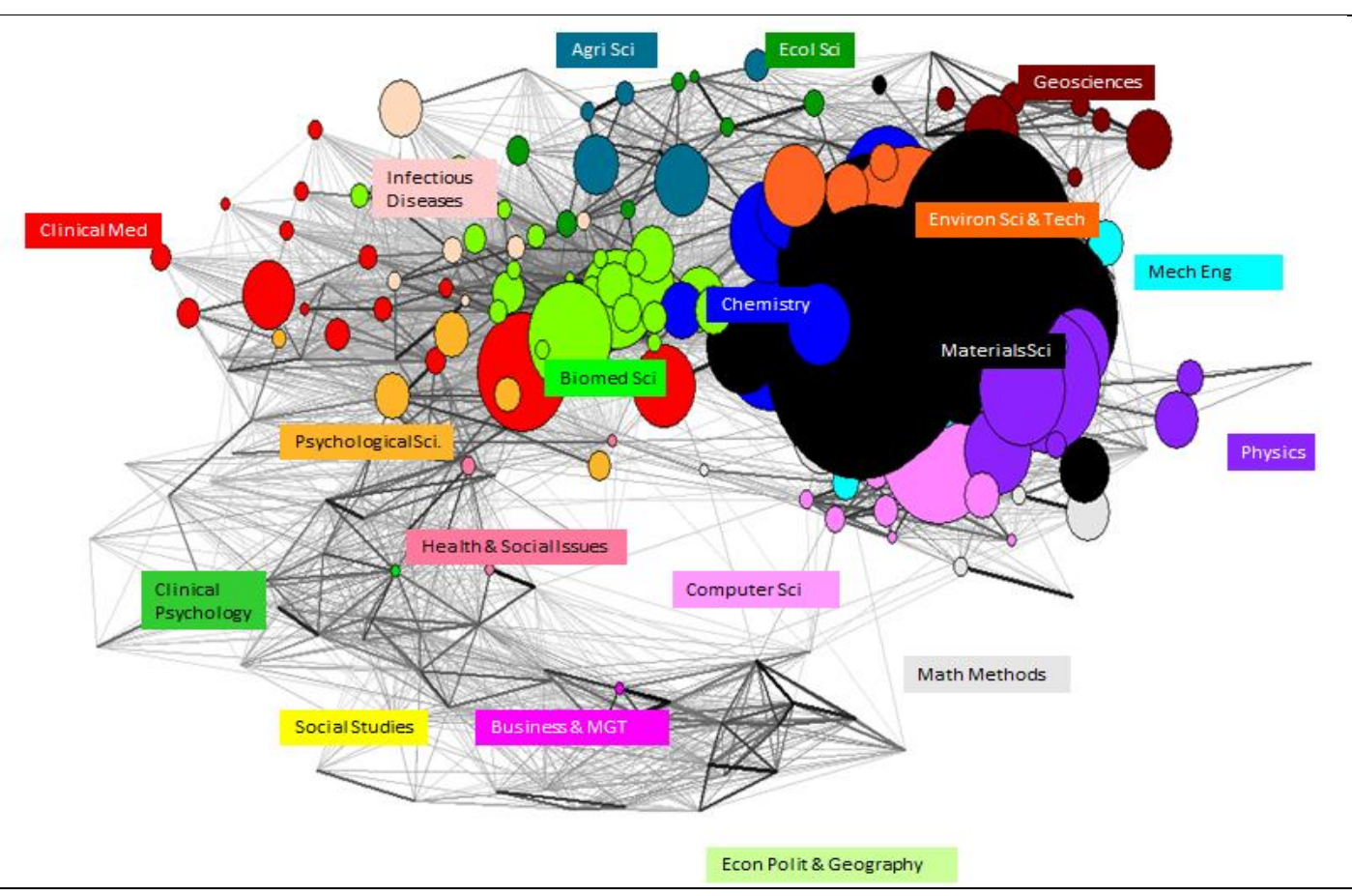

Figure 19. Publication profiles overlaid on the map of science of METU 2000-2005 
Overlay map for Bilkent University is distributed containing several scientific subject fields. Although Material Science, Physics, and Chemistry appear dense, Biomedical Science is in the center of the map. Bilkent University is also active in Mechanical Engineering, Environmental Science \& Technology and Geoscience in which the use of nano-related technology is vast. Bilkent University collaborates mostly with universities in Europe and North America in research. The statistical results for the overlaid map based on Subject Categories for Bilkent are as follows: betweenness of 0.124, degree centrality of 0.515 , and closeness centrality of 0.495 (Fig. 20).

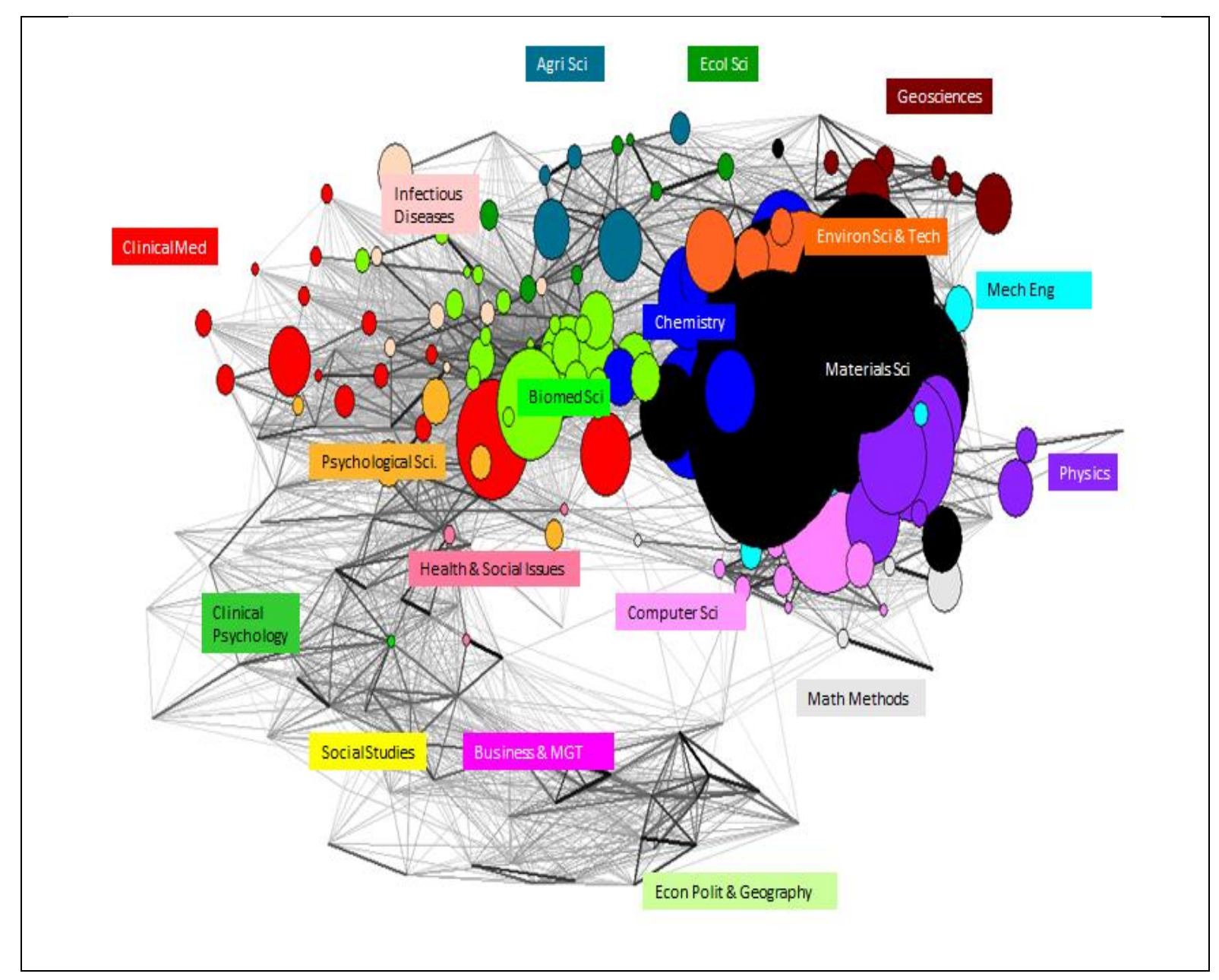

Figure 20. Publication profiles overlaid on the map of science of Bilkent University, 2000-2005 
Hacettepe University is more active in nano-related technology applications of Clinical Medicine. In addition, Hacettepe University is actively involved in other scientific fields such as Chemistry and Material Science. At Hacettepe University, Medical and Biomedical Science applications are a focal point in the network structure indicating nanotechnology/Nanoscience growth in the medical sciences. Black, red and green mostly occupies the network structure with the biggest node size in the network structure. The statistical results from the overlaid map based on Subject Categories for Hacettepe University are following: betweenness of 0.072 , degree centrality of 0.401 and closeness centrality of 0.495 (Fig 21).

In contrast to the base map, betweenness centrality indicates that the flow of information in the network did not decrease at a higher rate. Importantly, all indicators yield that Hacettepe University plays an important role in the diffusion of nano-related technology in the whole network structure.

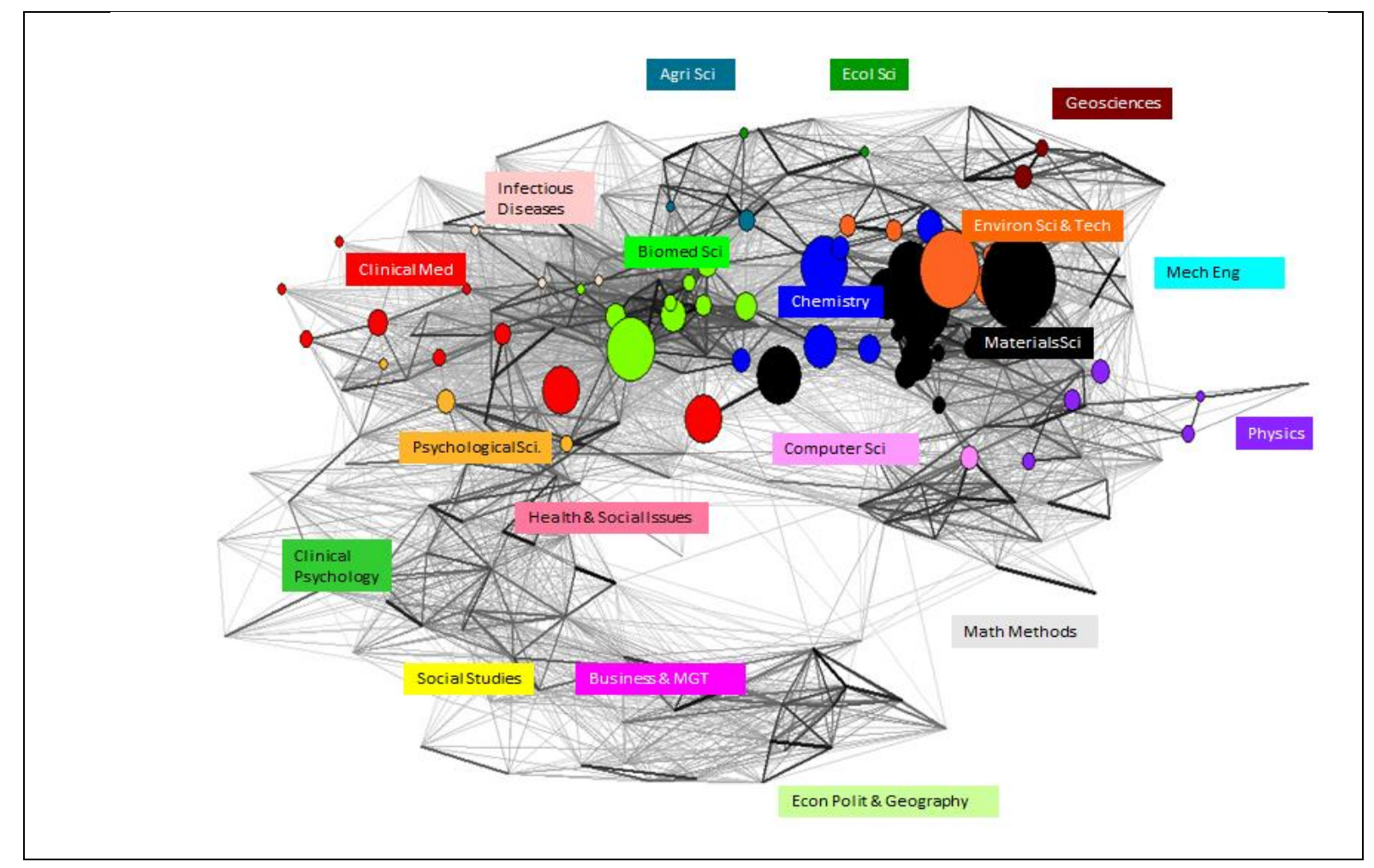

Figure 21. Publication profiles overlaid on the map of science of Hacettepe University 2000-2005 
Materials Sciences, Chemistry, Physics, Environmental Science \& Technology, and Clinical Medicine are the research subject fields in Ondokuz Mayis University. Knowledge diffusion in the network structure according to its centralities is slow, but it is higher within sub-components (Fig. 22). The statistical results from the overlaid map based on Subject Categories for Ondokuz Mayis University are as follows: betweenness centrality of 0.106, degree centrality of 0.357 and closeness centrality of 0.359 .

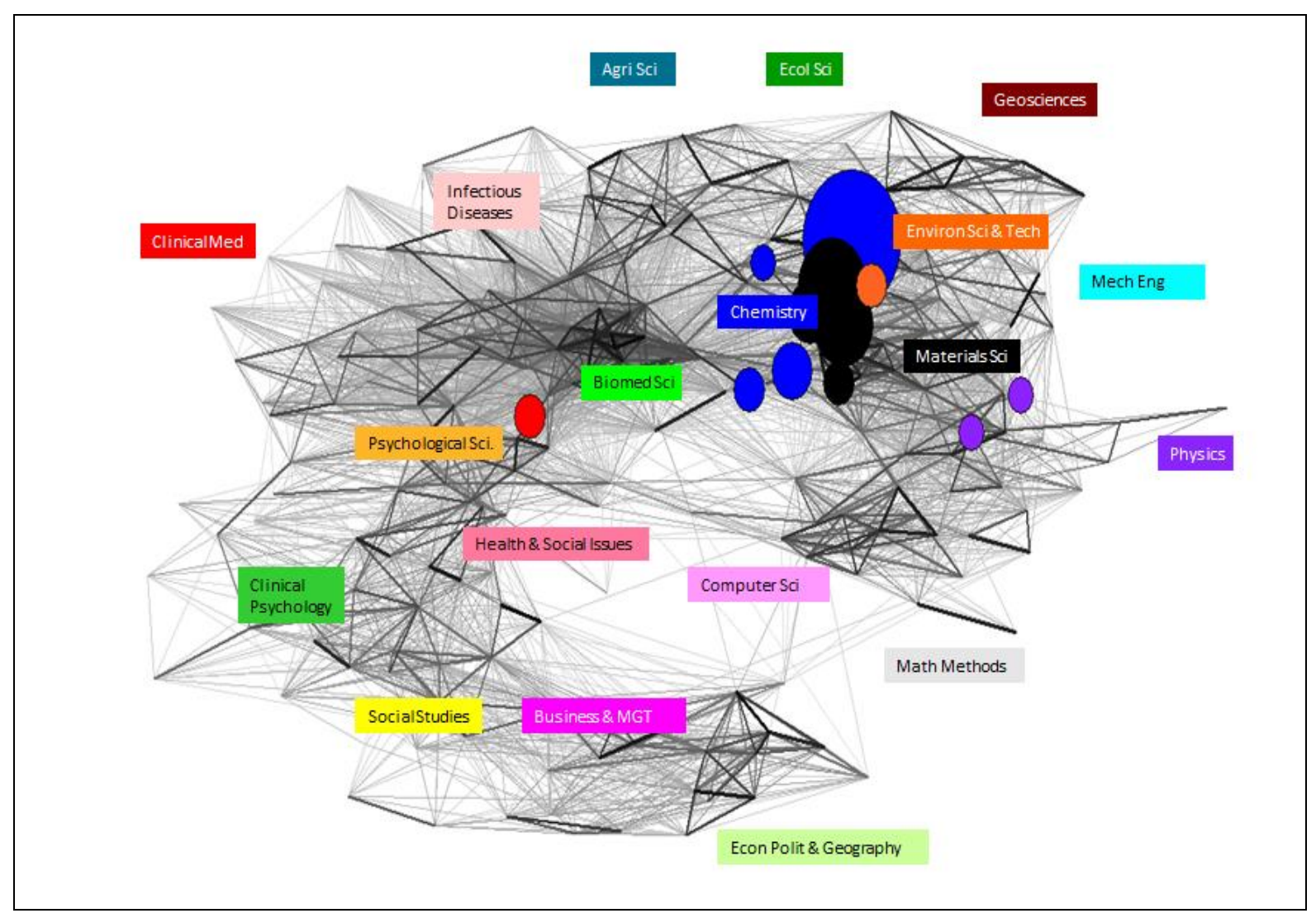

Figure 22. Publications, profiles overlaid on the map of science of Ondokuz Mayis University, 2000-2005

The next overlay maps are of Ankara and Gazi Universities (Fig. 23 \& Fig. 24). They work almost in the same research domains. However, they are more productive than others are at some research subject fields. For example, Gazi University produced more output in Infectious Diseases (rose-pink color node at the top of the graph) whereas Ankara University produced more output in Clinical Psychology. The Material Science and 
Clinical Science disciplines are central, whereas Computer Science and Clinical Psychology are peripheral.

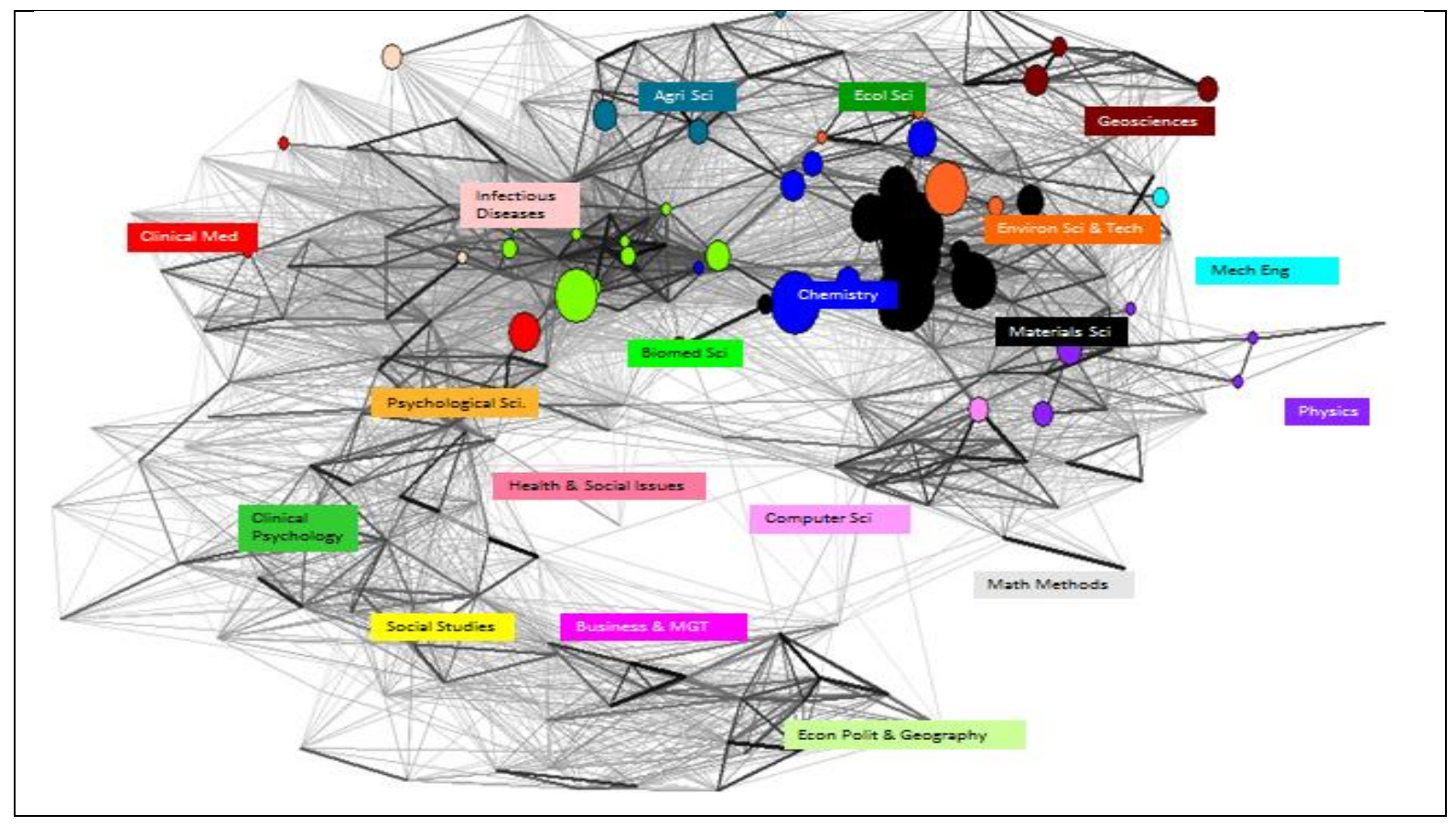

Figure 23. Publication profiles overlaid on the map of science of Ankara University, 2000-2005

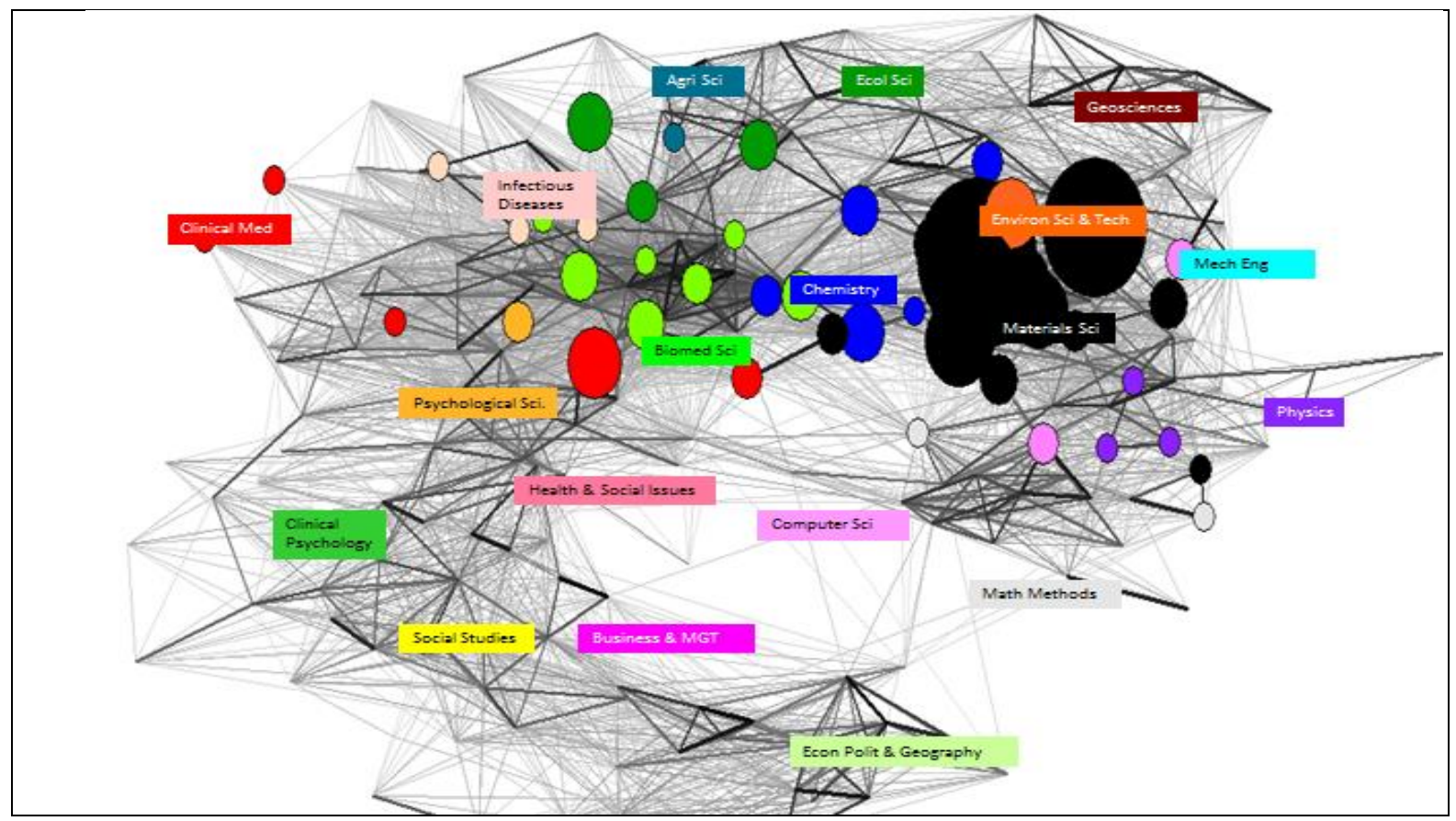

Figure 24. Publication profiles overlaid on the map of science of Gazi University, 2000-2005 
The statistical results from the overlaid map based on Subject Categories for Ankara University are as following: betweenness centrality of 0.072 , degree centrality of 0.224 and closeness centrality of 0.373 . Results indicate that the flow of information is high both among and within sub-clusters.

On the other hand, Gazi University's centralities results are following: betweenness degree of 0.156 , degree centrality of 0.244 and closeness centrality of 0.373 . Interestingly, Gazi and Ankara's University centralities are almost equal except their betweenness centrality, which indicates that the flow of information in Gazi University diffuses in a higher rate than that in Ankara University does. Moreover, the number of red nodes is (Clinical Medicine) higher in Gazi University as is in Ankara University. In both universities, Material Sciences are the most populated nodes in the network.

Fig. 25 displays that Istanbul Technical University (ITU), which is active in technical sciences mostly, is similar to METU. Material Science and Environmental Science \& Technology are focal points in the overlay map. Moreover, ITU is active in Economic Politics \& Geography, Science in the lower part of the map. Biomedical Science is obvious in the center of the map with two nodes, and, to the right, three Clinical nodes are displayed in the network structure.

The statistical results from the overlaid map based on WoS Subject Categories for Istanbul Technical University are following: betweenness centrality of 0.151 , degree centrality of 0.109 and closeness centrality of 0.363 . Comparing to the base map's result in Table 6, knowledge spreads between sub-clusters faster due to higher betweenness centrality. Nevertheless, degree centrality and closeness centralities affect the network in diffusion at a lower rate in ITU's network structure.

Gebze Institute of Technology is mostly active in several research subject fields: Materials Science, Environmental Science and Technology and, noticeably, on Clinical Medicine, which indicates that nanotechnology growth in a multidisciplinary research area (Fig 26). Moreover, it has published scientific articles in Health \& Social Issues, Psychological Science and Computer Science to a lesser extent. The statistical results of Gebze Institute 
of Technology are following betweenness centrality of 0.110 , degree centrality of 0.314 and closeness of 0.499 .

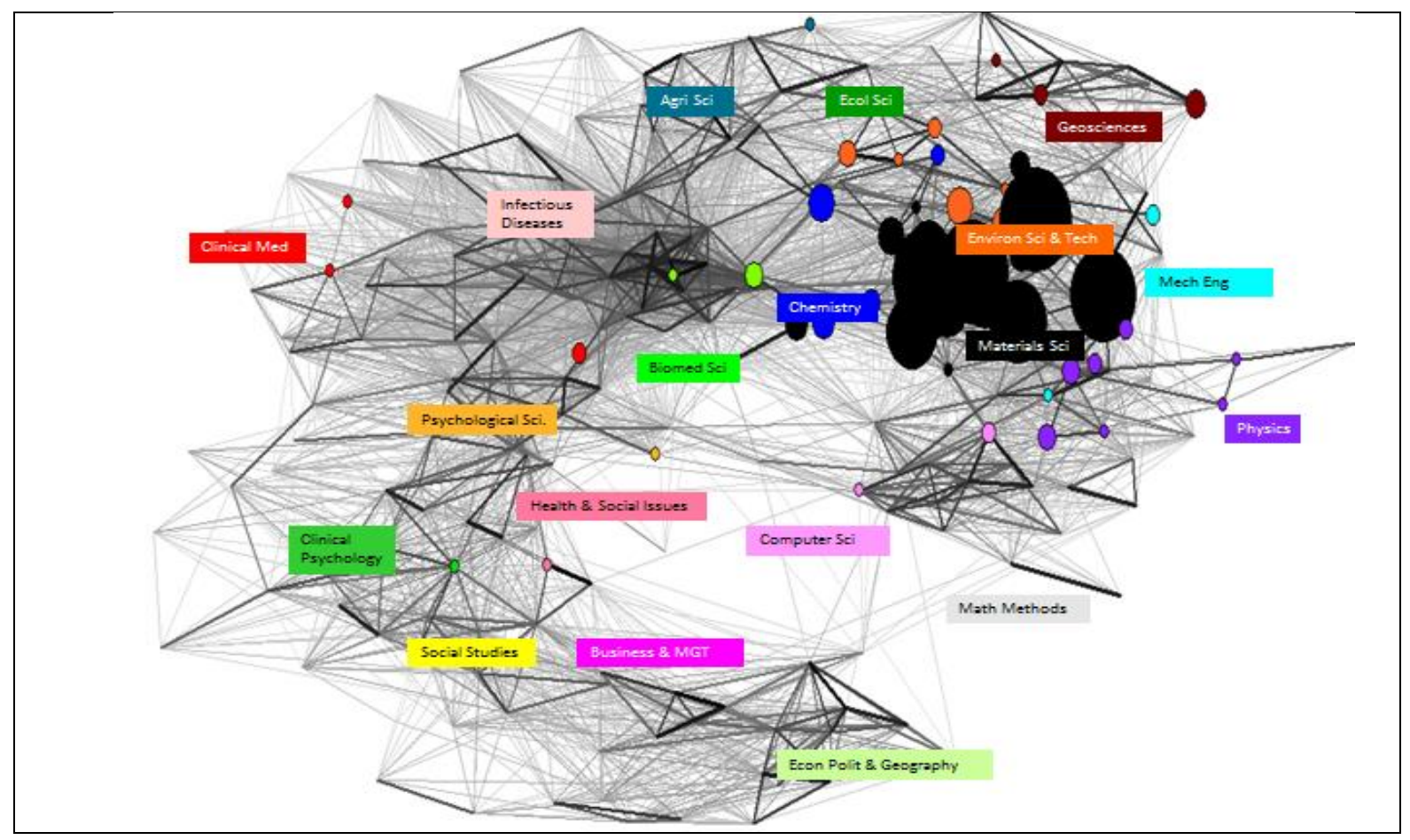

Figure 25. Publication profiles overlaid on the map of science of ITU, 2000-2005

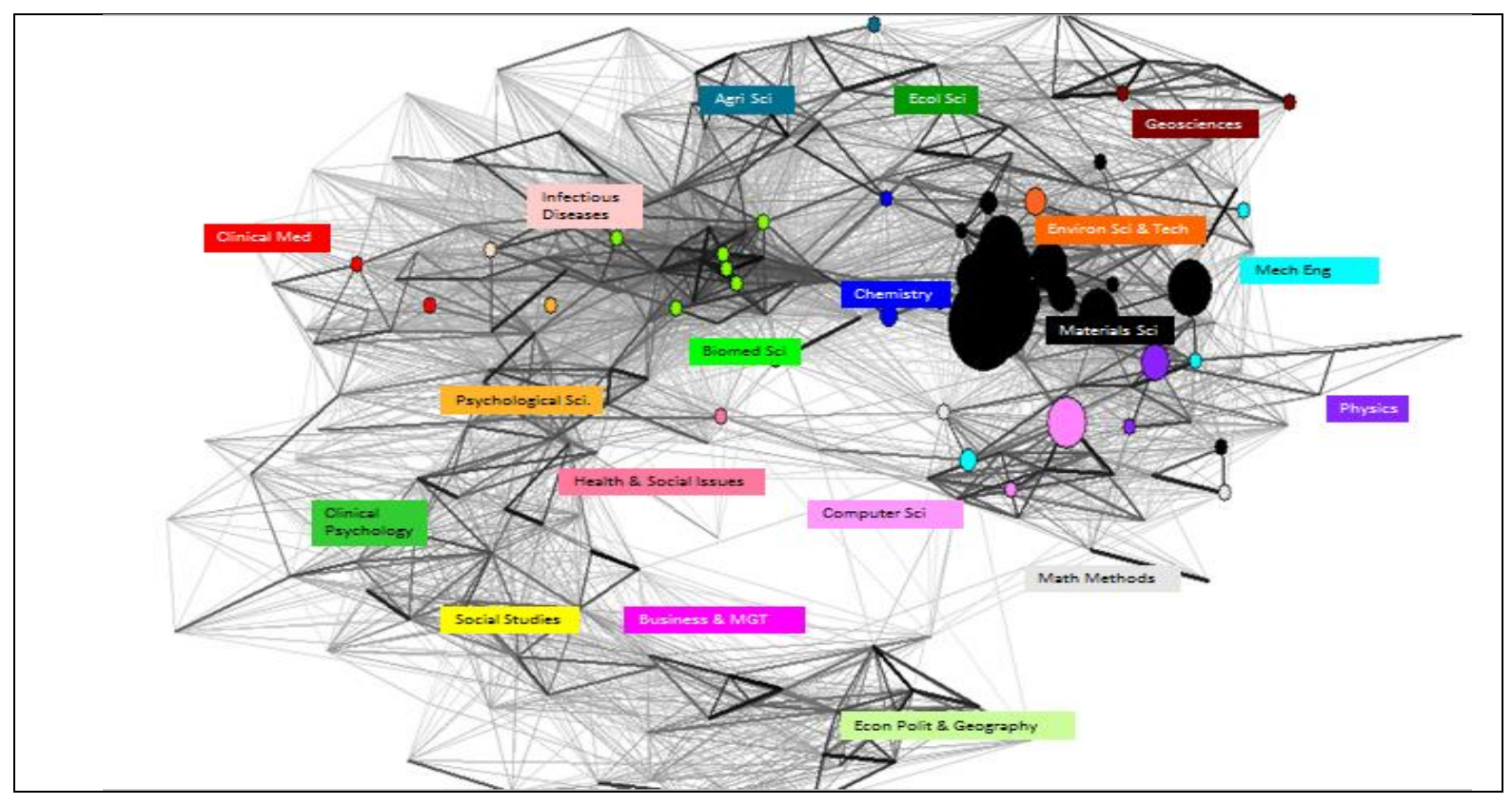

Figure 26. Publication profiles overlaid on the map of science of Gebze Institute of Technology, 2005-2005 
Dokuz Eylül University (Fig. 27) has created less output in terms of publication in Biomedical Science and Clinical Medicine than that of Marmara University (Fig 28). For example, there are 6 nodes in Biomedical Science and 2 nodes in Clinical Medicine at Dokuz Eylül University whereas there are 9 and 6 nodes each in Biomedical Science and Clinical Medicine at Marmara University, respectively. Statistical results for Dokuz Eylül University are following: betweenness centrality of 0.060 , degree centrality of 0.323 and closeness centrality of 0.322 (Fig. 27).

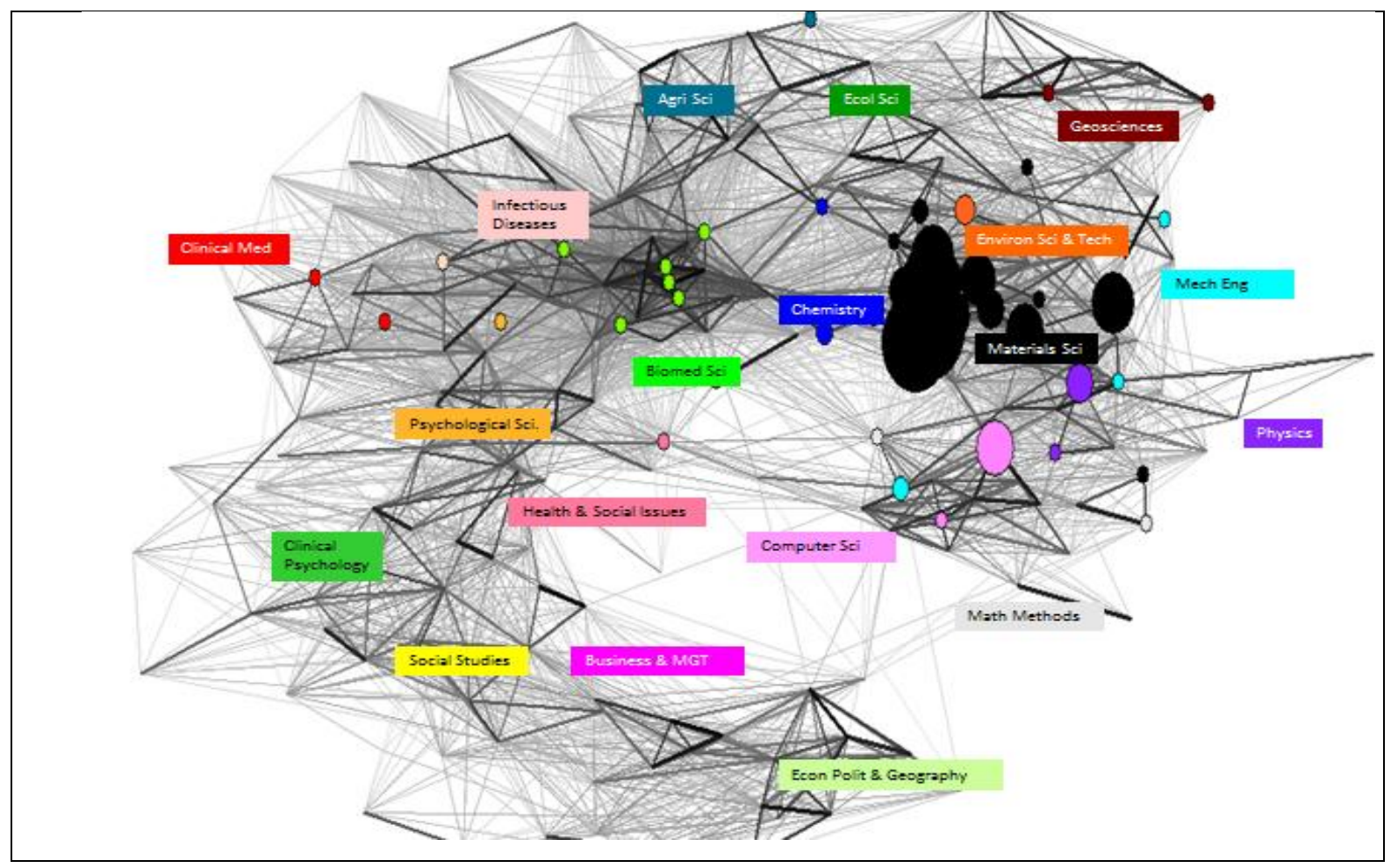

Figure 27. Publication profiles overlaid on the map of science of Dokuz Eylül University, 2000-2005

Marmara University is not only active in Clinical Medicine, Biomed Science and Material Science, but also in the subject field: Infectious Diseases, Agricultural Science, Psychological Science and Health \& Social Sciences. Nevertheless, Material Science is the most populated cluster in terms of nodes in which nano-related research fields are most applicable. Statistical results for Marmara University are following: betweenness centrality of 0.215 , degree centrality of 0.225 and closeness centrality of 0.336 (Fig. 28). 


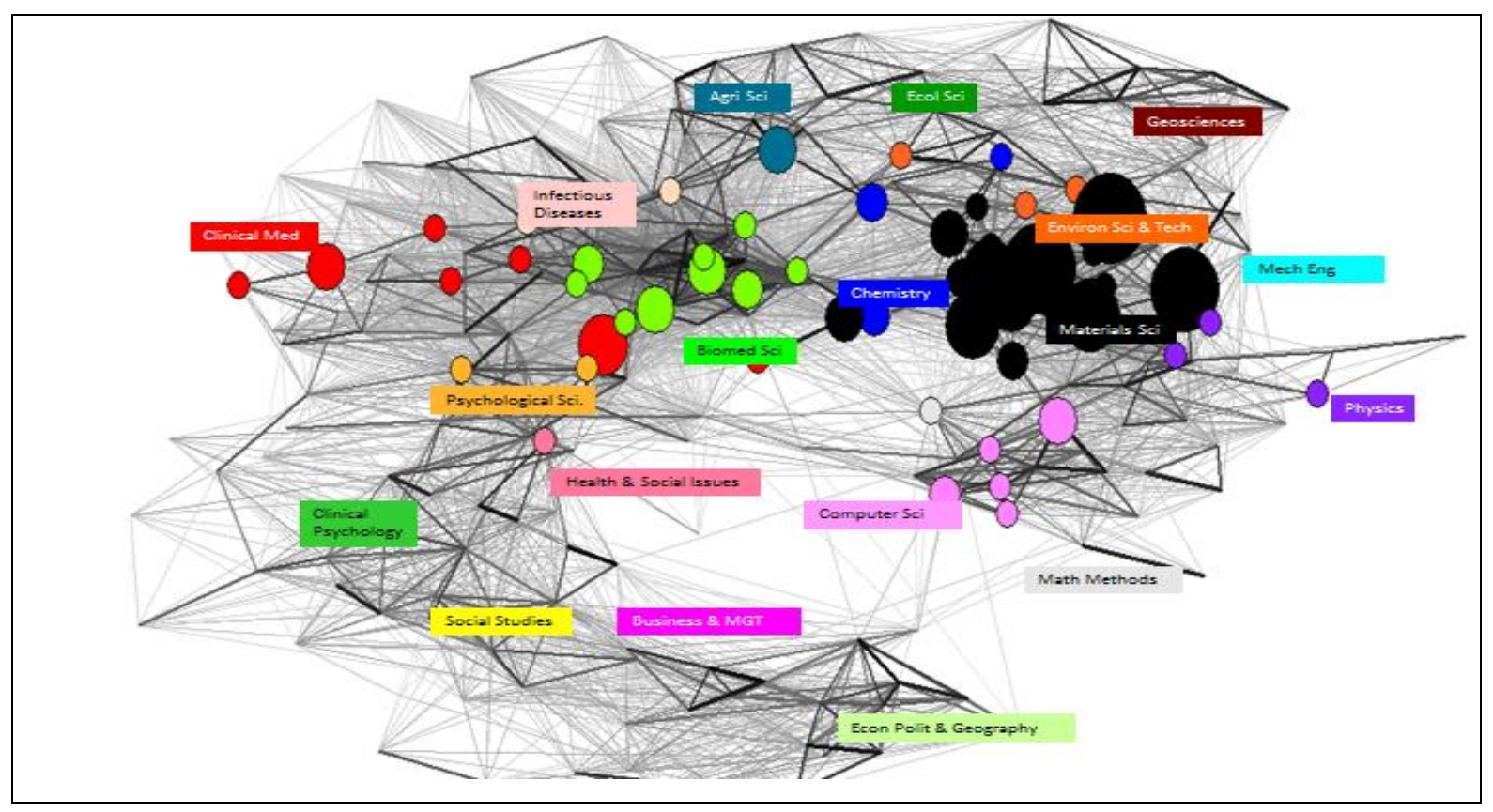

Figure 28. Publication profiles overlaid on the map of science of Marmara University, 2000-2005

Unlike previous network structures, Abant İzzet Baysal University contains two subject fields between 2000 and 2005: Chemistry and Material Science. The statistical results from the overlaid map based on Subject Categories for Abant İzzet Baysal University are as follows: betweenness of 0.184 , degree centrality of 0.252 , and closeness centrality of 0.612 (Fig. 29). Despite its size, in contrast to the base map, its network properties are relatively high, which indicates the flow of information among and within sub-clusters continues at a higher rate.

Kırıkkale University has published in Biomedical Science, Clinical Medicine and Materials Science. Moreover, there are a few clusters for Chemistry and one in Physics. The statistical results for the overlaid map based on Subject Categories for Kirıkkale University are following: betweenness of 0.119 , degree centrality of 0.288 and closeness of 0.457 (Fig. 30). In contrast with the base map, diffusion of information is high in subclusters, but it is slower among them. 


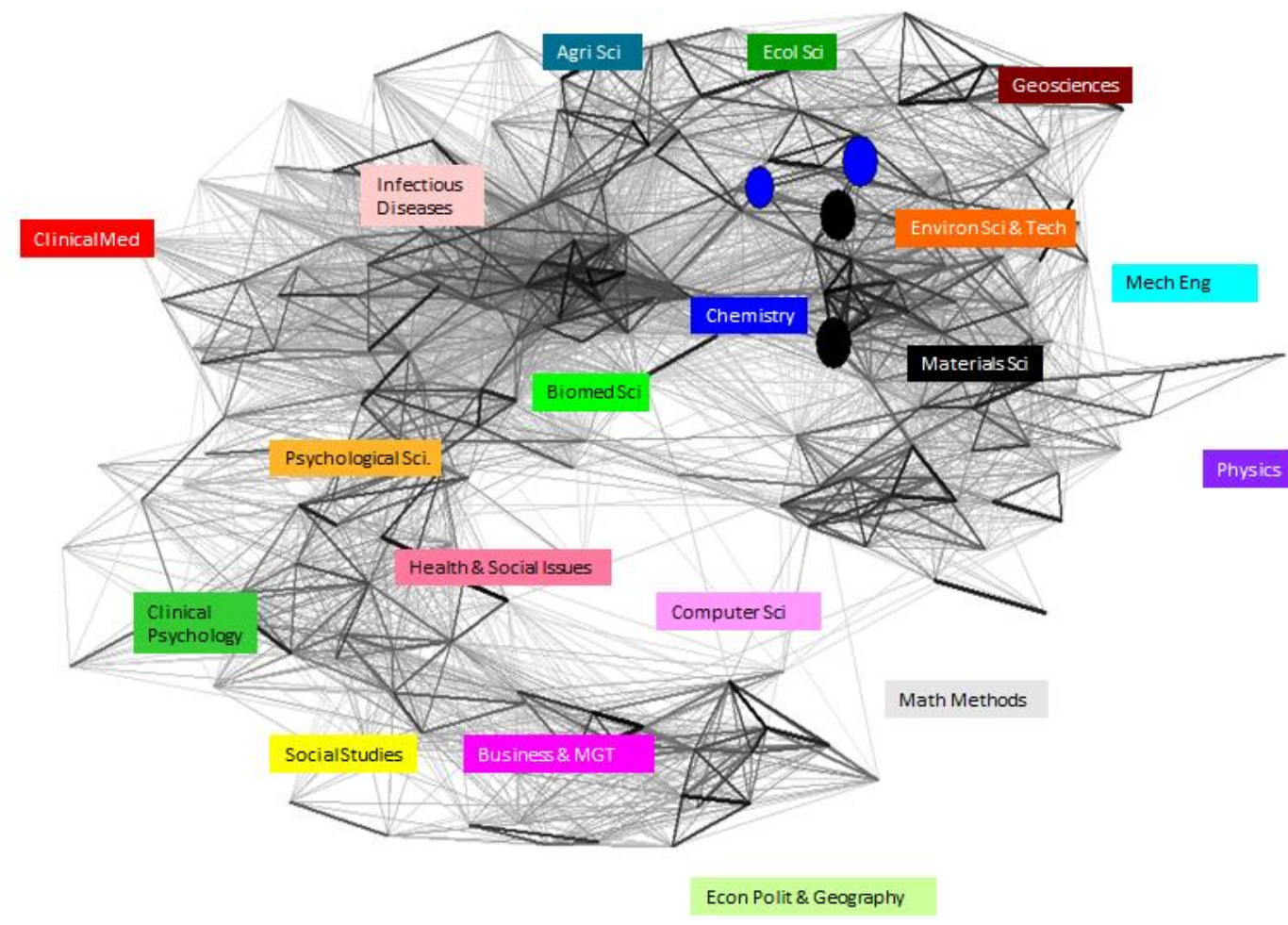

Figure 29. Publication profiles overlaid on the map of science of Abant İzzet Baysal University, 2000-2005

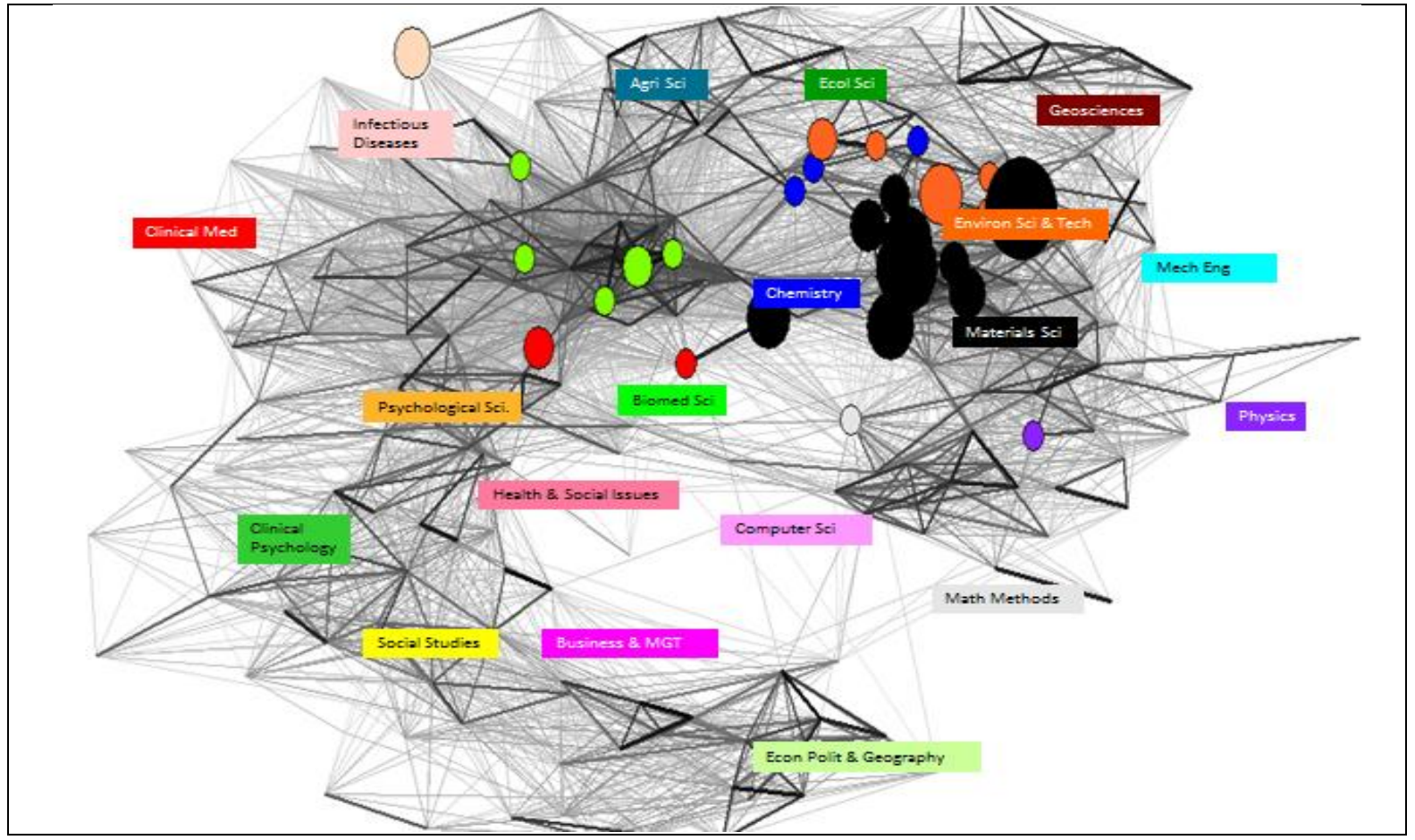

Figure 30. Publication profiles overlaid on the map of science of Kırıkale University, 2000-2005 
In contrast with most of earlier universities, which are mostly productive in Materials Science, Ege University is productive in Clinical Medicine, Biomedical Science, Infectious Diseases and Materials Science. The statistical results for the overlaid map based on Subject Categories for Ege University are as follows: betweenness centrality of 0.126 , degree centrality of 0.276 and closeness centrality of 0.359 (Fig. 31).

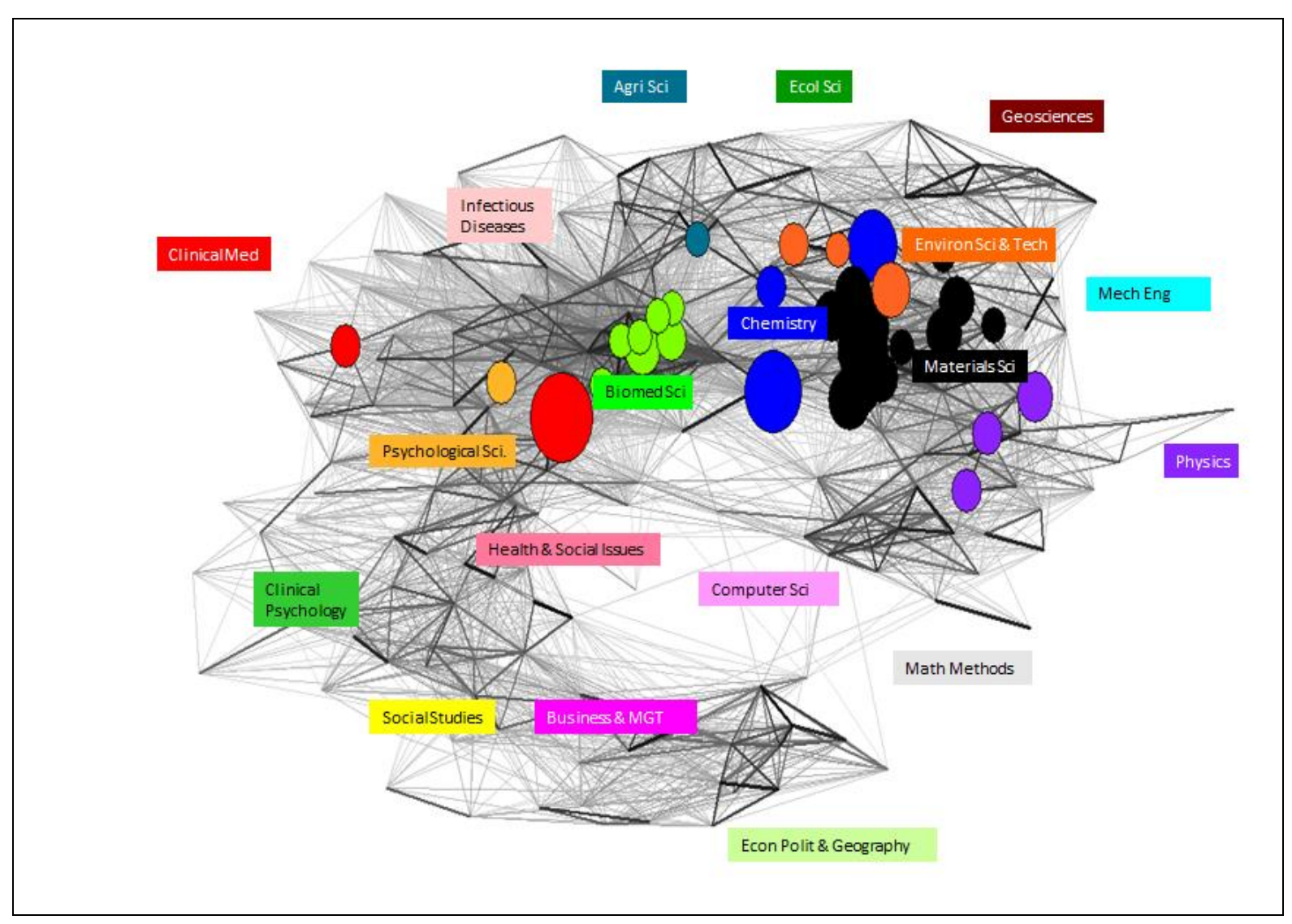

Figure 31. Publication profiles overlaid on the map of science of Ege University, 2000-2005 
Infectious Diseases, Chemistry, Environmental Science \& Technology, Geoscience, Computer Science, Physics, Mechanical Engineering and Materials Science occupied Erciyes' network structure between 2000 and 2005 in Turkey (Fig. 32). Erciyes University's network properties of betweenness of 0.098 , degree centrality of 0.162 and closeness centrality of 0.466 make it less influential in terms of flow of information within its sub-clusters in the network structure.

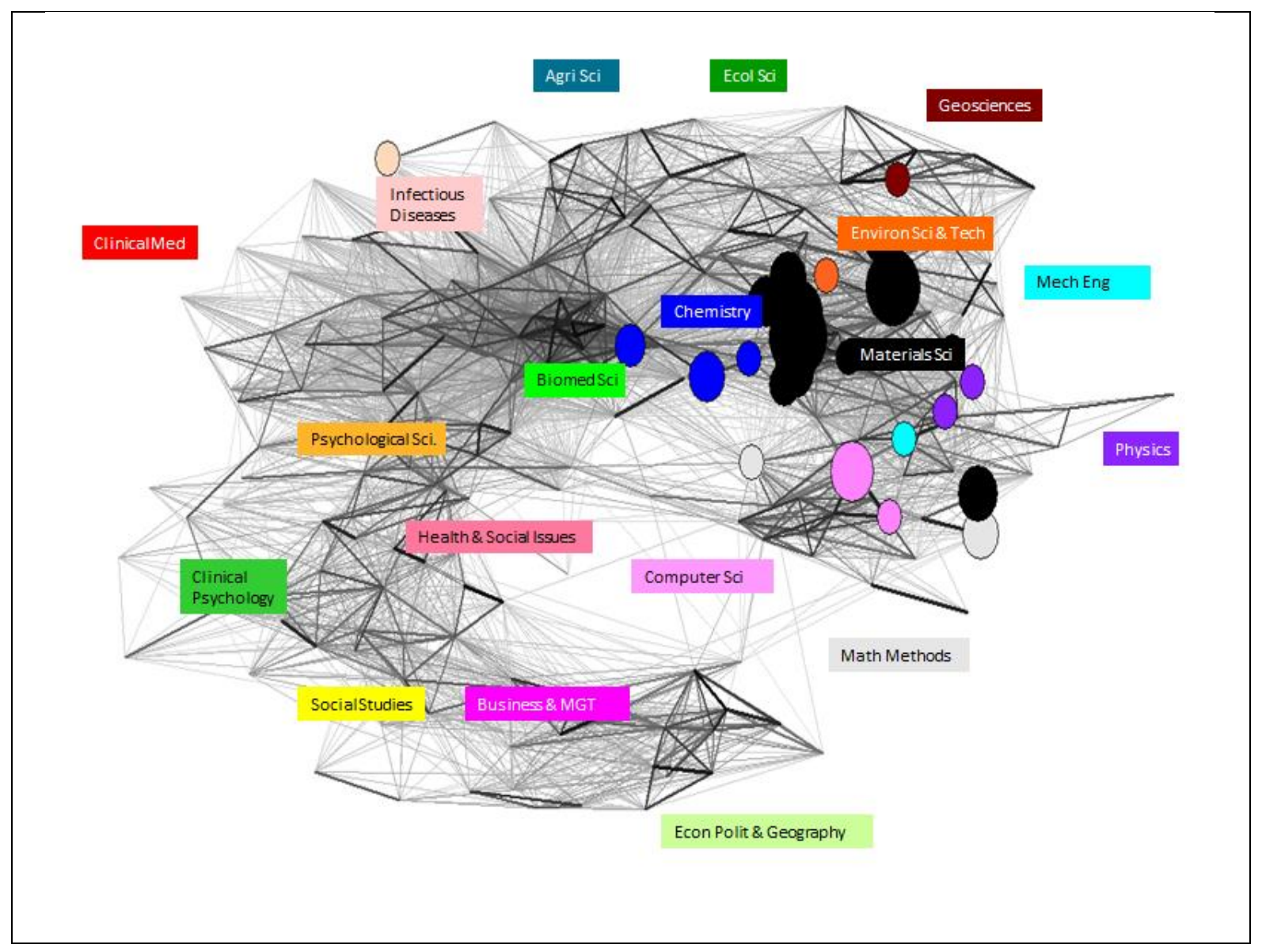

Figure 32. Publication profiles overlaid on the map of science of Erciyes University, 2000-2005 
Although Kocaeli University being active only in three subject fields( Materials Science with highest numbers of node, Clinical Medicine and Economical Science \& Technology), it has the highest betweenness centrality of 0.425 , which illustrates that the flow of information among its sub-clusters is higher compared to the base map (Fig. 33). Moreover, degree centrality and closeness centralities are 0.218 and 0.325 , respectively.

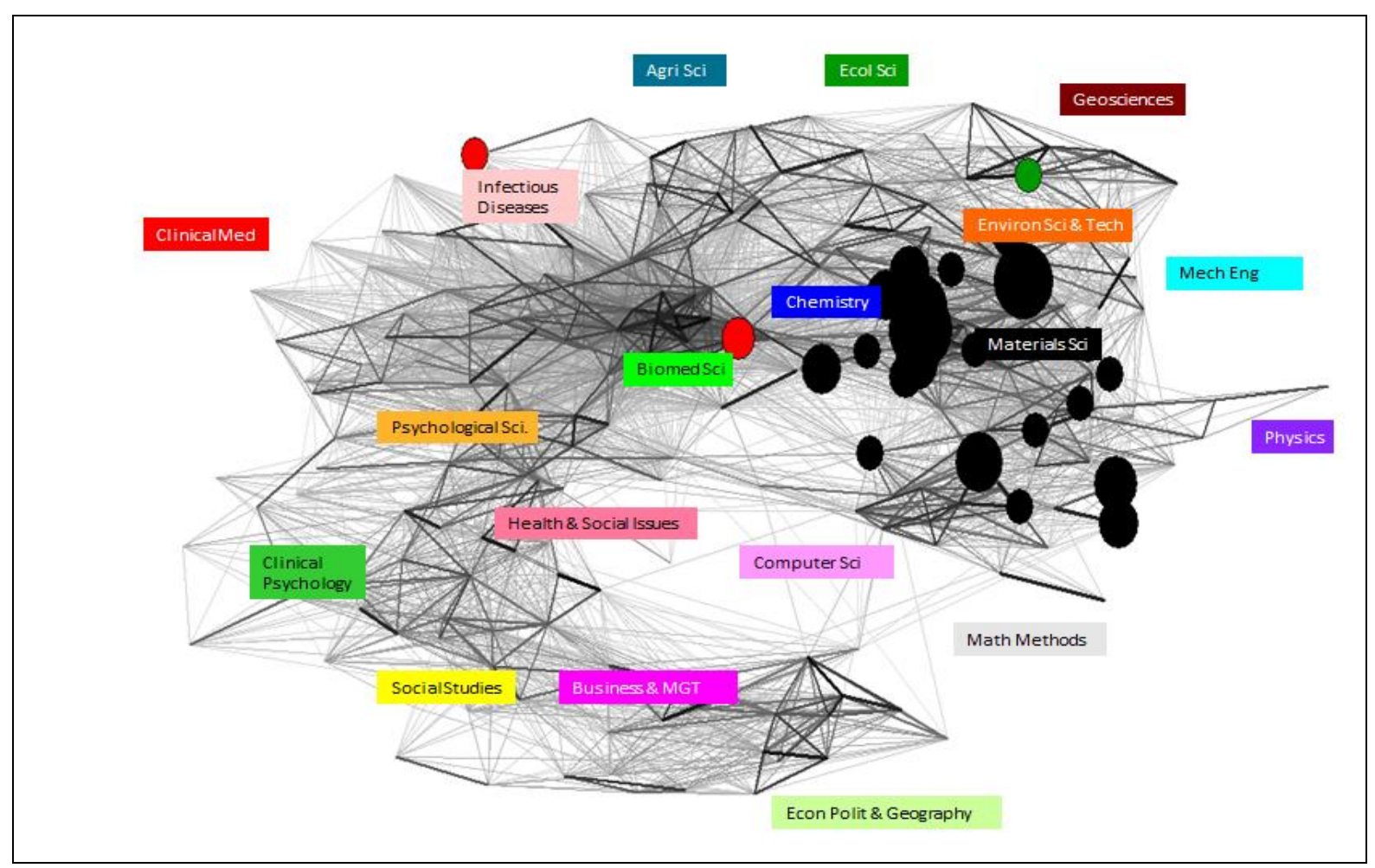

Figure 33. Publication profiles overlaid on the map of science of Kocaeli University, 2000-2005

In the next section, we review the overlay map of universities with the highest degree centrality coefficients based on their WoS subject categories on the scientific map from 2006 to 2011. 


\subsection{NETWORK OF NANO-RELATED TECHNOLOGY IN SELECTED UNIVERSITIES: 2006-2011}

Materials Science, Chemistry, Physics and Computer Science and to some extent, Environmental Science, Physiological Science are research subject fields in Bilkent University. The statistical results for the overlaid map based on Subject Categories for Bilkent University are as follows: betweenness of 0.069 , degree centrality of 0.620 and closeness centrality of 0.558 (Fig. 34).

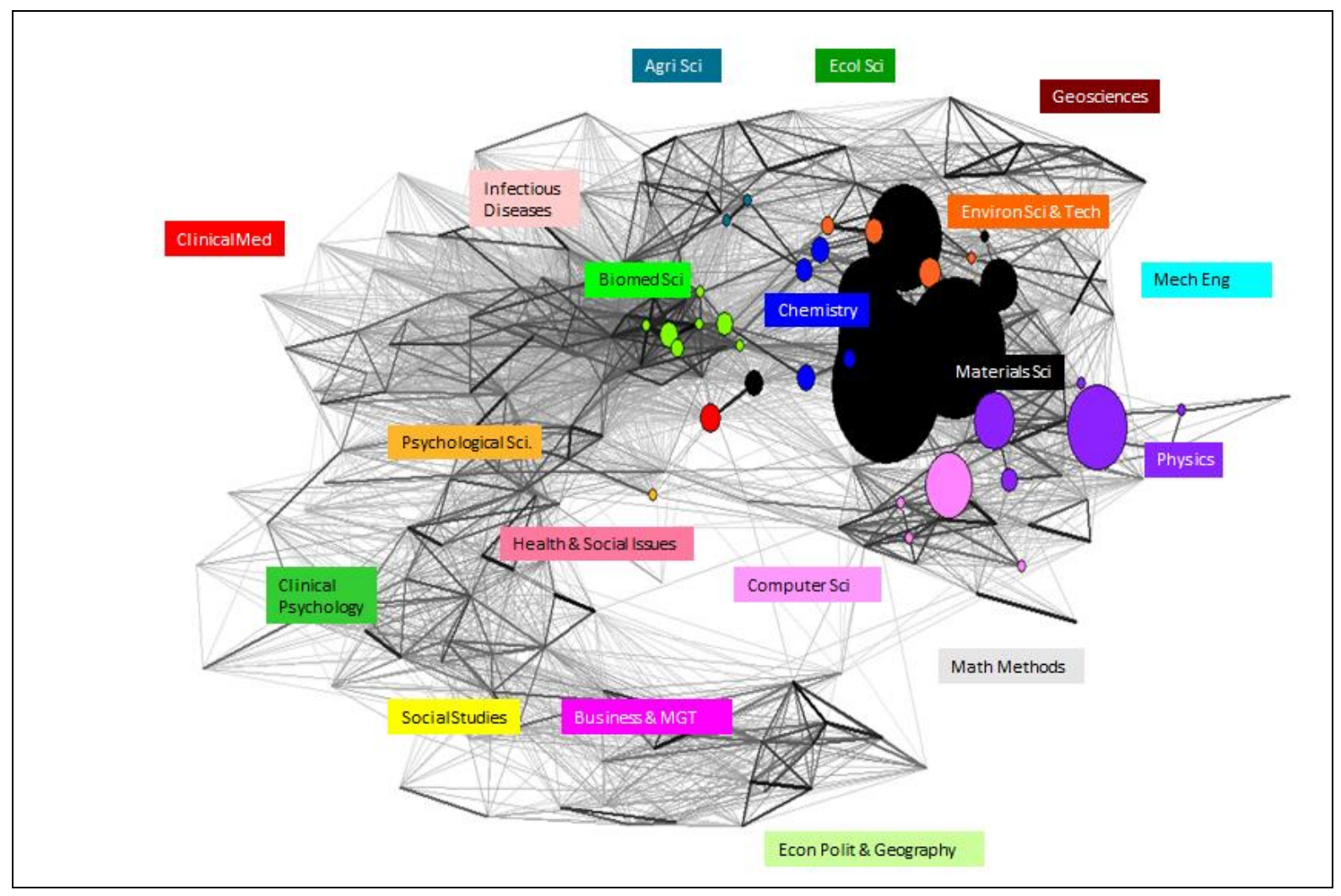

Figure 34. Publications profiles overlaid on the map of science of Bilkent University, 2006-2011 
Gebze Institute of Technology was not as active on Clinical Medicine as Ankara University was in 2006-2011. Biomedical Science and Materials Sciences, and to some extent, Business and Management, Physiological, Economic Policy, Geography and Physics were investigated by researchers between 2006 and 2011. The statistical results for the overlaid map based on Subject Categories for Gebze Inst of Technology are as follows: betweenness of 0.068 , degree 0.603 and closeness of 0.541 (Fig. 35).

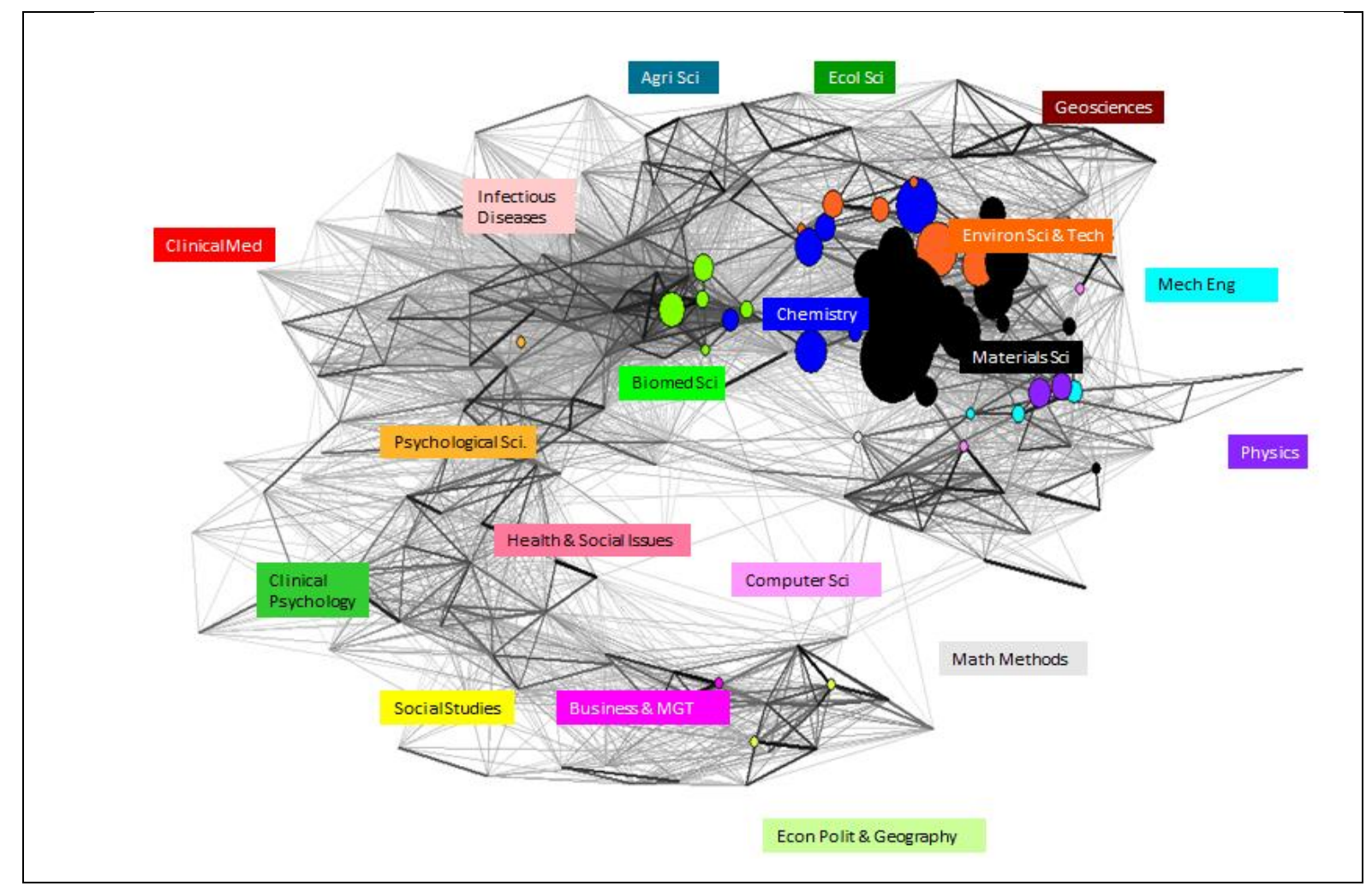

Figure 35. Publications profiles overlaid on the map of science of Gebze Inst Tech, 2006-2011 
Hacettepe University has the third highest degree coefficient centrality in the network structure: 2006-2011 (Table 7). Psychological Science and Infectious Diseases have become more apparent in the second period at Hacettepe University. Still, Materials Sciences and Clinical Medicine have grown in number of nodes. The number of nodes in Clinical Medicine has increased in the second period, 2006-2011. The statistical results for the overlaid map based on Subject Categories for Hacettepe University are following: betweenness of 0.022 (which is the lowest betweenness degree among 15 universities) (Fig. 36).

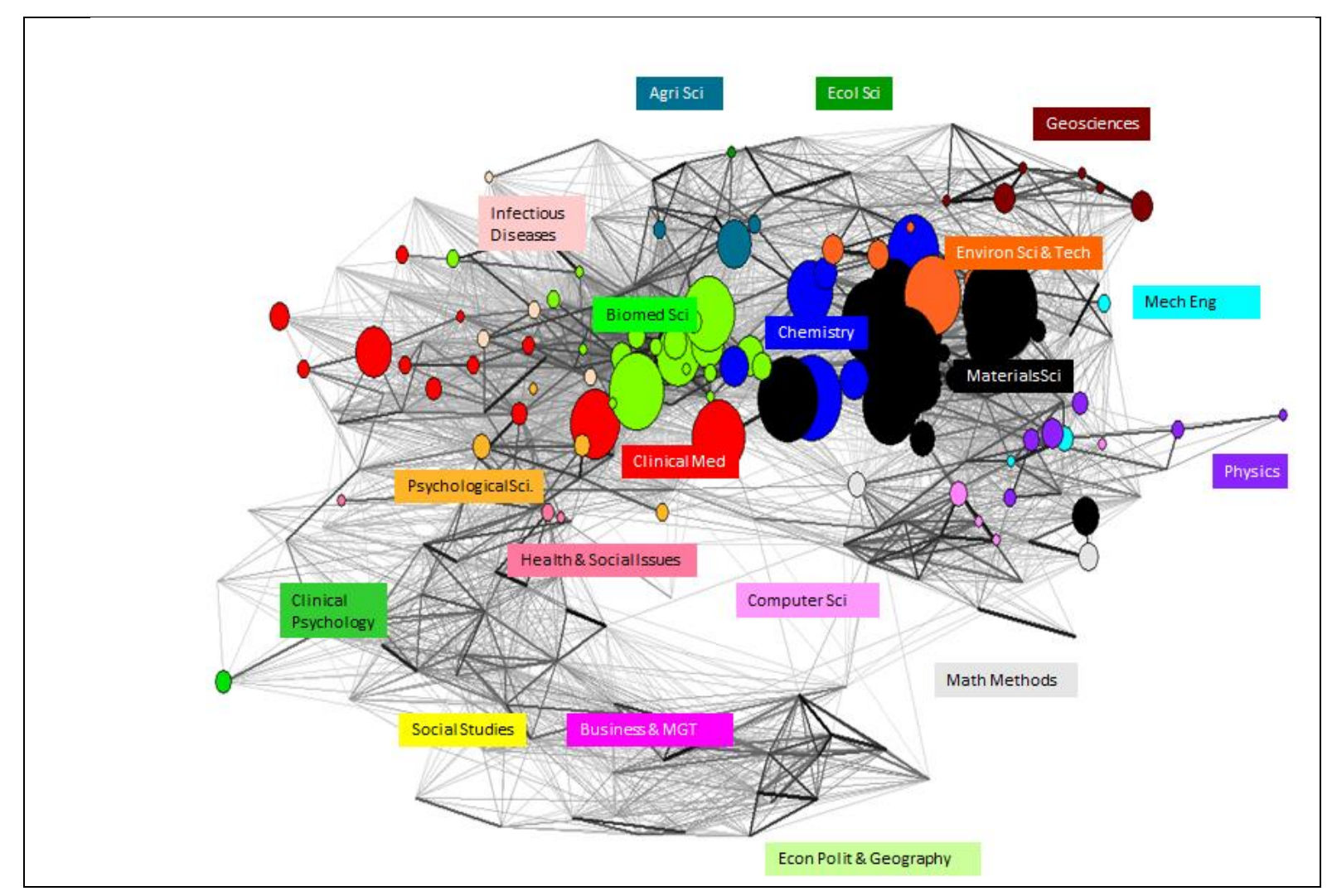

Figure 36. Publications profiles overlaid on the map of science of Hacettepe University, 2006-2011 
METU has published more articles in Clinical Psychology, Psychological Science and Social Studies; however, Materials Science, and Chemistry and Physics research fields are still front-runners in METU. The statistical results for the overlaid map based on Subject Categories for METU as follows: betweenness of 0.054 , degree centrality of 0.562 and closeness coefficient of 0.511 (Fig. 37).

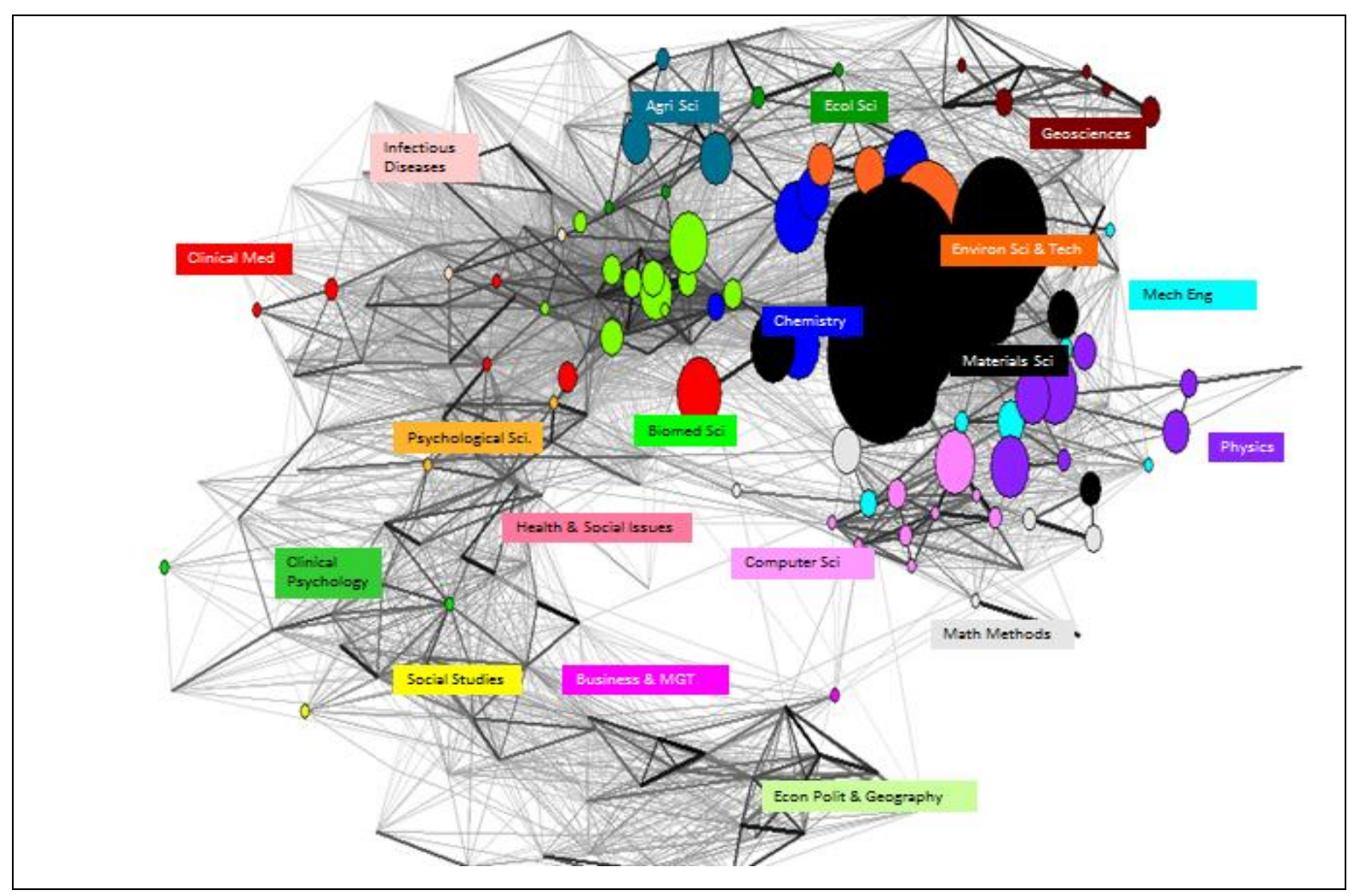

Figure 37. Publication profiles overlaid on the map of science of METU University, 2006-2011 
There are fewer nodes of Clinical Medicine in the center of the map in Gazi University; however, existing nodes are denser. Psychological Science, Health \& Social Issues and Clinical Psychology are denser in the second period for Gazi University The statistical results for the overlaid map based on Subject Categories for Gazi University are as follows: betweenness of 0.070 , degree centrality of 0.457 , and closeness centrality of 0.373 (Fig. 38).

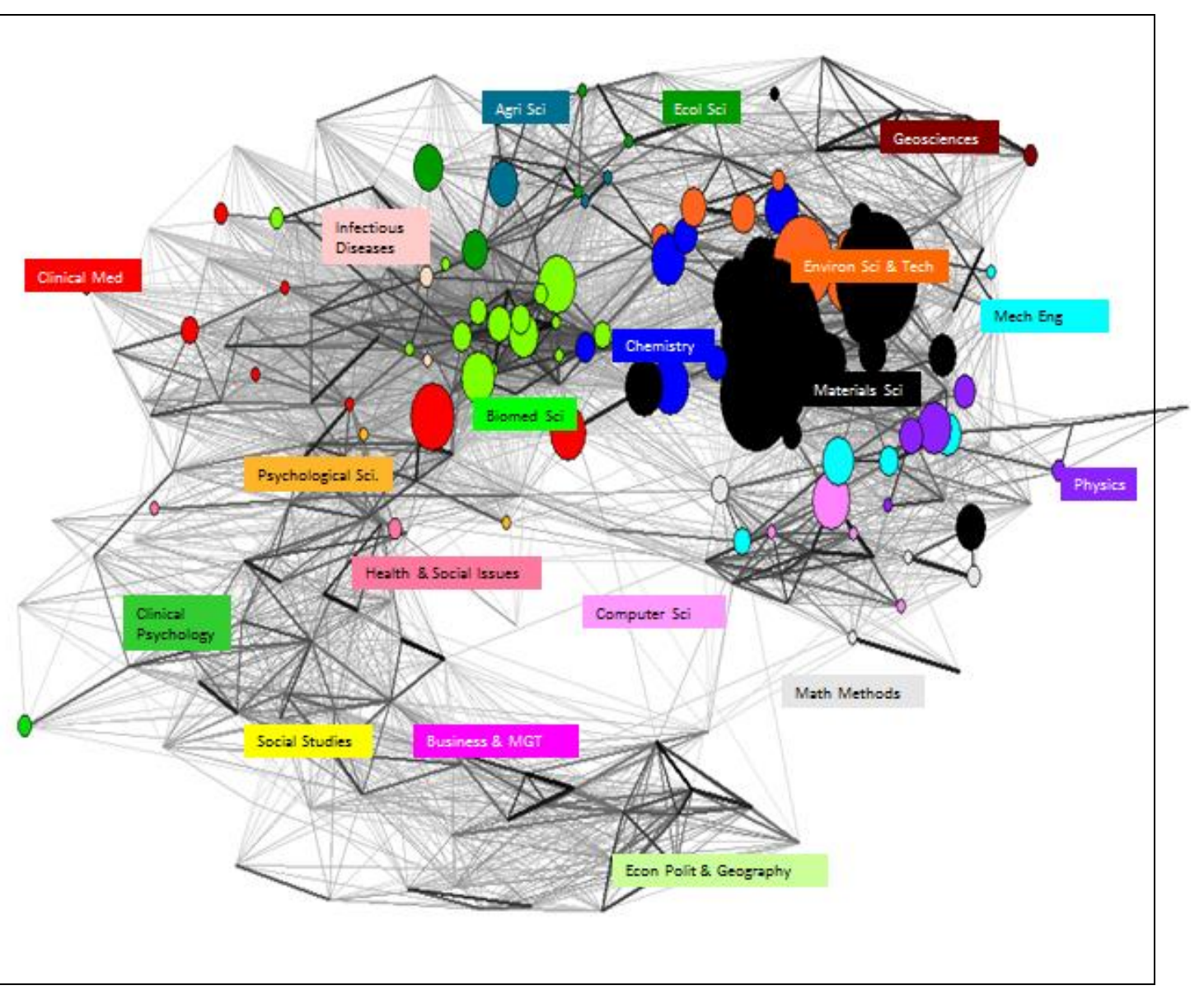

Figure 38. Publications profiles overlaid on the map of science of Gazi University, 2006-2011 
Istanbul Tech University (ITU) is illustrated in Figure 39. The right side of the graph is made up of Materials Science and so on. Business \& Management is shown in the bottom of the map. In the center of the graph, there is a reciprocity between a node of Clinical Medicine and a node of Materials Sciences designated with a black line, we can conjecture that there is a multi/inter disciplinary among Clinical and Materials Sciences. The statistical results for the overlaid map based on Subject Categories for ITU are as follows: betweenness of 0.031 , degree centrality of 0.534 , and closeness centrality of 0.468 .

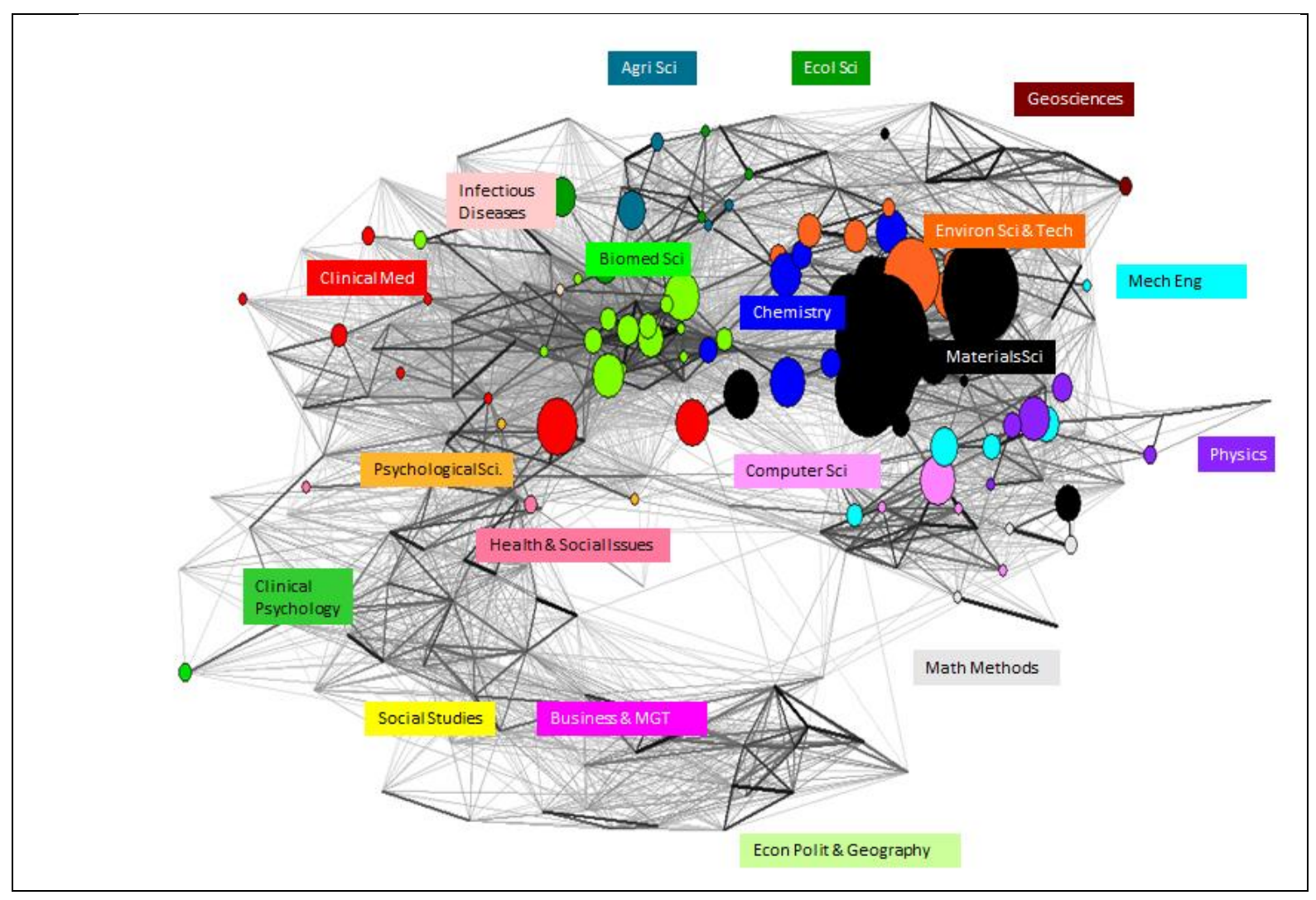

Figure 39. Publication profiles overlaid on the map of science of ITU, 2006-2011 
There is a relationship between two nodes in Materials Science and Clinical Medicine in Ankara University (Fig. 40). Social Studies is grown bigger than other research topics visible at the left hand side of the graph with a node. Likewise previous maps, Materials Science are identified by dense nodes which are proportioned to number of publications in 2006-2011. The statistical results for the overlaid map based on Subject Categories for Ankara University are as follows: betweenness of 0.071 , degree of 0.418 , and closeness centrality of 0.363 .

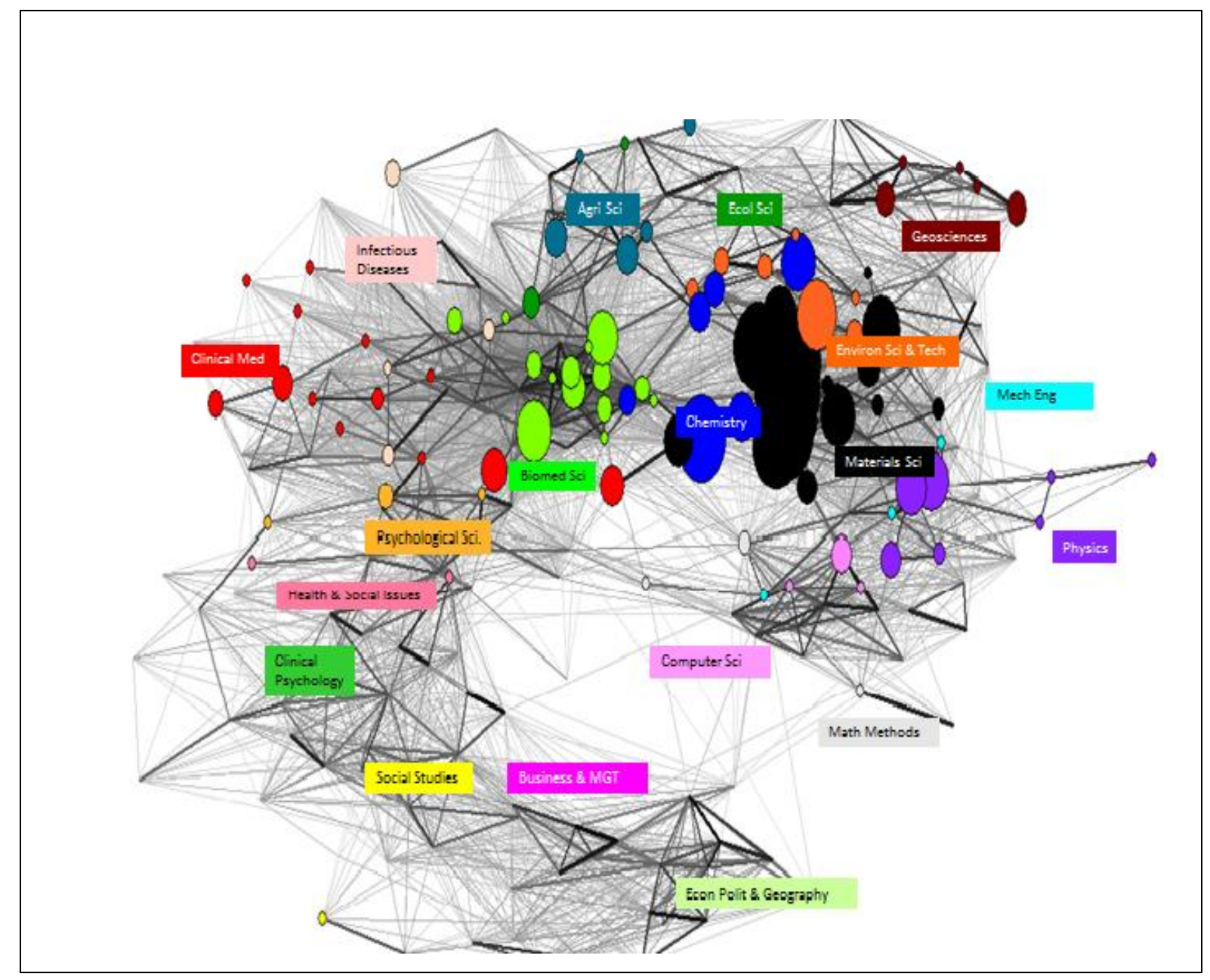

Figure 40. Publications profiles overlaid on the map of science of Ankara University, 2006-2011 
Ondokuz Mayis University did not appear in the network structure of 2000-2005. It carries out research in Clinical Medicine, Materials Science and Ecological Science while Gebze Institute of Technology conducts research on Biomedical Science, Materials Science, and Mechanical Engineering. Ondokuz Mayıs has become active in nano-related technology research. The statistical results for the overlaid map based on Subject Categories for Ondokuz Mayıs University are as follows: betweenness of 0.067, degree centrality of 0,455 and closeness centrality of 0.415 (Fig. 41).

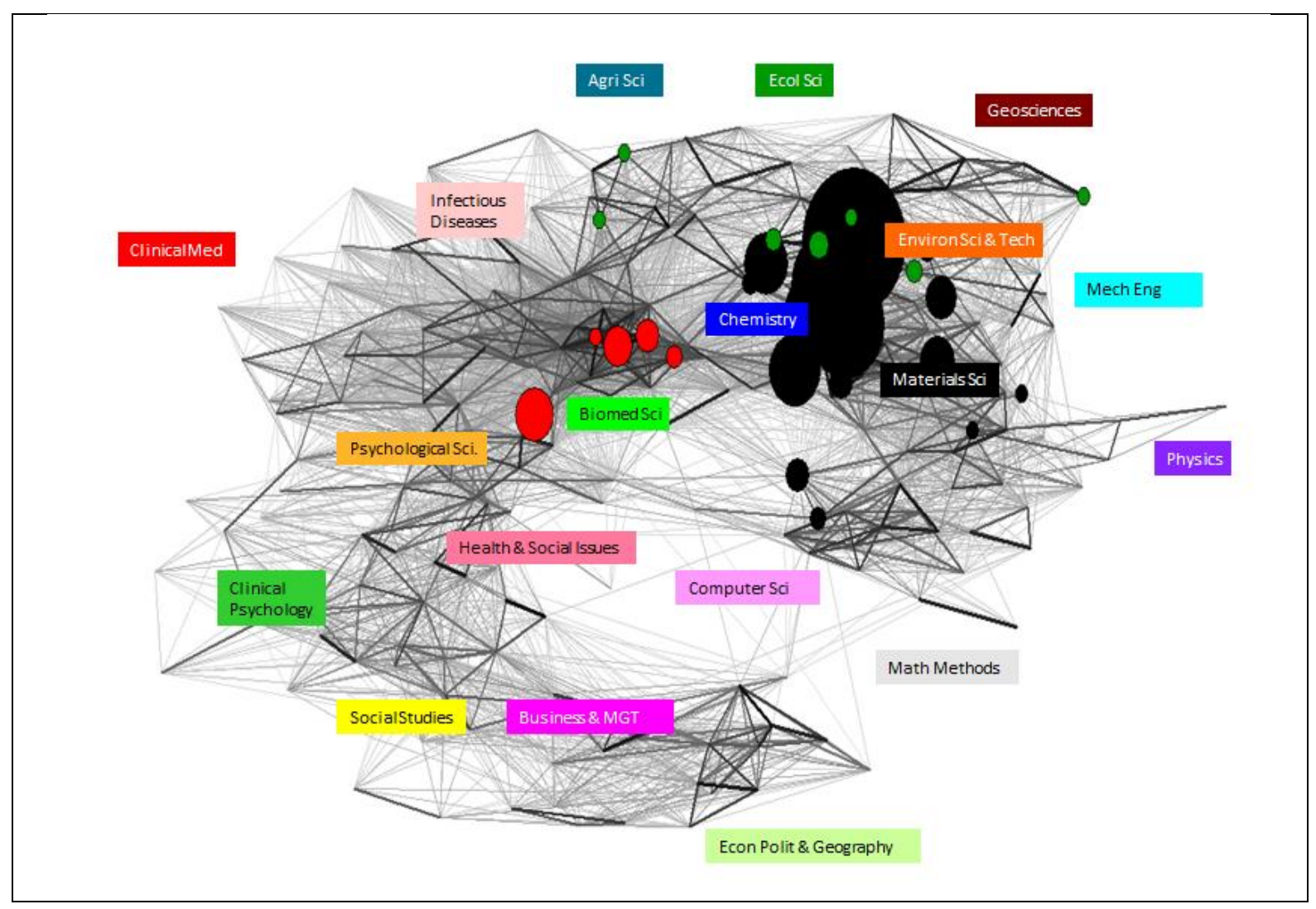

Figure 41. Publications profiles overlaid on the map of science of Ondokuz Mayis University, 2006-2011 
Ege University research activities spans on variety of subject fields: Clinical Medicine, Biomedical Science, Chemistry, Infectious Diseases, Agricultural Science, Ecological Science and so on. In contrast to a few preceding universities, Ege University participates in more research. The statistical results for the overlaid map based on Subject Categories for Ege University are as following: betweenness of 0.035 , degree centrality of 0.431 and closeness centrality of 0.382 (Fig. 42).

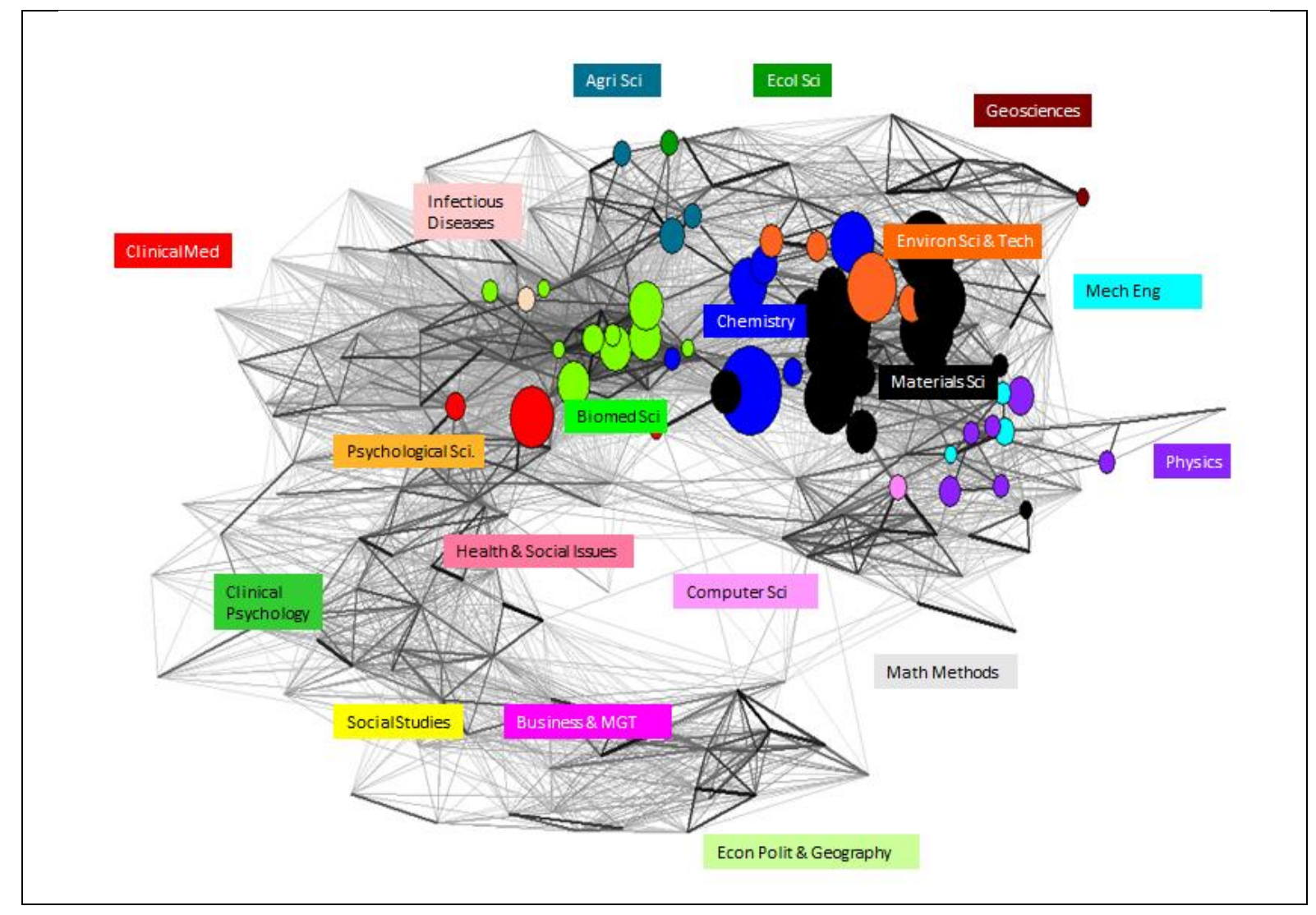

Figure 42. Publications profiles overlaid on the map of science of Ege University, 2006-2011 
Istanbul University mostly active in three subject fields: Materials Science Ecological Science and Clinical Medicine. The statistical results for the overlaid map based on Subject Categories for Istanbul University are as following: betweenness of 0.067 , degree of 0.445 , and closeness degree 0.415 (Fig. 43).

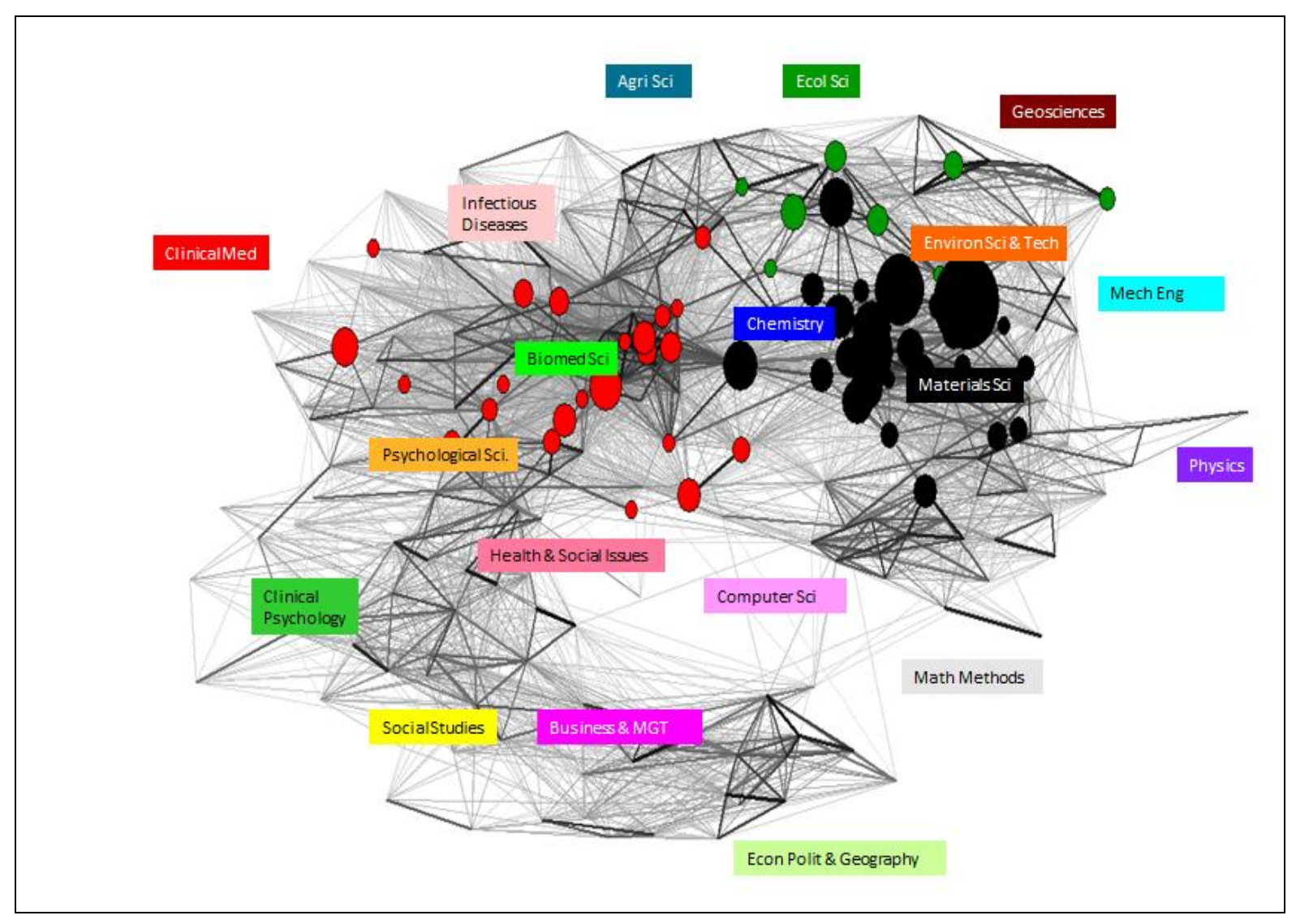

Figure 43. Publications profiles overlaid on the map of science of Istanbul University, 2006-2011 
Ecological Science, Agricultural Science, Clinical Medicine Biomedical Science, Chemistry, Physics and, to some extent, Computer Science and Mathematics Methods are some of the research subject fields investigated by researchers in Erciyes University. There is collaboration between Materials Science and Biomedical Science. However, Biomedical Science has not reached its final potential forming a node yet (see the center of the graph). The statistical results for the overlaid map based on Subject Categories for Erciyes University are as follows: betweenness of 0.049 , degree centrality of 0.256 and closeness centrality of 0.452 (Fig. 44).

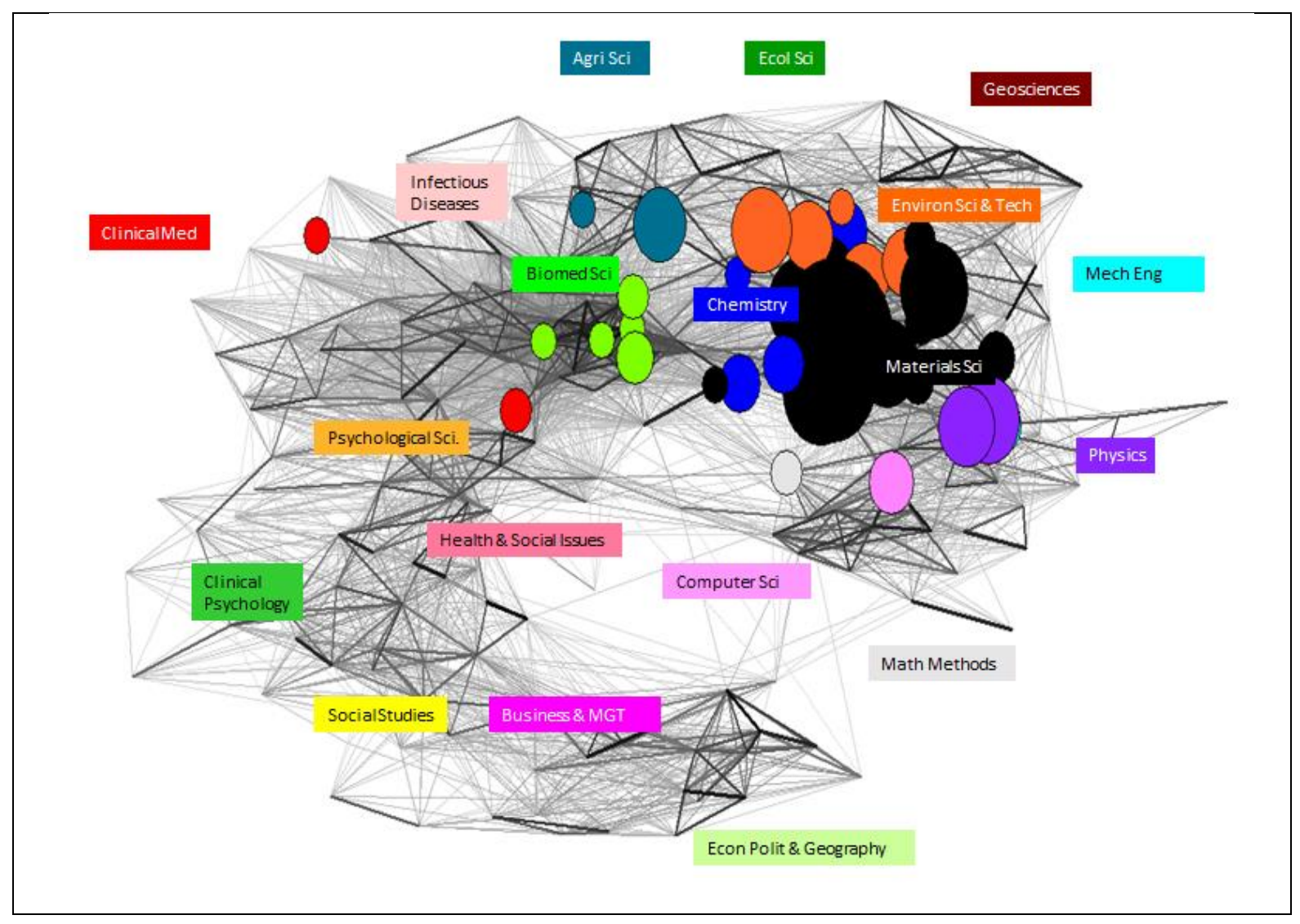

Figure 44. Publications profiles overlaid on the map of science of Erciyes University, 2006-2011 
In contrast to Dokuz Eylül University's network structure in 2000-2005 regarding its research subject areas (Fig. 45), growth in almost all research fields are noticeable. For example, the tie between Materials Science and Clinical Medicine is stronger, and is shown by a line. Moreover, we can see a relationship between Mathematics Methods and Materials Science. The statistical results for the overlaid map based on Subject Categories for Dokuz Eylül University are as follows: betweenness of 0.060 , degree centrality of 0.323 , and closeness centrality of 0.322 .

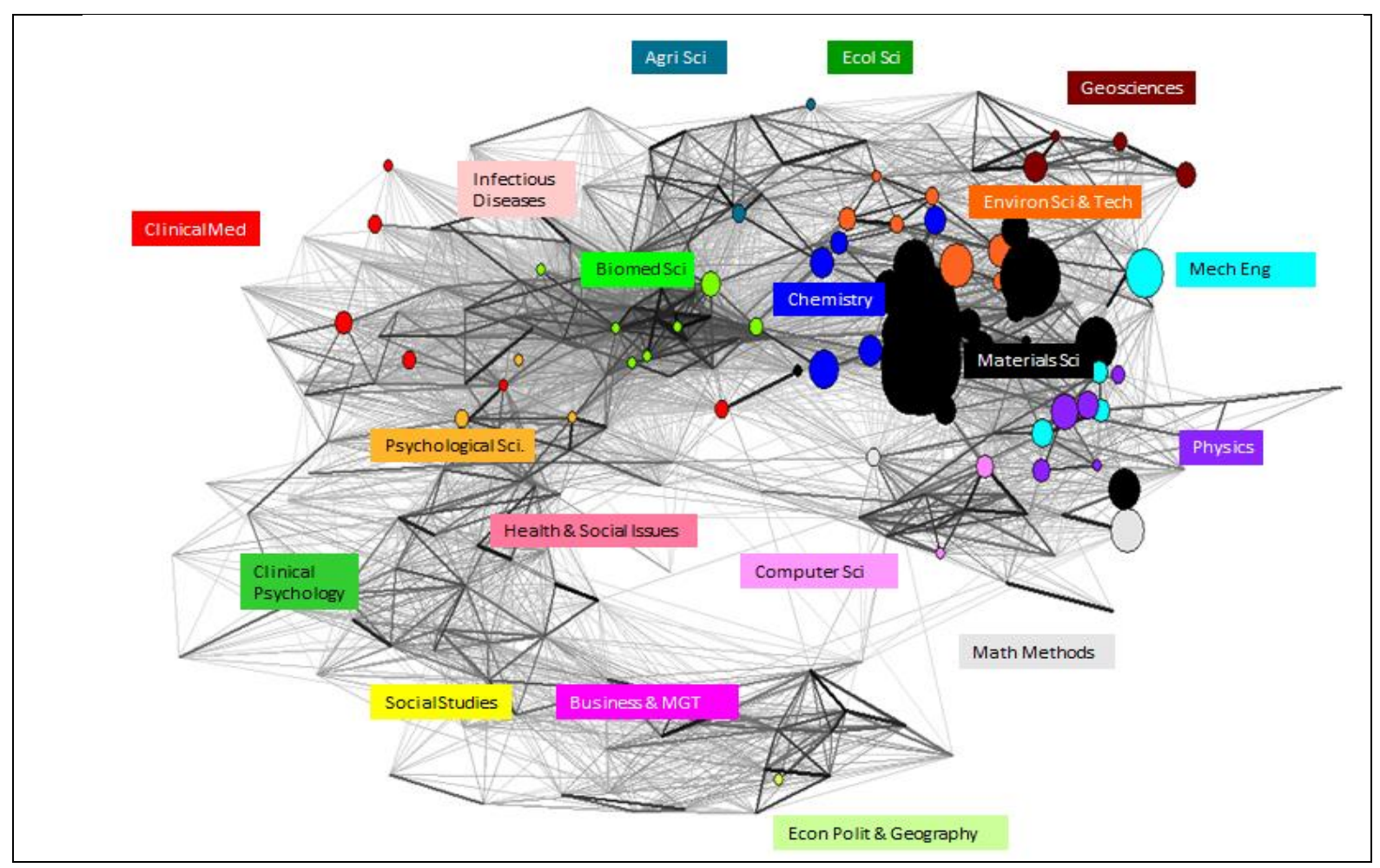

Figure 45. Publications profiles overlaid on the map of science of Dokuz Eylül University, 2006-2011 
Anadolu University appeared with high degree centrality in the second period in network structure with Biomedical Science, Agricultural Science, Chemistry, Physics, Environmental Science and Technology, Materials Science and, to some extent, Geosciences, Computer Science and Mechanical Engineering. Statistical results for the overlaid map based on Subject Categories for Anadolu University are as follows: betweenness of 0.042 , degree centrality of 0.470 and closeness centrality of 0.379 (Fig. 46).

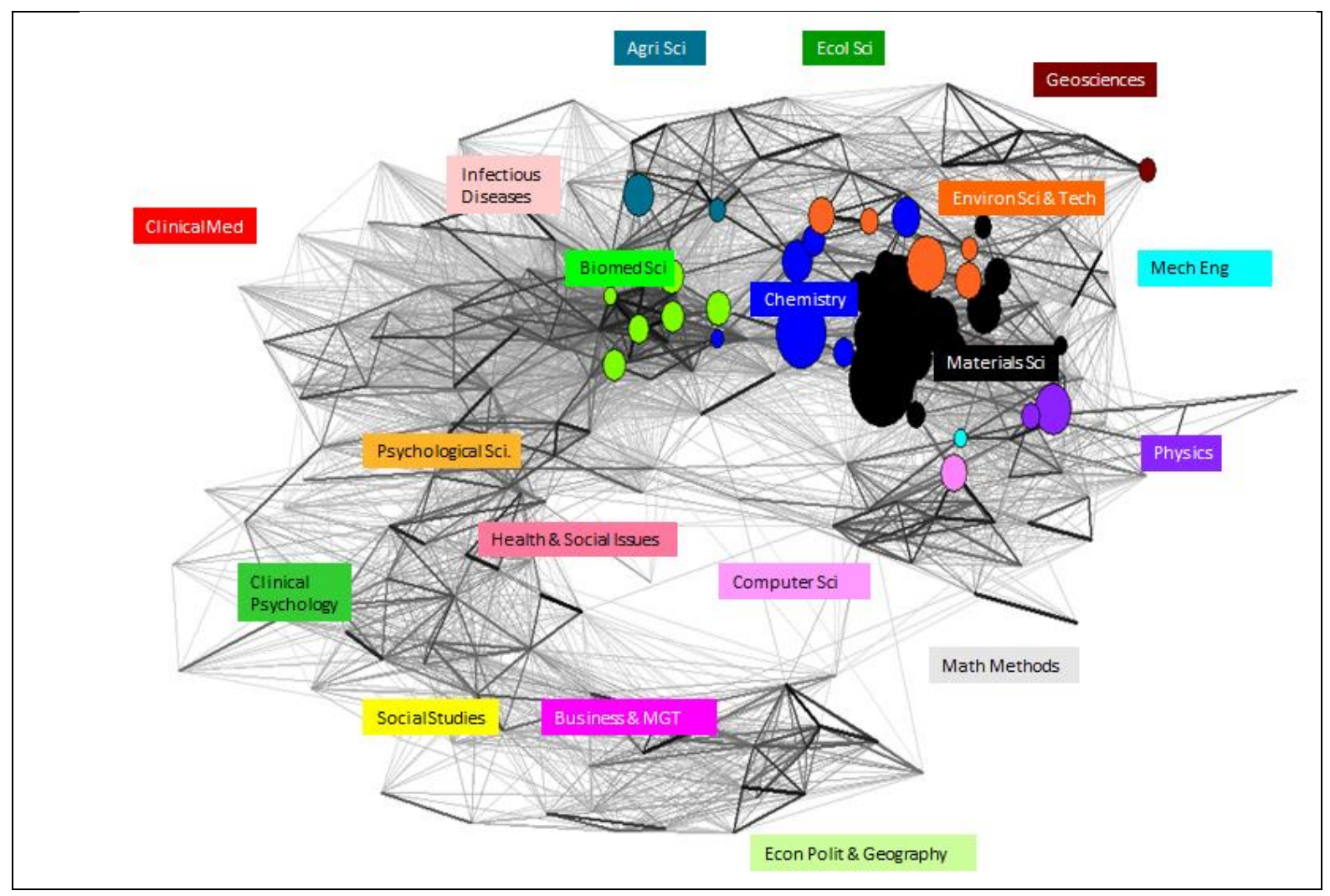

Figure 46. Publications profiles overlaid on the map of science of Anadolu University, 2006-2011 
Atatürk University's publications profiles consist of Clinical Medicine, Chemistry, Agricultural Science, Environmental Science, Physics, and Materials Science. We see that there is a tie between Chemistry and Agricultural Science, Mechanical Engineering and Physics in Atatürk University. Statistical results for the overlaid map based on Subject Categories for Atatürk University are as follows: betweenness of 0.091, degree centrality of 0.230 and closeness centrality of 0.316 (Fig 47).

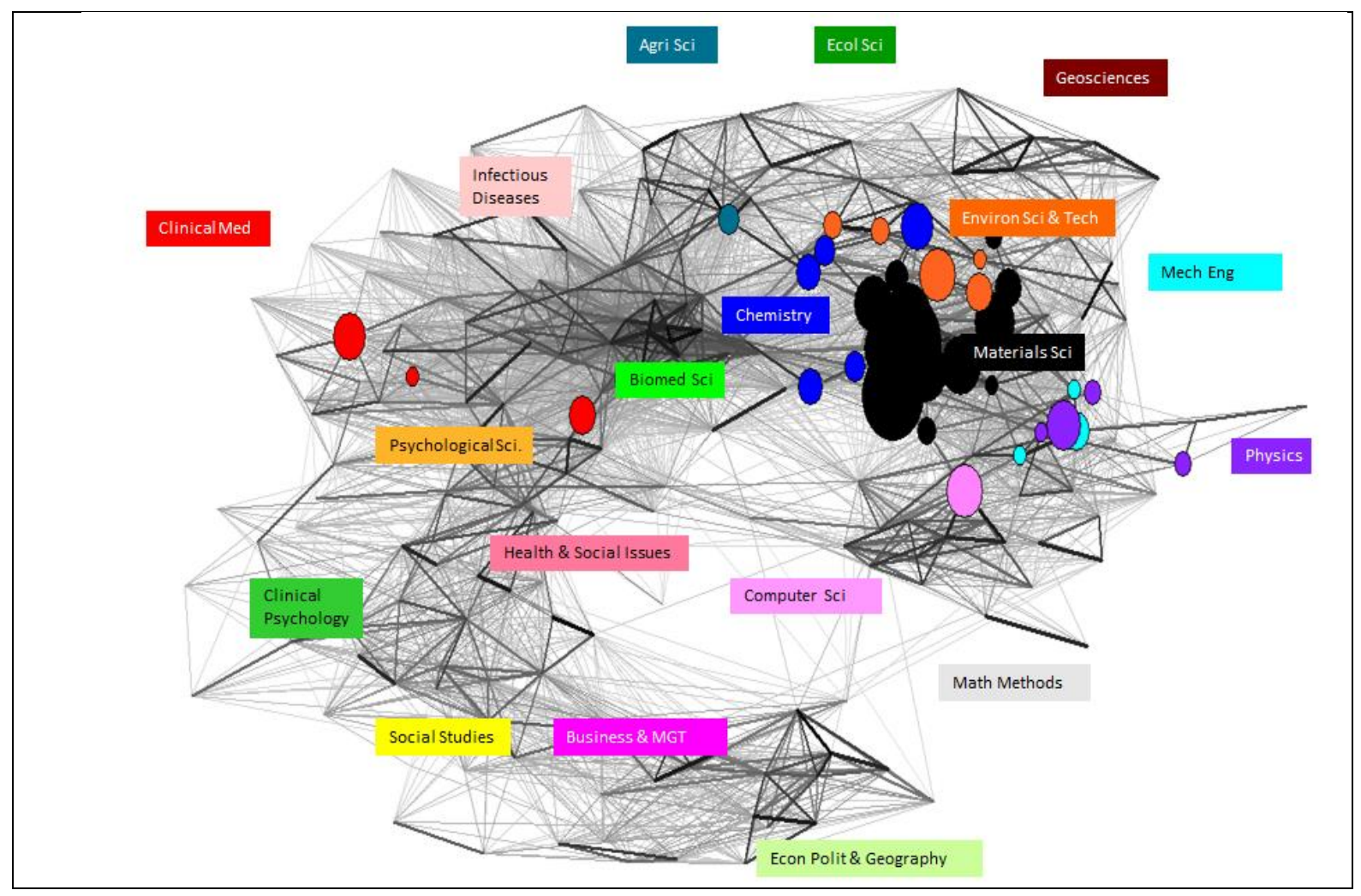

Figure 47. Publications profiles overlaid on the map of science of Atatürk University, 2006-2011 
Finally, Firat University researchers are active on Infectious Diseases, Biomedical Science, Chemistry, Environmental Science and Technology, Materials Science and Physics. Moreover, we see that in the center of the graph there is a relationship between Clinical Medicine and Materials Science, and, at the bottom right side, between Mathematical Methods and Materials Science. Statistical results for the overlaid map based on Subject Categories for Firat University are as follows: betweenness of 0.051 , degree centrality of 0.317 and closeness centrality of 0.452 (Fig 48).

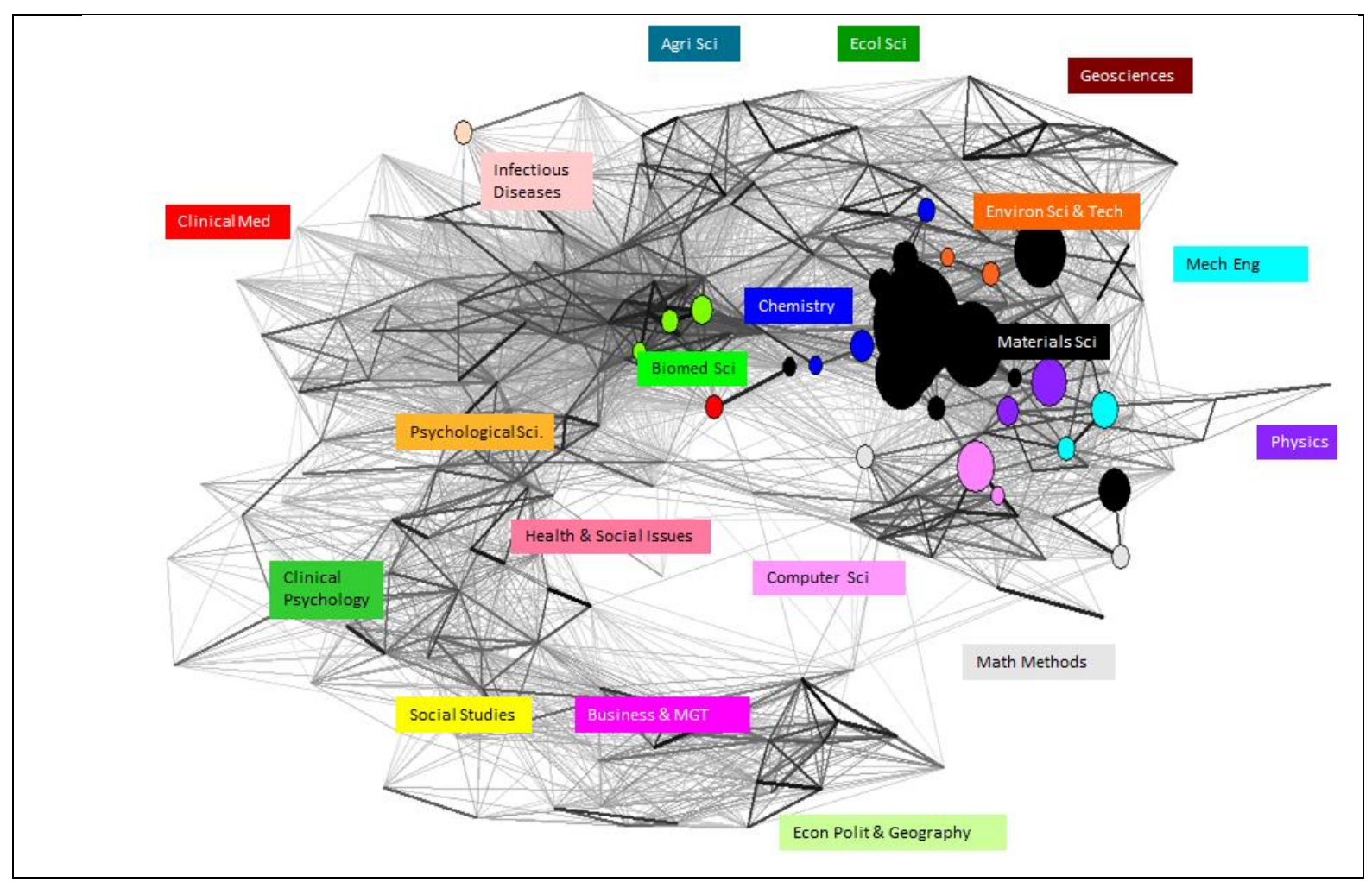

Figure 48. Publications profiles overlaid on the map of science of Firat University, 2006-2011

\subsection{SUMMARY OF NANO-RELATED TECHNOLOGY IN SELECTED UNIVERSITIES}

The overlay map for all universities revealed that the Materials Science is a new trend in research endeavors that is a multidisciplinary research subject that has many applications in nano-related technology research area. For example, most of nano-related technologies' publications are multidisciplinary or interdisciplinary, which indicates that 
nano-related technology research fields are composed of the basic sciences, explicitly Mathematics, Physics, Chemistry, and Biology. However, Management and Economics and Social Studies also have their share in term, of describing nano-related technologies and its applications to the public at large.

As mentioned earlier, high betweenness centrality indicates flow of information among sub-clusters while high closeness centrality yields cohesiveness of clusters in a network structure.

Despite the growth in the network structure in the second period (2006-2011), the overall density of the network structure is still low. The mean value of betweenness centrality of selected universities decreased from 0.142 to 0.056 . However, the degree and closeness centrality coefficients rose from 0.295 to 0.446 , and from 0.420 to 0.433 , respectively. We infer that network structures in both periods have characteristics of a small-word existence. In the next section, we review the network structure of co-authorship in both periods. Coauthorship network structure reveals the authors who may act as "brokers" who facilitate the flow of information among sub-clusters.

\subsection{CO-AUTHORSHIP ANALYSIS OF UNIVERSITIES: 2000-2005 AND 2006-2011}

Previously, overlay science maps revealed the profiles of publications of nano-related technologies in each university with the highest degree centralities. In addition, the maps below (Fig. 49 and Fig. 50) are blueprints for all universities, which have participated, in nano-related technology mapped by Gephi.

Network of co-authorship in 2000-2005 consists of clusters with high degree centralities, which are centered in the middle of the graph. Away from the center, we see several isolated sub-clusters in the periphery. Yet, some of the sub-clusters are connected through some precise nodes, which are instrumental in the diffusion of nano-related technology in the whole network structure (Fig. 49). 


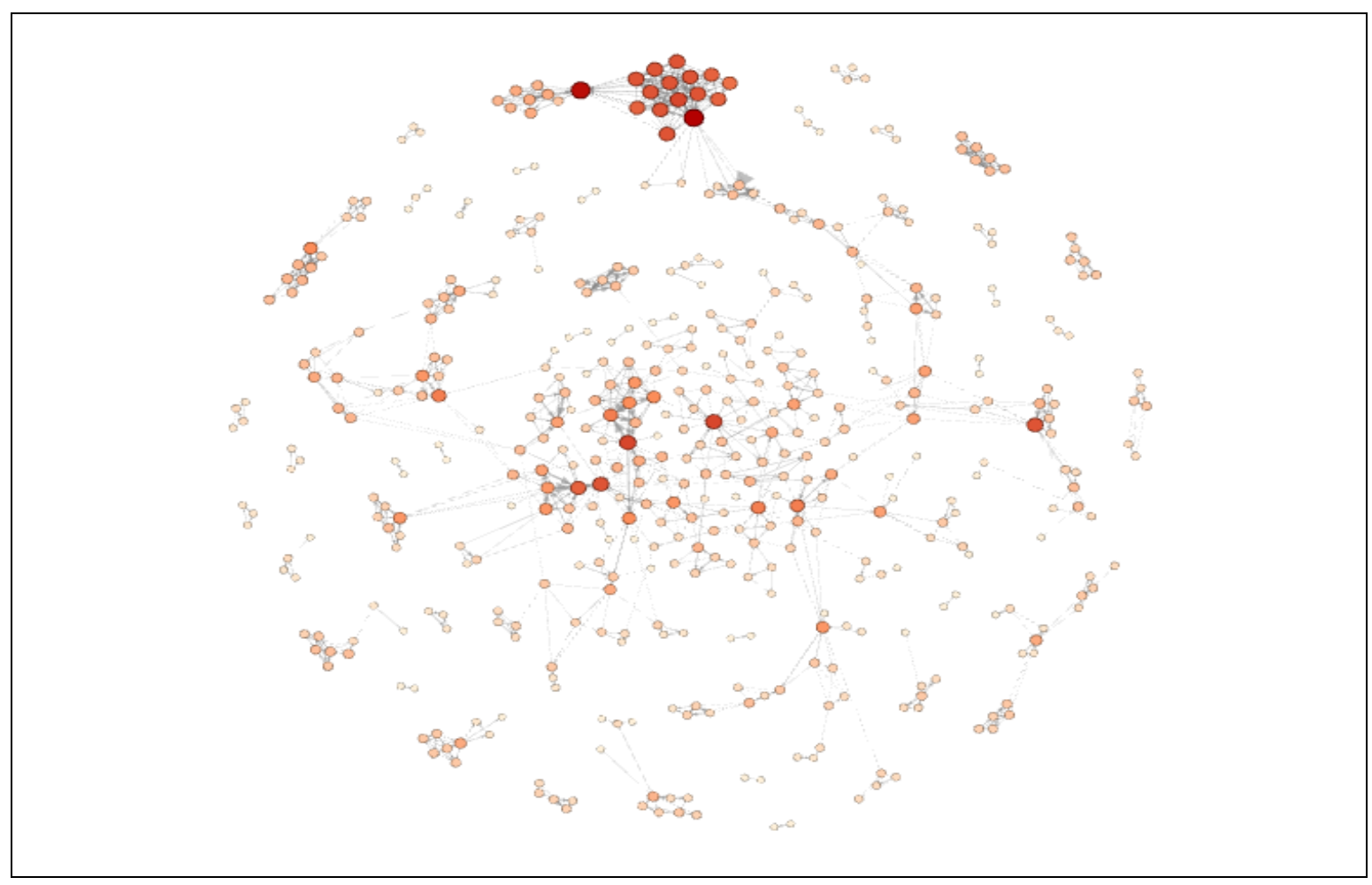

Figure 49. Co-authorship network of scientists working on nano-related technology: 2005-2011

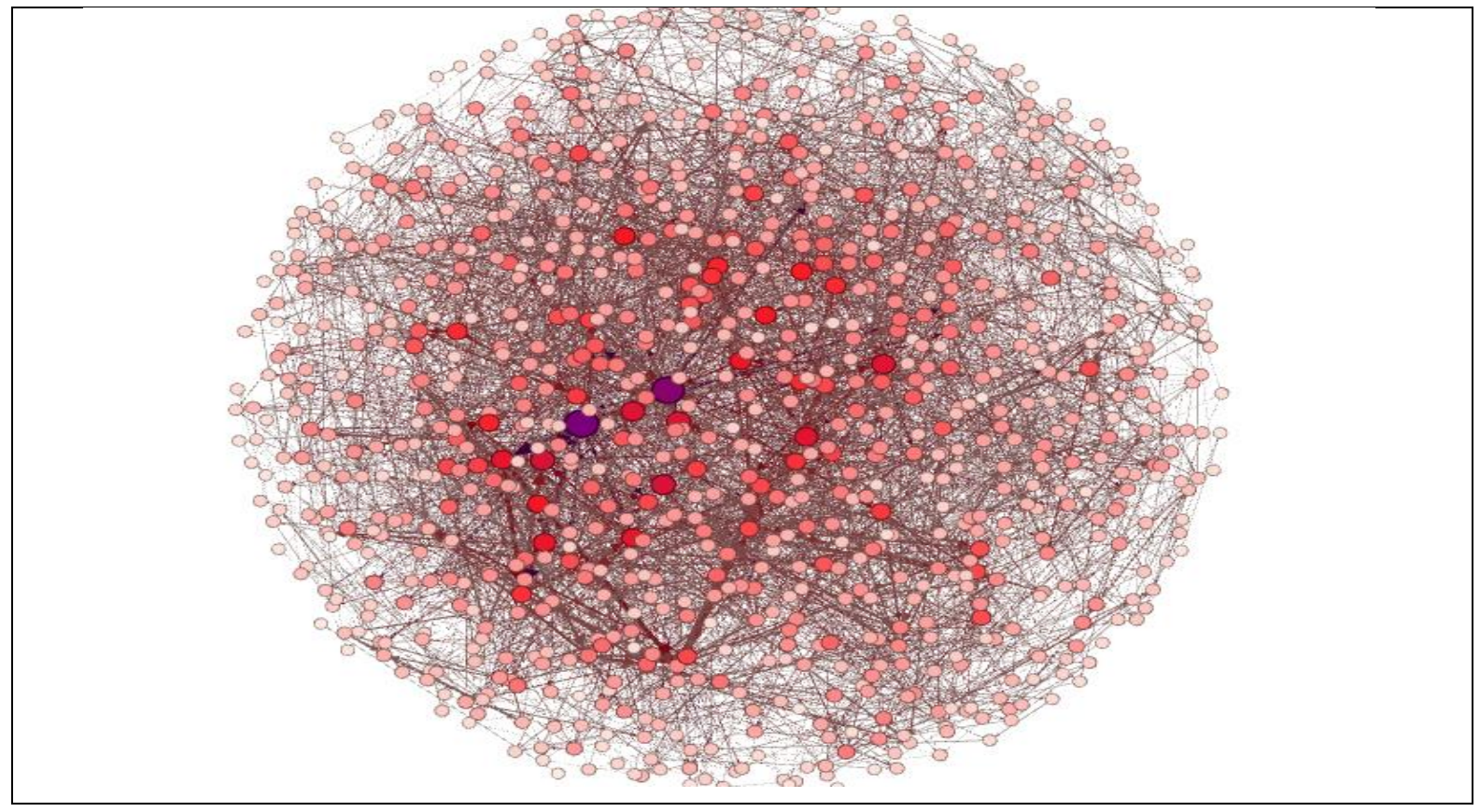

Figure 50. Co-authorship network of scientists working on nano-related technology: 2006-2011 
The numbers of nodes and edges rose from 470 and 1042 in 2000-2005 to 945 and 4915 in 2006-2011. The network structure has grown in number of nodes and ties almost twofolds for the former and four folds for the latter between the two periods, but the level of collaboration has not changed so much. Although, there is a minimal change in density (from 0.009 to 0.011 ) between the two periods, the network is still quite sparse. Nonetheless, the average degree and clustering coefficients show that clusters within the network are somehow connected for both periods. For example, the average clustering coefficient for 2000-2005 is 0.75 , indicating that $75 \%$ of the nodes are connected. However, as the network has grown in the second period, the rate of connectedness has decreased (0.51), indicating that newly formed clusters were not that cohesive in the second period.

The network in the second period adheres to transitivity relations, indicating that the network at meso level is well connected, even though the sub-clusters are not that well connected, especially in the periphery of the network (Fig. 50).

The results indicate that there have been progresses in new sub clusters in the coauthorship network. However, there are no links among sub clusters, yet. In other words, almost all scientists have co-authored with one or more other authors in their own cluster.

\subsection{CO-AUTHORSHIP ANALYSIS OF SELECTED AUTHORS: 2000-2005 AND 2006-2011}

Table 8 below shows the top 15 Turkish authors having the highest centralities (closeness, betweenness, degree, and PageRank) and their affiliations between 2000 and 2005 who have contributed to the diffusion of nano-technology in terms of scientific publications in the last decade. Some scientists appear in more than one centrality lists due to their high collaboration in the network structure. For example, Yakuphanoğlu has the high centrality: betweenness centrality (broker \& gate keeper), degree centrality (high collaborator), and

PageRank (productive). Co-authorship map of first authors is shown in Fig. 51. Most of the authors listed in table are also seen in the map. Although most participants are from 
universities with high degree centralities, we found other authors (Yilgor E and Yilgor I from Koç, Koralay H from Firat, Yakuphanoğlu E from Fırat and Kasapoğlu E from Cumhuriyet Universities) who are instrumental in the diffusion of nano-related technology in the network structure during 2000-2005 in Turkey, even though their universities did not have high degree centralities.

Table 8. Network properties of the top 15 Turkish authors based on co-authorship degree centralities: 2000-2005

\begin{tabular}{|c|c|c|c|c|}
\hline Rank & Closeness & Betweenness & Degree & PageRank \\
\hline 1 & Sar1 H (Bilkent) & Yilmaz F( METU) & Balkan N (Fatih) & Ovecoğlu MN (ITU) \\
\hline 2 & Sökmen I (Dokuz Eylül) & Gencer A (Hacettepe) & Teke A (Balıkesir) & Çelik E (Dokuz Eylül) \\
\hline 3 & Kasapoğlu E (Cumhuriyet) & Koralay H (Firat) & Yağci Y (ITU) & Denizli A (Hacettepe) \\
\hline 4 & Çiraci S (Bilkent) & $\begin{array}{l}\text { Okur S (Izmir Inst } \\
\text { Tech) }\end{array}$ & Yakuphanoğlu F(Firat) & Hasçiçek YS (Gazi) \\
\hline 5 & Aytor O (Bilkent) & $\begin{array}{l}\text { Denizli A } \\
\text { (Hacettepe) }\end{array}$ & Ovecoğlu MN (ITU) & Yağci Y (ITU) \\
\hline 6 & Biyikli N (METU) & Yavuz H (Hacettepe) & Çelik E (Dokuz Eylül) & Yakuphanoğlu F(Firat) \\
\hline 7 & Özbay E (Bilkent) & Güneş M (Kirikkale) & Yilmaz F (METU) & Toppare L (METU) \\
\hline 8 & Doğan S (Bilkent) & $\begin{array}{l}\text { Yakuphanoğlu F } \\
\text { (Firat) }\end{array}$ & Toppare L (METU) & Yilmaz VT (Ondokuz Mayıs) \\
\hline 9 & Morkoç H (Atatürk) & Balkan N (Fatih) & Doğan S (Bilkent) & Peşkin E (Hacettepe) \\
\hline 10 & Sari B (Gazi ) & Çelik E (Dokuz Eylül) & Morkoç H (Atatürk) & Erkoç Ş (METU) \\
\hline 11 & Talu M (Gazi) & Pişkin E (Hacettepe) & Denizli A (Hacettepe) & Kurt A ( Koç) \\
\hline 12 & Kartaloğlu (Bilkent) & Güven K (Erciyes) & Erol A (Istanbul) & Elmali A (Ankara) \\
\hline 13 & Yilgor E (Koç) & Yağci Y (ITU) & Özdemir I (Dokuz Eylül) & Hincall AA (Hacettepe) \\
\hline 14 & Yilgor I (Koç) & Ovecoğlu MN (ITU) & Turan R ( METU) & Ozdemir I (Dokuz Eylül) \\
\hline 15 & Andaç O (Ondokuz Mayıs) & $\begin{array}{l}\text { Menceloğlu YZ } \\
\text { (Sabancı) }\end{array}$ & Dag O ( Bilkent) & Oral A (Sabanc1) \\
\hline
\end{tabular}

Table 9 shows the top 15 authors who are influential in diffusion of nano-related technology in Turkey in 2006-2011. Interestingly, Büyükgüngör almost has the highest degree centrality in all categories, except the betweenness centrality. He can be seen in the center of the graph (Fig. 52). Not only is he a prestigious author, but also he plays an important role in the dissemination of knowledge, in the network structure. His research field is Crystallography. However, there are scientists who might do not have high degree centrality coefficient although they are placed in important positions in the network. For 
example, Yeşilel Öz from Eskisehir Osmangazi University does not have a high degree centrality, but his/her position is prestigious in the network structure. Moreover, Fatih University fails to have the highest degree centrality in neither period; yet, its scientists play an important role in the diffusion of nanotechnology in the network structure. For example, Yildiz A. appearance is in degree and betweenness centralities. Bacaksiz E. in Karadeniz Technical University is another example. Further, we infer that co-authorship analysis using SNA enables the information scientists to discern nodes, which might be crucial to the diffusion of nanotechnology or to any other topics.

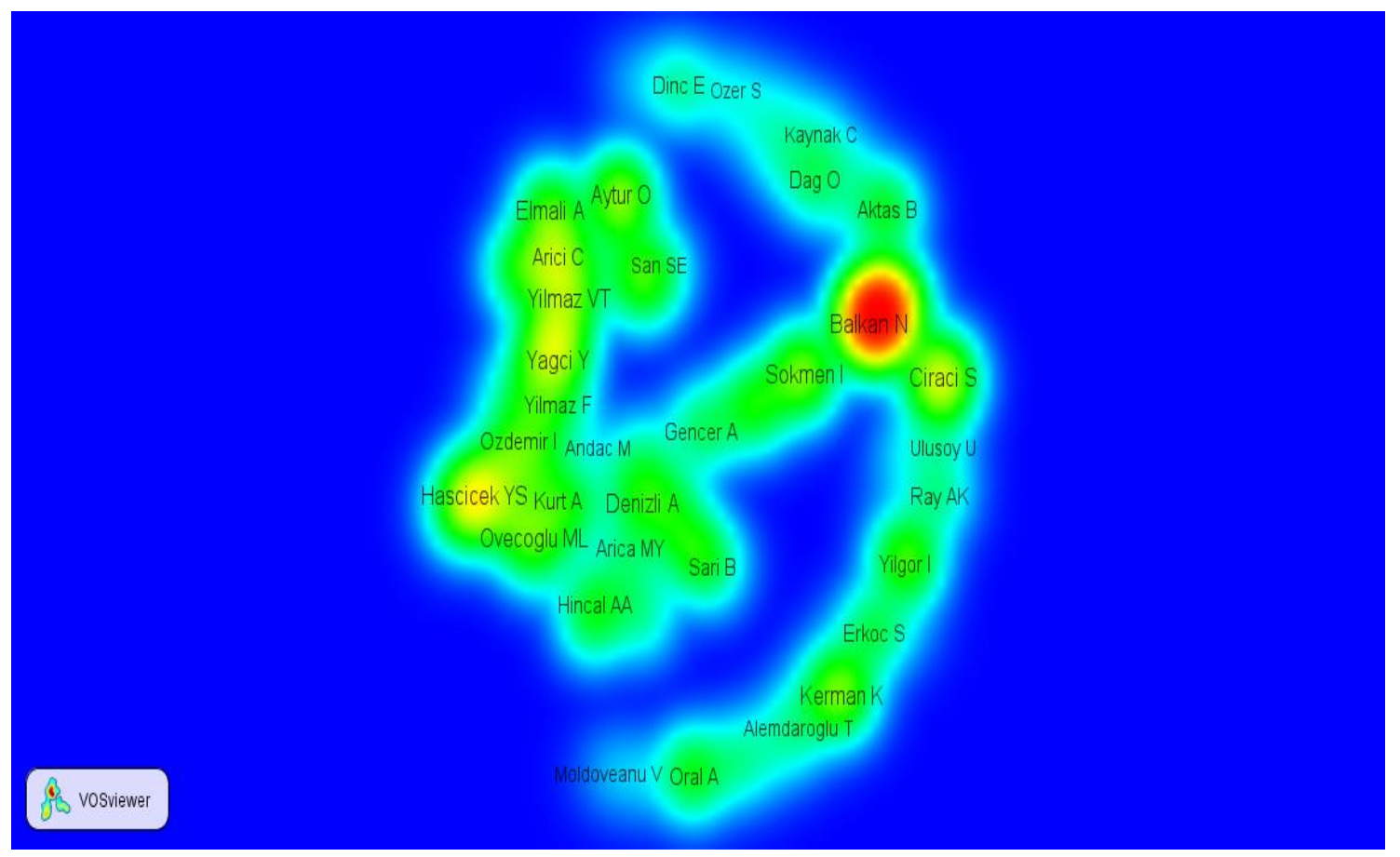

Figure 51. Co-authorship map of scientists between 2000 and 2005 
Table 9. Network properties of the top 15 authors based on degree centralities: 2006-2011

\begin{tabular}{lcccc}
\hline Rank & Closeness & Betweenness & Degree & Page Rank \\
\hline 1 & Büyükgüngör O & Yilmaz F (METU) & Büyükgüngör O (Ondokuz & Büyükgüngör O (Ondokuz \\
(Ondokuz Mayis) & Mayis) \\
2 & Yeşilel ÖZ & Büyükgüngör O (Ondokuz & Şahin E (Gazi) & Özbay E (Bilkent) \\
3 & (Osmangazi) & Mayis) & Toppare L (METU) & Özçelik S (Gazi) \\
4 & Demir HV (Bilkent) & Özçelik S (Gazi) & Toppare L (METU) \\
5 & Nizamoğlu S & Toppare L (METU) & Yilmaz F (METU) & Tont) \\
6 & Çağlar Y (Anadolu) & Yağcı Y (ITU) & Özçelik S (Gazi) & Denizli A (Hacettepe) \\
7 & İlican S (Anadolu) & Şahin E (Gazi) & Yağci Y(ITU) & Turan R (Ege) \\
8 & Çağlar M (Anadolu) & Yildiz A ( Fatih) & Özbay E (Bilkent) & Şahin E (Gazi) \\
9 & Özbay (Bilkent) & Çakmak M (Koç) & Turan R (Ege) & Çıracı S (Bilkent) \\
10 & Özçelik S (Gazi) & Şahin O (Dokuz Eylül) & Çakmak M (Kirikkale) & Yeşilel ÖZ (Osmangazi) \\
11 & Baykal A (Fatih) & Yilmaz M (Istanbul) & Yerli A (Sakarya ) & Yağci Y (ITU) \\
12 & Köseoğlu Y(Fatih) & Turan R (METU) & Yildiz A(Fatih) & Sökmen I (Dokuz Eylül) \\
13 & Toprak MS (Fatih) & Bacaksiz E (Karadeniz) & Çetin K (Ege) & Arslan H ( Hacettepe) \\
14 & Çiraci S (Bilkent) & Denizli A (Hacettepe) & Çiraci S (Bilkent) & Oskar S (METU) \\
15 & Durgun E (Bilkent) & Şen S (Yalova) & Denizli A (Hacettepe) & Çakmak M (Koç) \\
\hline
\end{tabular}

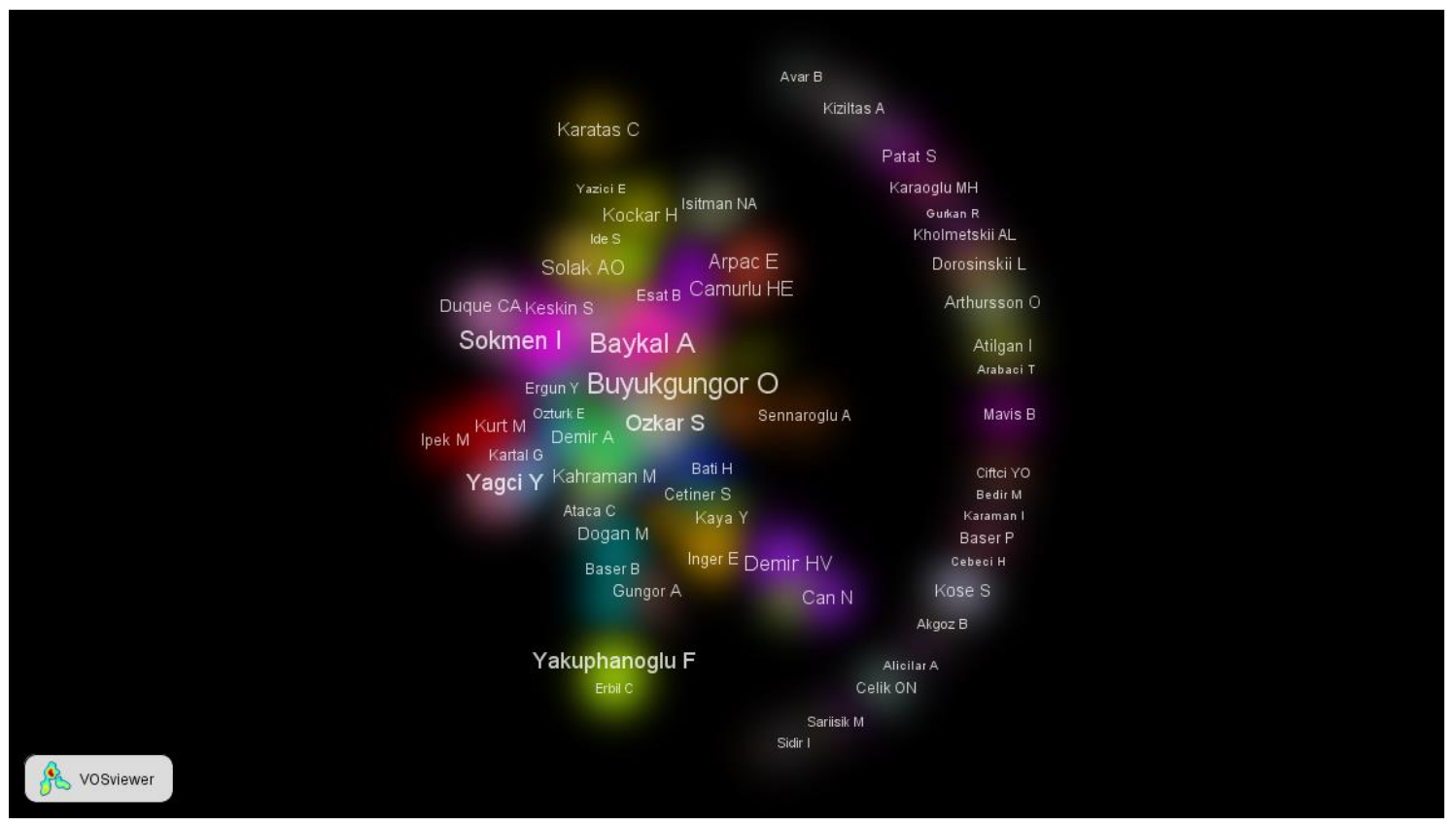

Figure 52. Co-authorship map of scientists between 2006 and 2011 
Although almost all universities hold higher network clustering coefficients indicating that sub-clusters in the system are embedded and that the small world effect is present in the network structure. We can categorize the collaboration among scientists who work on nano related technologies in Turkey in the last decade on three levels following:

Micro Level: Since co-authorship networks of selected universities comprise high closeness degree centrality coefficients, we can infer that sub-clusters at the micro level are well embedded. In other words, there is a high probability of any one node collaborating with another node.

Meso Level: Although clustering coefficients are high in all networks mentioned above, networks are not dense at all. The overall co-authorship network structure is not as dense as it is at the micro level.

Macro Level: The number of scientific publications on nanotechnology has increased from 2664 in 2000-2005 to 7398 in 2006-2011 in Turkey. It has increased in three folds, which is impressive in a short period. Yet, findings from co-authorship networks of universities indicate that social networks are not well connected.

\subsection{FRACTIONAL COUNTING OF CO-AUTHORSHIP: 2005-2005 AND 2006- 2011}

Almost all scientists have collaborated with other scientists and most have participated in research activities. Interestingly, as the numbers of collaboration increases, the clustering coefficients do, too, indicating that sub clusters within network are connected which supports the small-world phenomenon. Table 10 shows the 30 most prolific first authors appearing in 2000-2005 and 2006-2011 with their co-authors. Bibexcel was used to count the fractional counting of co-authorship.

Table 10 shows the top thirty prolific authors who appeared between 2000-2005 and 20062011 in nano-related network structure. Interestingly, some authors became less 
collaborative in 2006-2011 than in 2000-2005. For example, Erkoç dropped from number 1 in 2000-2005 to number 26 in 2006-2011, even though his frequency is still high. Some of the authors who appeared in the first period became more collaborative in the second period or appeared for the first time with a high centrality coefficient. Denizli, Yağci and Toppare for the former and Büyükgüngor for the latter are a few examples to name. Incidentally, the correlation between frequency and the number of co-authors rose from 0.77 in 2000-2005 to 0.90 in 2006-2011. Moreover, Table 10 shows the overall frequency and numbers of collaborates of the first frequent authors, and the total number of coauthors in 2000-2011. We conjecture that due to higher collaboration rate in the second period stimulates the diffusion of nano-related technology in the network structure.

Researchers who appeared with high centrality coefficient in the networks also co-authored more with other researchers. For example, Erkoç (METU) has the highest number of coauthors in 2000-2005 begin an influential person in his cluster. Incidentally, he appears $7^{\text {th }}$ in the 2000-2011 networks. Exceptionally, Büyükgüngör who did not appear in the first period turns out to be the person to be collaborated with in the second period. He has collaborated with more authors, which makes Crystallography an important subject field in nano-related technology development. 
Table 10. Highly prolific scholars in nano-related technology: 2000-2005 and 2006-2011

Source: WoS (as of November 2013)

\begin{tabular}{|c|c|c|c|c|c|c|}
\hline \multirow{3}{*}{$\begin{array}{c}\text { Freq } \\
53\end{array}$} & \multirow{2}{*}{$\begin{array}{c}2000-20005 \\
\text { First author \& Affiliation }\end{array}$} & \multicolumn{5}{|c|}{$2006-2011$} \\
\hline & & $\begin{array}{c}\text { \# of } \\
\text { co- authors }\end{array}$ & & First author \& Affiliation & $\begin{array}{c}\# \text { of } \\
\text { co-authors }\end{array}$ & 1 \# of co- \\
\hline & Erkoc S (METU) & 29 & 149 & Buyukgungor O (Ondokuz Mayıs) & 37 & 66 \\
\hline 49 & Sokmen I (Dokuz Eylül) & 16 & 78 & Yagci Y (ITU) & 19 & 35 \\
\hline 42 & Ciraci S (Bilkent) & 13 & 75 & Denizli A(Hacettepe) & 18 & 31 \\
\hline 39 & Denizli A (Hacettepe) & 12 & 72 & Yakuphanoglu F (Firat) & 28 & 40 \\
\hline 38 & Yagci Y (ITU) & 10 & 67 & Ozkar S (METU) & 23 & 33 \\
\hline 37 & Celik E (Bilkent) & 11 & 67 & Toppare L (METU) & 15 & 26 \\
\hline 37 & Sari H (Bilkent) & 11 & 64 & Ozbay E (Bilkent) & 13 & 24 \\
\hline 36 & Turker L (METU) & 28 & 62 & Yesilel OZ (Eskisehir Osmangazi) & 17 & 45 \\
\hline 30 & Yilmaz VT (Dokuz Eylül) & 8 & 61 & Sokmen I (Dokuz Eylül) & 17 & 25 \\
\hline 30 & Toppare L (METU) & 7 & 58 & Ozcelik S (Gazi ) & 12 & 19 \\
\hline 29 & Hascicek YS (Gazi) & 8 & 52 & Demir HV (Bilkent) & 13 & 21 \\
\hline 28 & Ovecoglu ML (ITU) & 7 & 49 & Baykal A (Bilkent) & 10 & 17 \\
\hline 27 & Elmali A (Ankara) & 8 & 45 & Turan R (METU) & 10 & 18 \\
\hline 26 & Elerman Y (Ankara) & 8 & 44 & Sahin E (Bilkent) & 11 & 19 \\
\hline 26 & Piskin E (Hacettepe) & 8 & 44 & Yilmaz VT (Dokuz Eylül) & 13 & 21 \\
\hline 26 & Kasapoglu E (Cumhuriyet) & 8 & 43 & Caykara T (Gazi ) & 15 & 23 \\
\hline 26 & Balkan N (Bilkent) & 5 & 41 & Sari H (Ankara) & 9 & 14 \\
\hline 22 & Yilmaz F (METU) & 6 & 40 & Ciraci S (Bilkent) & 12 & 18 \\
\hline 22 & Turan S ( Marmara) & 8 & 39 & Kasapoglu E (Cumhuriyet) & 12 & 20 \\
\hline 22 & Ozbay E (Bilkent) & 5 & 39 & Albayrak C (Ondokuz Mayıs) & 11 & 16 \\
\hline 20 & Yildirim T (Penn Univ) & 5 & 39 & Bozkurt A (Fatih) & 12 & 17 \\
\hline 19 & Dag S (California) & 5 & 38 & Gasanly NM (METU) & 23 & 28 \\
\hline 19 & Ozturk E (Gülhane Mil) & 7 & 38 & Yildiz A (Ahi Evran) & 9 & 16 \\
\hline 19 & Oral A (Çanakkale Onsekiz Mart ) & 4 & 38 & Sen S (Yalova) & 12 & 16 \\
\hline 19 & Kara A (Florida State) & 7 & 37 & Caglar M (Firat ) & 10 & 17 \\
\hline 18 & Ozdemir I (Dokuz Eylül) & 4 & 36 & Erkoc S (METU) & 17 & 21 \\
\hline 17 & Suzer S (Bilkent Univ) & 6 & 35 & Ahsen V (Gebze Inst Tech) & 7 & 13 \\
\hline 17 & Sarac AS (ITU) & 5 & 35 & Ilican S (Anadolu Univ) & 9 & 14 \\
\hline 17 & Tanatar B (Bilkent ) & 7 & 35 & Caglar Y (Anadolu Univ) & 9 & 16 \\
\hline 17 & Erkoc F (METU) & 7 & 39 & Bozkurt A (Yildiz) Technical) & 12 & 19 \\
\hline
\end{tabular}


Furthermore, using Lotka's software designed by Rousseau (1997), we calculated the first author publication frequencies, which match the Lotka's square power law as follows:

$$
f(y)=.2459 \div y^{1.2881}
$$

Where $\mathrm{f}(\mathrm{y})$ denotes the relative number of authors with y publications (the K-S DMAX = 0.6323). In other words, a small number of well-known scientists acquire stronger positions in the network. For example, well-known scientists have collaborated at least with 10 more scientists.

\subsection{CO-CITATION ANALYSIS: 2000-2005 AND 2006-2011}

An analysis of the citation based relationship among scientists in the 2000-2005 period reveals that scientists cited documents as old as 1951 (Fig. 53).

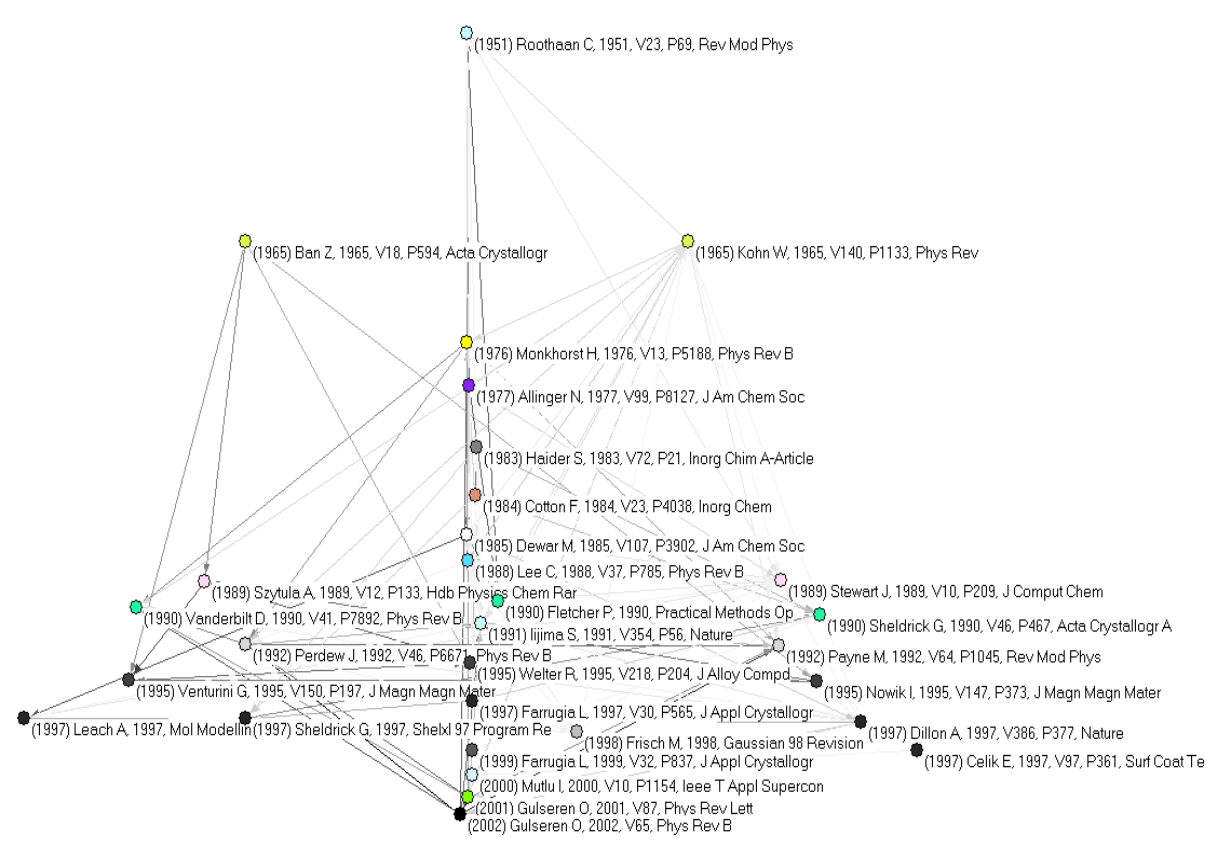

Figure 53. Document co-citation map of nano-related technology from 2000 to 2005 
Table 11 and 12 summarize the document co-citation of Turkish scientists based on WoS data. Scientists are mostly from Bilkent University, who participated in research among each other. It is noticeable that scientists frequently publish in high impact factor journals such as Physical Rev B. Gülseren's papers are the most co-cited ones in the first period (Table 11). Similarly, Demir and Nizamoğlu of Bilkent University are the authors of the most co-cited papers in the 2006-2011 period (Table 12). Data from Scopus database also shows that papers by scientists in Bilkent University are more visible in international arena. Demir, Özbay, Gülseren and Aydin have been co-cited more often while Özbay appears three times in the network (Fig. 54). Özbay collaborates with local and international scientists extensively, which contributes positively to his positional and relational standpoints in the network effectively. We can infer that even though Turkish articles are not the most cited documents in nano-related technology, their presence in the 2006-2011 period is an indication of the diffusion of nano-technology in Turkey.

Table 11. The most co-cited papers in nano-related technology in Turkey, 2000-2005

\begin{tabular}{ccc}
\hline $\begin{array}{c}\text { \# of co- } \\
\text { cocitations }\end{array}$ & & \\
& & Co-cited document \\
\hline 29 & Gulseren O, 2002, V65, Phys Rev B & Perdew J, 1992, V46, P6671, Phys Rev B \\
27 & Gulseren O, 2001, V87, Phys Rev Lett & Gulseren O, 2002, V65, Phys Rev B \\
24 & Gulseren O, 2002, V65, Phys Rev B & Payne M, 1992, V64, P1045, Rev Mod Phys \\
22 & Szytula A, 1989, V12, P133, Hdb Physics & Venturini G, 1995, V150, P197, J Magn Magn Mater \\
20 & Gulseren O, 2002, V65, Phys Rev B & Vanderbilt D, 1990, V41, P7892, Phys Rev B \\
20 & Fletcher P, 1990, Practical Methods Op & Roothaan C, 1951, V23, P69, Rev Mod Phys \\
19 & Dewar M, 1985, V107, P3902, J Am Chem & Leach A, 1997, Mol Modelling \\
\hline
\end{tabular}

Table 12. The most co-cited papers in nano-related technology in Turkey, 2006-2011

\begin{tabular}{cll}
\hline \# of co-citations & & \multicolumn{1}{c}{ Co-cited document } \\
\hline 22 & Nizamoglu S; Demir HV & Nizamoglu S; Ozel T; Sari E; Demir HV \\
13 & Demirbas A & Saidur R; Lai YK \\
10 & Nizamoglu S; Ozel T; Sari E; Demir HV & Schubert EF \\
9 & Aydin K; Ozbay E & Veselago VG \\
10 & Nizamoglu S; Ozel T; Sari E; Demir HV & Schubert EF \\
4 & Aydin K; Ozbay E & Pendry JB \\
1 & Caglayan H; Bulu I; Ozbay E & Shelby RA; Smith DR; Schultz S \\
\hline
\end{tabular}




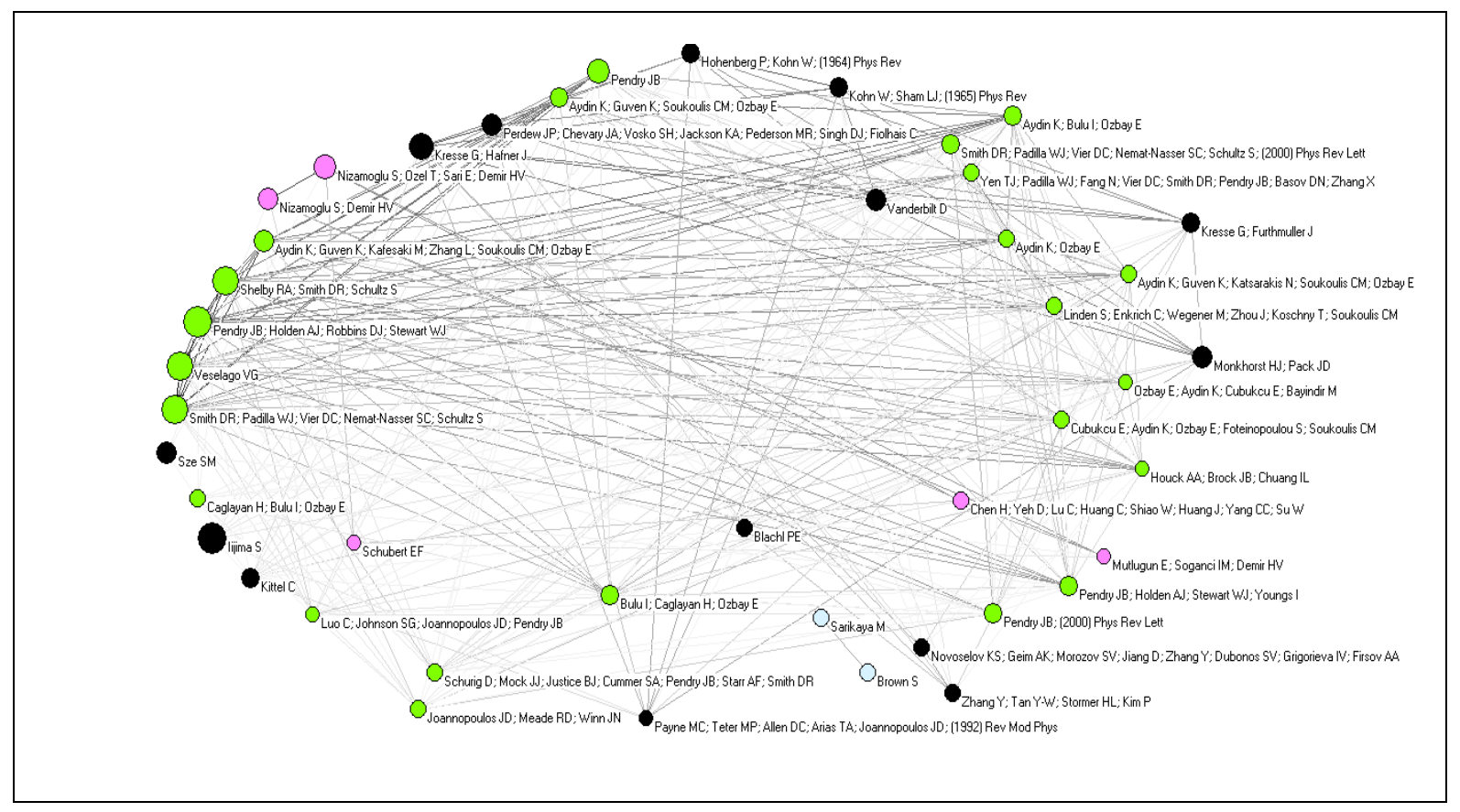

Figure 54. Document co-citation map of nano-related technology from 2006 to 2011

\subsection{JOURNALS CO-CITATION ANALYSIS: 2000-2005 AND 2006-2011}

Journal-to-journal citation relations illustrate knowledge diffusion among disciplines and their developments. Four main clusters appear in the social network structure in four different colors: red, green, blue and yellow (Fig. 55). The journal co-citation map reveals the leading journals: Phys Rev B (red), Journal of American Chemistry Society (yellow), Polymer (light blue), Biomaterials (green) and the list goes on. We can infer that Chemistry, Polymer Science, Biomaterials and their derivatives are leading research areas for scientists in 2000-2005 with a density of 0.205 and clustering coefficient of 0.289 .

More journals are included in the network structure in 2006-2011. Fig. 56 shows scientists published in nano-related subject fields, which indicate the diffusion of nanotechnology in the multidisciplinary research area in Turkey. The network of journals in the second period has expanded, encompassing more journals between 2006 and 2011 with a density of 0.160 and clustering coefficient of 0.570 . Although the density has decreased, the clustering coefficient has increased which endorses the small-world model. 


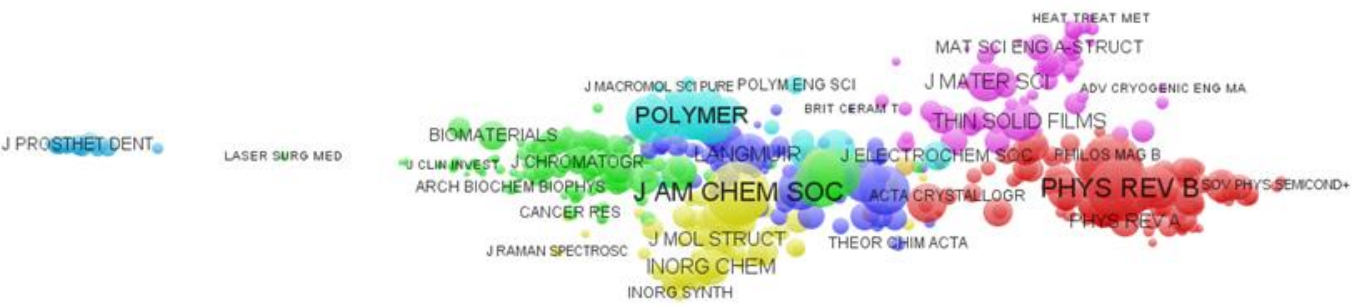

of vosviewer

Figure 55. Journal co-citation in nano-related technology articles in Turkey between 2000-2005

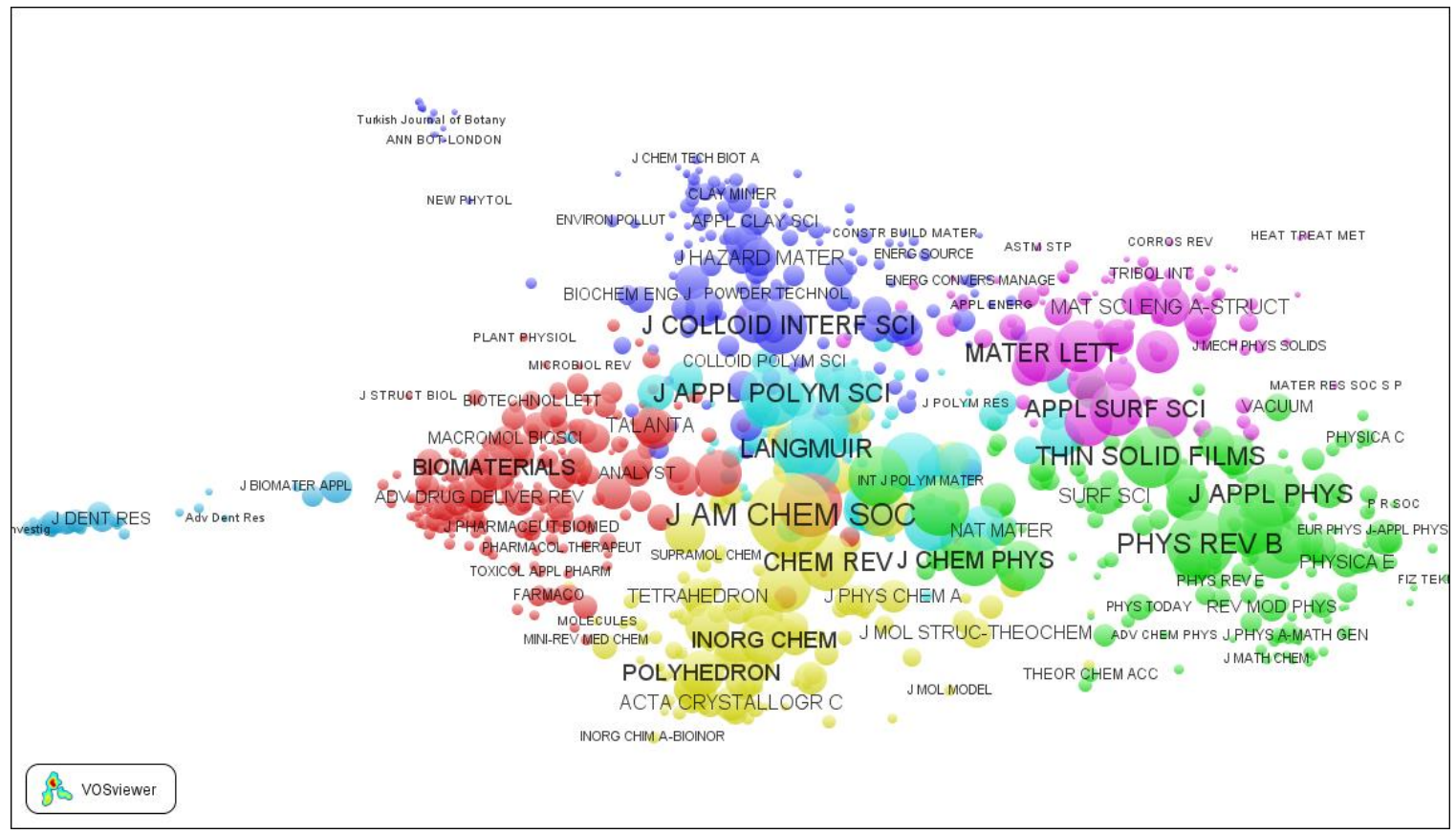

Figurre 56. Journal co-citation in nano-related technology articles in Turkey between 2006 and 2011 


\subsection{CO-WORD ANALYSIS: 2000-2005 AND 2006-2011}

In Chapter 2, we discussed how the latent semantic analysis of the words in vector space reveals the meaning of "communication" in a network structure of a scientific domain. A factor analysis was conducted on the words that appear in the titles of records extracted from WoS. The most frequently used words in the title of the records between 2000 and 2005 were gathered together. The most frequently occurring 75 words in the title of the nano-related technology articles between 2000 and 2005 were collected, processed and compiled by the software. ${ }^{13}$ Non-trivial words were eliminated. Then, in order to analyze the word/document occurrence matrix in terms of its latent structure, SPSS software version 16.0 was used to factor analyze the co-occurrence of words. Factor analysis creates a different component for each word. SPSS created two factors from the list of the cowords. Table 13 shows the output of two factors for 2000-2005 and loading of different words in each component (see Appendix E for the list of all words in nano-related technology between 2000 and 2005).

Table 13. Factor analysis of co-words in the titles of nano-related articles produced in Turkey between 2000 and 2005

\begin{tabular}{lrlr}
\hline Words & 1 & Words & 2 \\
\hline CHEMICAL & .999 & PLASMA & .999 \\
QUANTUM & .999 & TREATMENT & .999 \\
STEEL & .998 & CONDUCTING & .990 \\
HYDROGEN & .997 & CERAMIC & .982 \\
COPOLYMER & .992 & SOL-GEL & .982 \\
FIELD & .992 & LAYER & .945 \\
PROPERTIES & .984 & OPTICAL & .945 \\
ELECTRICAL & .973 & SURFACE & .945 \\
\hline
\end{tabular}

Extraction Method: Principal Component Analysis.

The first factor explains $56 \%$ of variance in the entire data while the second explains the rest of the variance. Visualization is based on Kamada \& Kawai embedded in Pajek. Each component is formed of a color representing a factor, for example, pink and green.

\footnotetext{
${ }^{13}$ Software at http://www.leydesdorff.net/software/fulltext/index.htm was used to create a normalized cosine symmetric co-occurrence matrix of labels.
} 
Table 14. Eigenvalues of the top two factors from 2000-2005

\begin{tabular}{lccc}
\hline \multicolumn{2}{l}{ Factor Eigenvalue } & Percent of variance & Cumulative Percent \\
\hline 1 & 41.8 & 56.4 & 56.4 \\
2 & 32.2 & 43.5 & 100.0 \\
\hline
\end{tabular}

In Figure 57, Table 14, factor 1 and factor 2 show that scientists mostly work on Material Science and its derivatives: Physics and Chemistry. Network structure is made of almost two evenly distributed partitions, green in the bottom left side and pink in up right side. After sharing the result with professors in Material Science Department at Çankaya University, they are certain that words "Quantum" and "Optics" in Physics whereas "Crystal" and "Sol-Gel" are used in Chemistry.

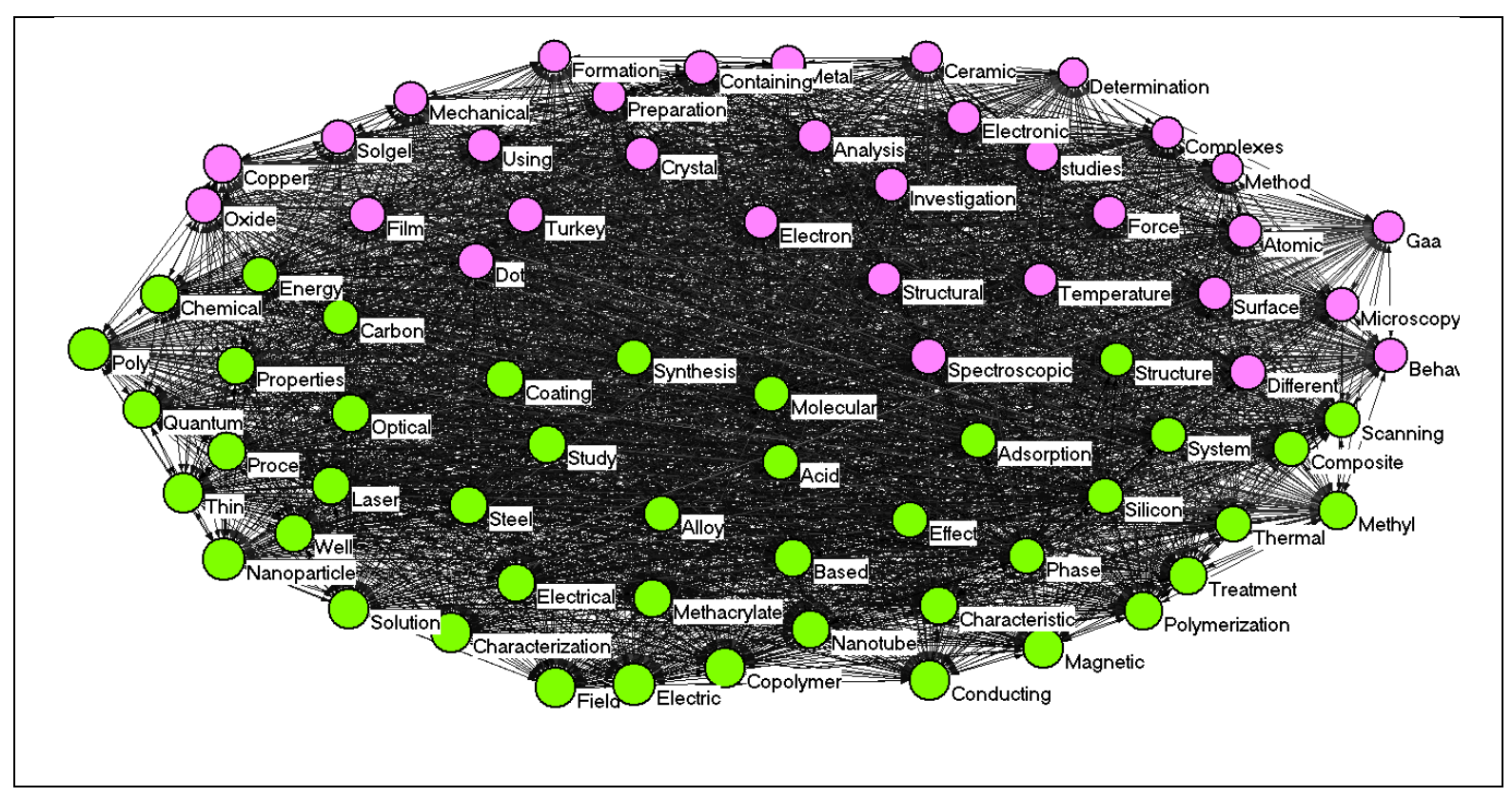

Figure 57. Nodes are colored according to factor solution of this network: 2000-2005

Similarly, a factor analysis was done on words in the abstract of articles to see the topological development in 2006-2011. To be consistent with the previous map, we also utilized about 75 frequently co-occurred words. However, we noticed the new words used in 2006-2011 indicating that scientists' works have taken a new horizon. Three factors were extracted from the co-occurrence network of words. Table 15 shows several words, 
which are loaded on three factors identified by factor analysis (see Appendix $\mathrm{F}$ for the complete list of words used in nano-related technology between 2006 and 2011).

Table 15. Factor analysis of co-words in the titles of nano-related articles produced in Turkey: 2006-2011

\begin{tabular}{lrlrlr}
\hline \multicolumn{1}{c}{ Words } & 1 & \multicolumn{1}{c}{ Words } & 2 & & Words \\
\hline COPOLYMER & .766 & STEEL & .673 & DOT & .687 \\
COMPLEXES & .697 & WELL & .655 & MORPHOLOGY & .676 \\
CRYSTAL & .674 & AQUEOU & .651 & ADSORPTION & .654 \\
THERMAL & .653 & ZNO & .642 & ENERGY & .644 \\
SPECTROSCOPIC & .650 & PARTICLE & .626 & PREPARED & .641 \\
CHARACTERISTIC & .643 & MATERIAL & .625 & QUANTUM & .620 \\
COPOLYMER & .766 & TEMPERATURE & .620 & ELECTRICAL & .619 \\
METAL & .636 & CELL & .618 & MODIFIED & .610 \\
\hline
\end{tabular}

Extraction Method: Principal Component Analysis.

Table 16 shows the first factor explains $35 \%$ of the variance in the entire data while the second explains $33 \%$ and the third explains $32 \%$ of the variance. Visualization is based on Kamada \& Kawai embedded in Pajek. Each component is shaped after a color representing a factor, for example, pink, green and blue.

Table 16. Eigenvalues of the top three factors from 2006-2011

\begin{tabular}{crrr}
\hline Factor Eigenvalue & Percent of Variance & Cumulative Percent \\
\hline 1 & 24.402 & 34.8 & 34.8 \\
2 & 22.891 & 32.7 & 67.5 \\
3 & 22.316 & 31.8 & 99.4 \\
\hline
\end{tabular}

Fig. 58 graphically depicts the network made of three factors: (1) Pink, which occupies most of the network, (2) Green in the right side with a fewer nodes and (3) finally, the blue one that located on the left hand side in the periphery. We categorize the topological development mainly in three components. The green one ("Doped", "Alloy", and "Plasma") represents research fields in Surface Material. The pink one ("Coating", "Crystal" and "Catalyst") represents research fields in Chemistry and its sub-fields. The blue one ("Quantum", "Dot” and "Nanotube”) represents research fields in Physics. 
A normalized cosine extraction of the words shows that words mainly in two periods belong to two frames: Multidisciplinary Science and Material Sciences, which matches universities' research activities on nano-related technologies in each period between 20002005 and 2006-2011. For example, overlay maps show that most universities are active in Material Sciences and its derivatives whereas they are less active in Biotechnology. We compared our results to Kostoff's results with scientists in Material Science Department at Çankaya University regarding the co-words map. They are almost certain that Turkish scientists conduct research activities on mostly Material Science and its sub-fields. Moreover, relying on our results and Kostoff's taxonomy, we conjecture that nano-related technology in Turkey is mostly Material Science-oriented, followed by Physics and, to a certain extent, Biotechnology.

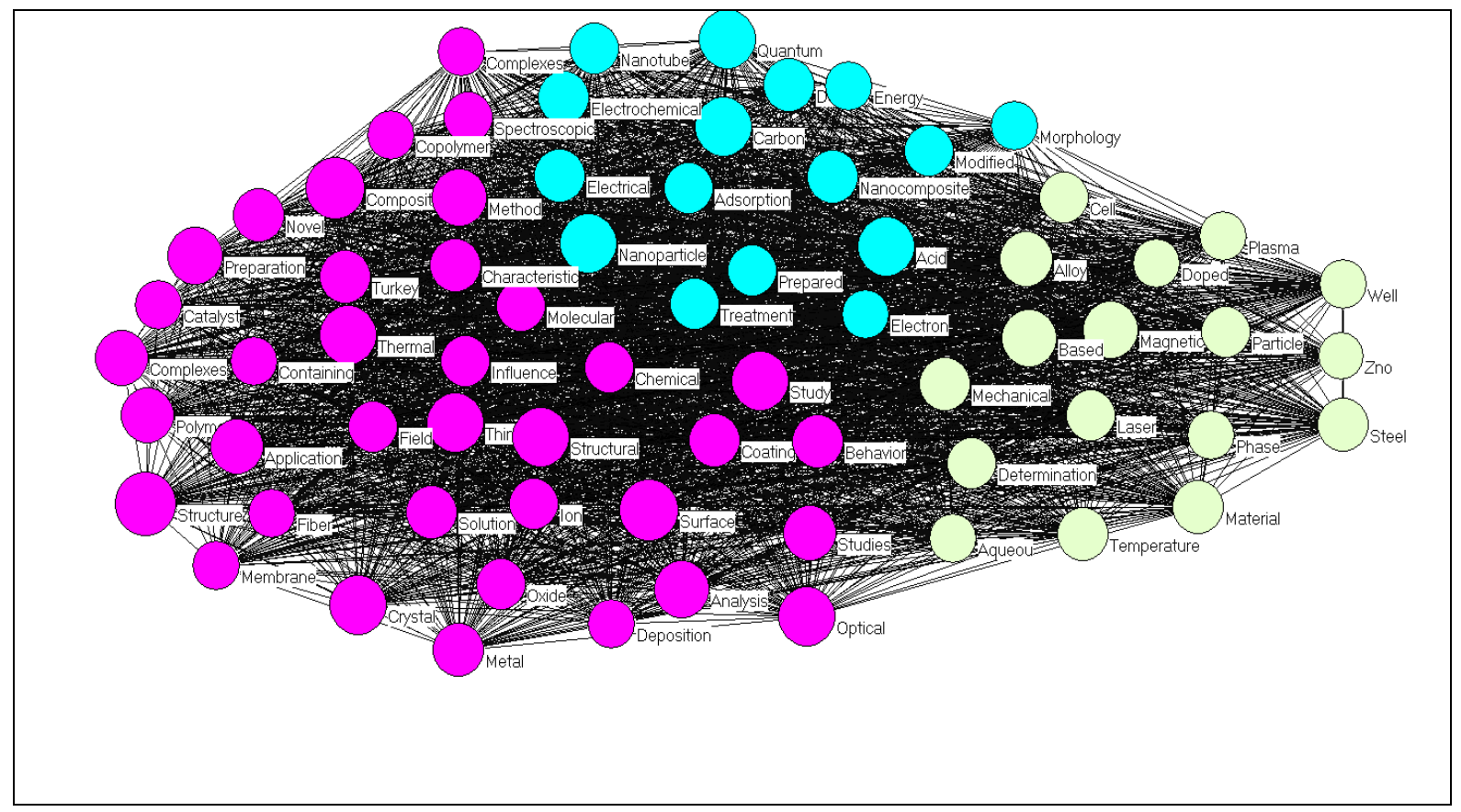

Figure 58. Nodes are colored according to factor solution of network: 2006-2011

\subsection{GEOGRAPHICAL DIFFUSION}

Another way to envision the scientific collaboration is geographical topology. Figure 59 and 60 show a map created by Google locating Turkish cities having universities 
publishing papers on nanoscience and nanotechnology. Number of cities have increased from 2000-2005 to 2006-201. Almost the number of the cities has doubled. Several universities in Turkey to have participated in nano-related technology projects or have published an article on nanoscience and nanotechnology. Number of cities has increased in which nano-related technology related especially in eastern part of Turkey.

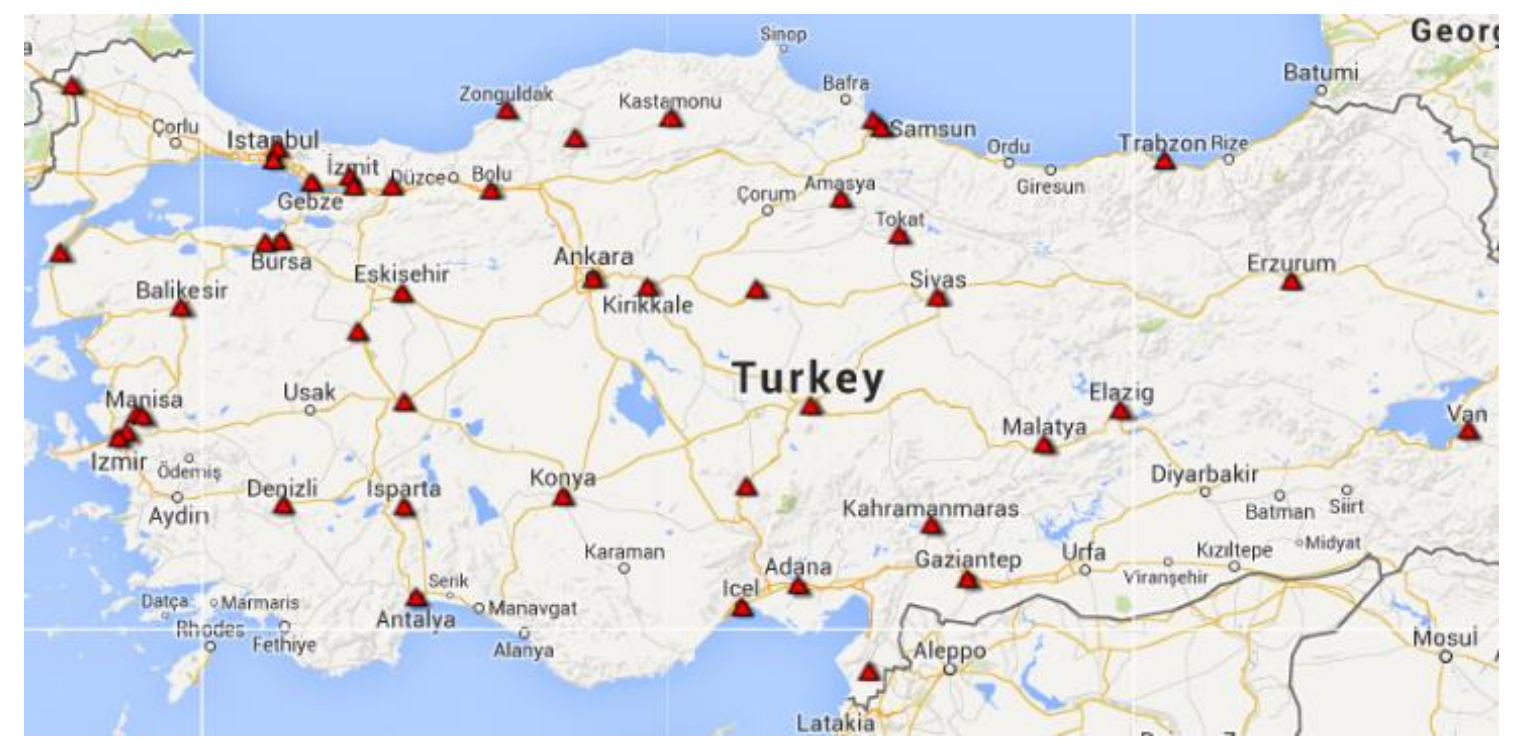

Figure 59. Geographical distribution of nano-related research activities of cities in Turkey, 2000-2005

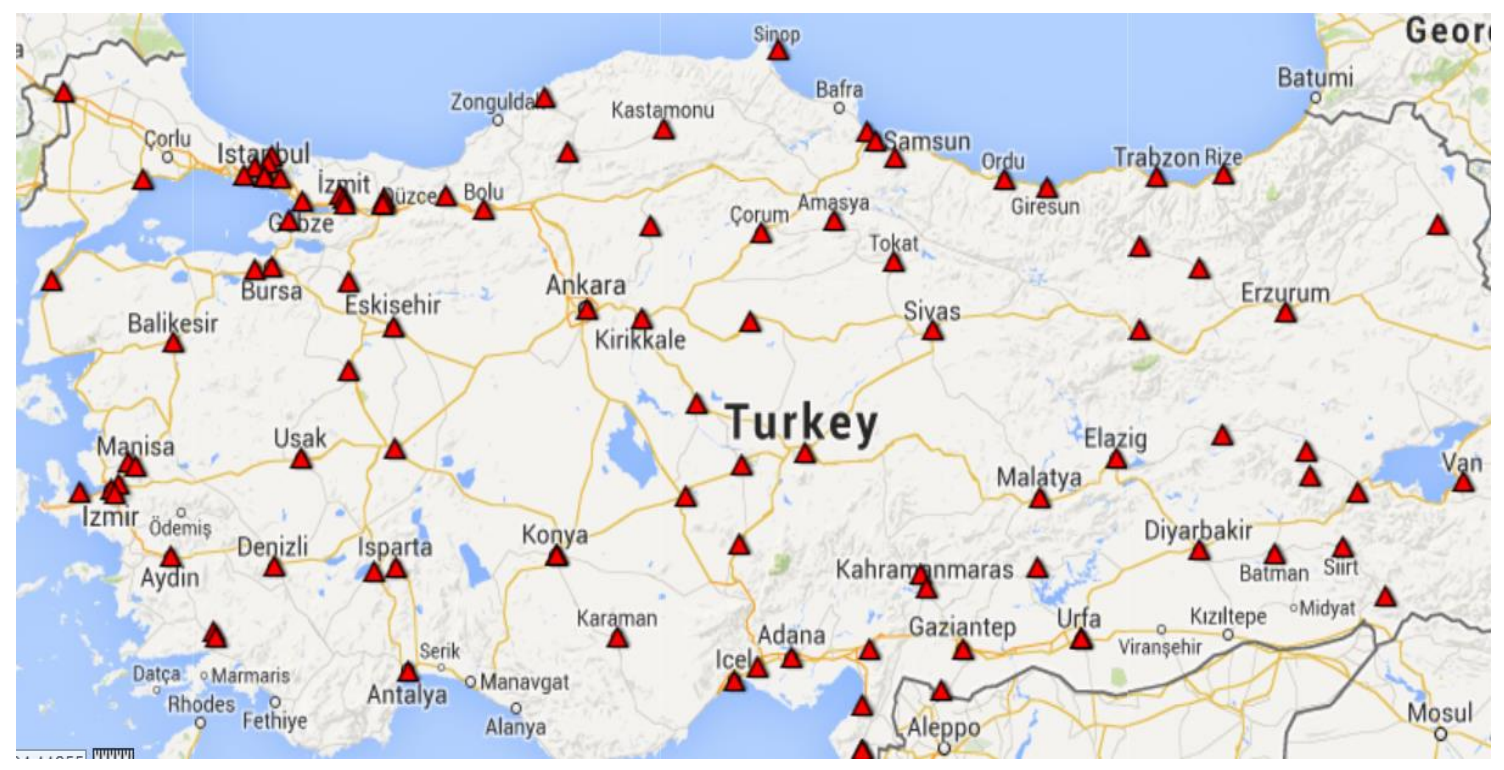

Figure 60. Geographical distribution of nano-related research activities of cities in Turkey, 2006-2011 
As we mentioned earlier, diffusion of nano-related technology took momentum in the second period. Figure 61 shows that Turkey collaborated in nano-related technology in 2000-2005 mostly with a few European Union, United State of America and a Far Eastern country. However, in 2006-2011 Turkey has expanded its horizon and collaborated with more countries.

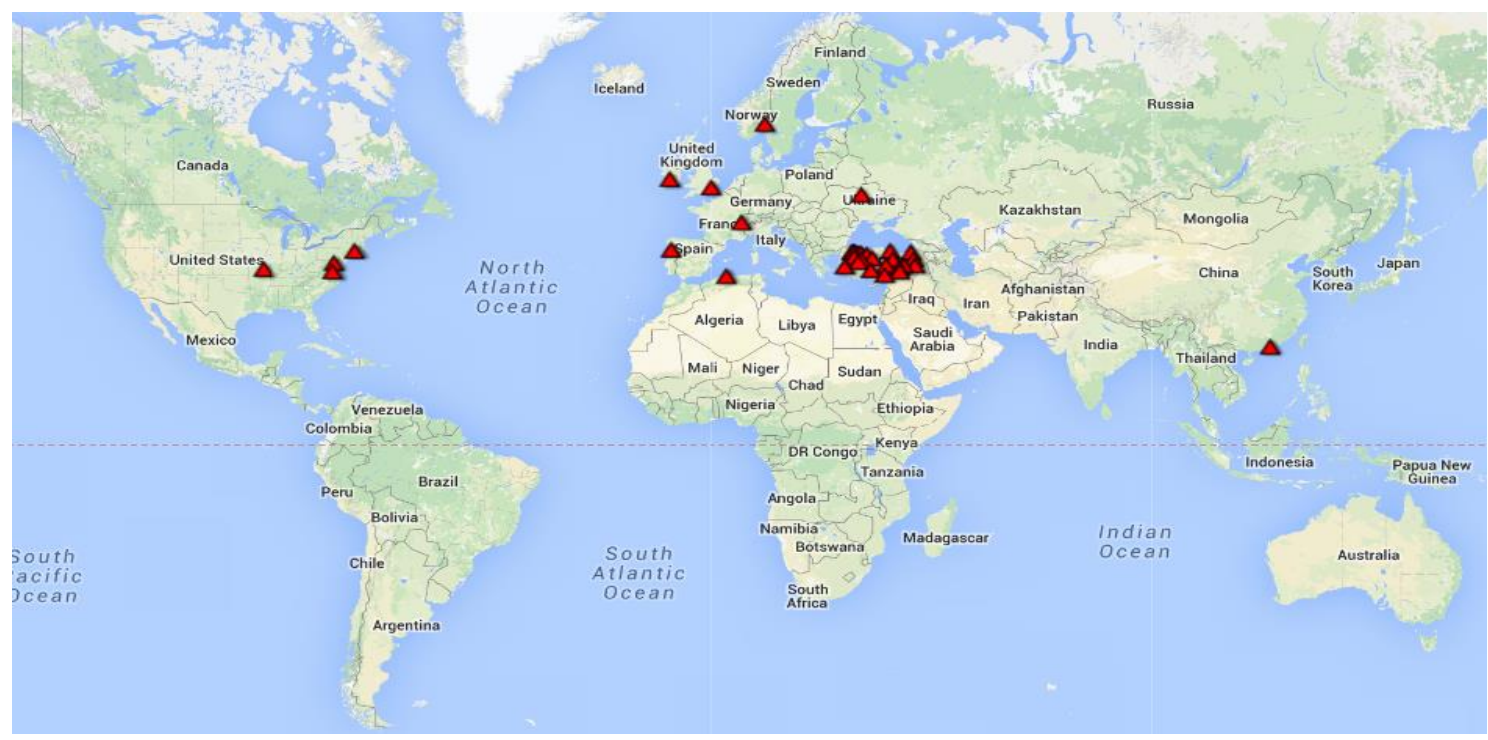

Figure 61. The network of co-authors of international and Turkish scientists working on nano-related technologies, 2000-2005

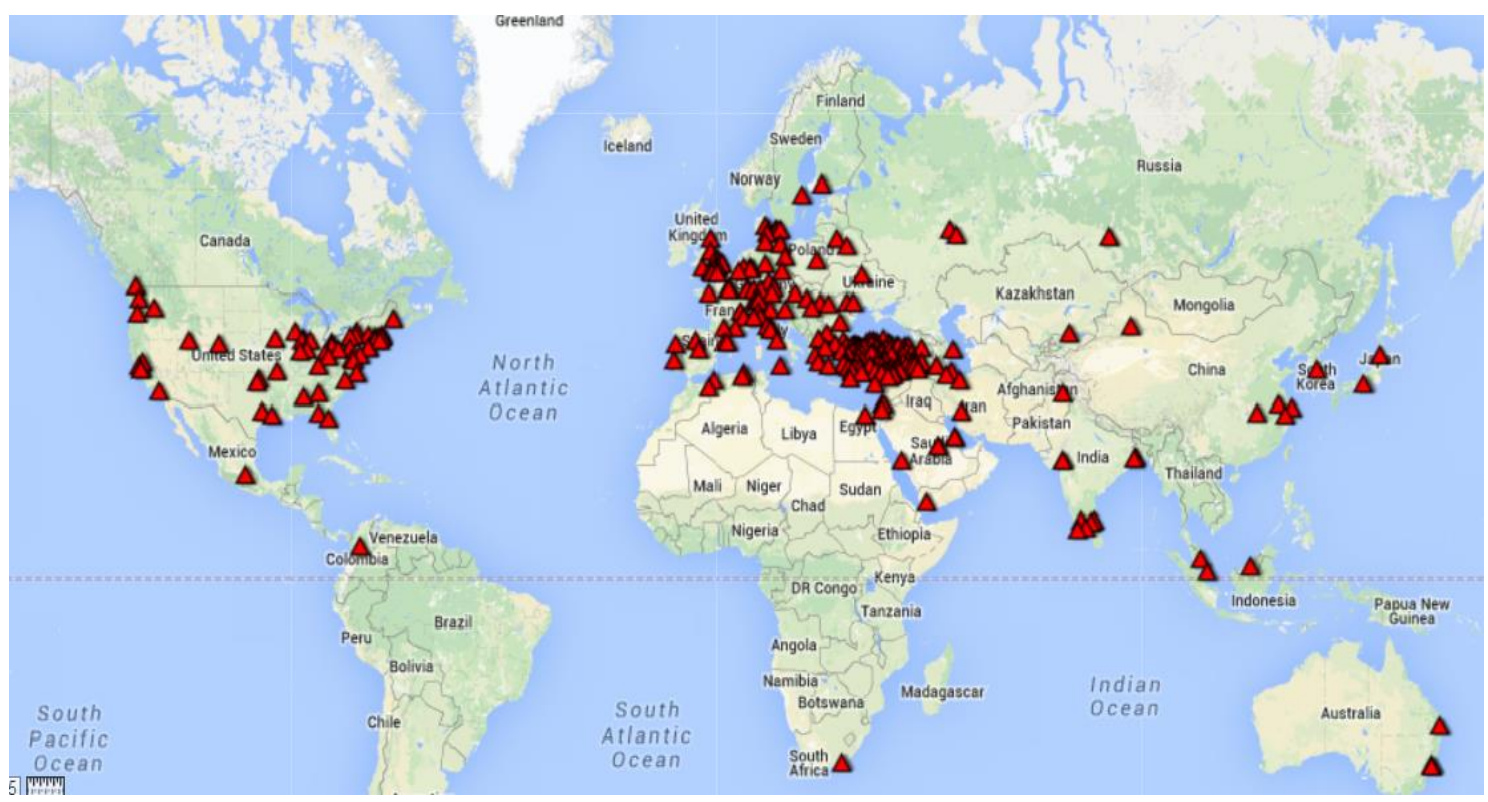

Figure 62. The network of co-authors of international and Turkish scientists working on nano-related technologies, 2006-2011 
One of the reasons, which make Turkish scientists collaborate with the European Union countries and the United States, is that their articles are published in well-known journals. Another reason is funding. The European Union and United States tend to invest in nanorelated technologies, which create big opportunities as joint projects that draw collaborators from Turkey. Figure 62 illustrates that Turkey also collaborates with South Africa, a South American Country, India, Australia, to some extent with several Middle Eastern and North African countries.

The network density of network structure in 2000-2005 rose from 0.014 to 0.018 in 20062011 indicating the growth in the Turkish scientists' community internationally.

\subsection{ETHNOGRAPHIC INTERVIEWS: RESULTS AND ELABORATIONS}

Formal interviews were conducted with 10 interviewees composing of 5 senior and 5 junior scientists. A form regarding interviewees' consent is found in Appendix B. One of the advantages of a formal interview is that the questions define certain goals and specific outcomes. For example, junior interviewees were asked to answer specific structured questions regarding their educational background, their supervisors or the topics about which they are conducting research, whereas senior faculty were just interviewed and informed of co-authorship maps. The first part of the interview consists of an informal conversation followed by the interviewee's specific response on the co-authorship graph. The interviewees were selected from METU, Bilkent, Hacettepe, Sabanc1, TOBB-ETU and Çankaya Universities. A full ethnographic structured and semi-structured interview scripts can be found in Appendices $\mathrm{C}$ and $\mathrm{D}$, respectively. 


\subsection{ETHNOGRAPHIC ELABORATION OF THE CO-AUTHORSHIP MAPS}

We asked the researchers about their opinion regarding co-authorship maps. Each researcher was shown his or her co-authorship map. Following statements are their verbal responses to the co-authorship maps compiled by the researcher.

- $\quad$ Prof. A, a senior scientist from the Middle East Technical University (METU) Physics Department, was interviewed. He published his first scientific article in 1977. His research area is theoretical physics and he utilizes computers as research tools for simulation techniques. Prof. A. is the founder of the graduate level Nanotechnology program at METU. Prof. A. has supervised several $\mathrm{PhD}$ students from different universities in Turkey (for example, Gazi and Firat Universities). Moreover, he participates in programs in which students from other universities (i.e., Anatolian Universities) are trained for their $\mathrm{PhD}$ degrees. It is therefore not surprising that he and his co-authors compose a dense cluster in the social network structure. For his research purposes, he uses a cluster of computers at ULAKBIM remotely. As a research scientist, financial support is one of the factors for scientific endeavors. However, it has never been a constraint for him. In other words, his group has had access to financial support from TÜBİTAK, international organizations or from METU itself. His response to the map was somewhat casual since his co-authors are mostly $\mathrm{PhD}$ students conducting research activities at local or international universities.

- Associate Prof. B. is originally from the United States of America. She states that there are talented people in Turkey, and, therefore, they are able to publish scientific articles. Prof. B states that in order to commercialize nano-related technologies in Turkey, the need for nanotechnologies must be identified. Her response to the map was that whoever initiates an article initially, her/his name ought to appear first in the publication hence her name does not appear as a hub in the network cluster.

- $\quad$ Assistant Prof. C. from the Metallurgy Department at the Middle East Technical University was concerned about the procurement of materials in Turkey. He complained 
that it is easier to obtain materials from abroad. In his opinion, financial support is as important as trained staff in the laboratory. His response to the map was such that academic promotion ought to be based on publications, especially single-authored ones.

- $\quad$ Assistant Prof. D. of the Bio-Engineering Department from TOBB-ETU University has recently returned from the USA. He is new here but has already secured several research projects from TÜBİTAK. In his opinion, it is too early to assess the diffusion of nano-related technologies in Turkey since nanotechnology is new in Turkey. His response to the map was vague in that his name appearing in the network was deemed adequate for him.

- $\quad$ Prof. F. is from UNAM (National Nanotechnology Research Center). He is in charge of UMRAM (National Magnetic Resonance Imaging Research Center), which is regarded as a highly important research institute at Bilkent University. His team is carrying out cutting-edge research that no other research institute is. This creates leverage and advantage when applying for different projects locally and abroad. They mostly work on nano-related projects in collaboration with European and North American universities. For example, their projects have been supported by NIH (National Institute of Health in the United States), European Commission (FP7), TÜBİTAK and the Ministry of Development. Regarding finance, Prof. F. emphasized that funding plays an important role in research. However, if a research group is formed properly, "finding funds is trivial". For example, to publish scientific articles for his team is trivial, since the financial return on investments for his research team is substantial. In terms of collaboration with other universities in Turkey, he agreed that their cluster is isolated. That is, they prefer to work within their own sphere. In order to disseminate their knowledge more actively to other universities, their institutes have recently and eagerly been recruiting students for Master's, PhD and postdoctoral programs from other universities in Turkey. They also lease out their equipment in laboratories on an hourly basis to students from other universities. His response to the map was that in order to be cooperative, they need to interact with other scientific communities. 
- Prof. G. from Hacettepe University's Chemistry Department was aware of the content of our conversation since one of his PhD students had brought up my paper "Diffusion of nanotechnology in Turkey: a social network analysis" (Darvish, 2011). Prof. G. was surprised how his name appeared with students who recently started their $\mathrm{PhD}$ programs in the Department. He constantly informed me about his team and research. To my observation, his collaborative attitude has made him to be a star in the whole network structure. He is not only the Head of the Biochemistry Research Group but also was the Head of the Faculty of Science Program at Hacettepe University at that time. Therefore, he shared several statistical facts about Hacettepe University regarding its output rates in terms of students' graduations. Prof. G. works with $20 \mathrm{PhD}$ students actively. This year Hacettepe University held a national conference on nanoscience and nanotechnology. Prof. G. published his first scientific article in 1984. His $\mathrm{PhD}$ adviser is still at Hacettepe University. Although he finished his PhD studies in 1984, he still keeps in contact with his $\mathrm{PhD}$ advisor, and occasionally co-operates with him in scientific publications. They have a direct link between the nodes which represent them in social network. Prof. G. was not certain that financial support provided by TÜBİTAK reaches the right place. He, however, argued that financial support has motivated many scientists to publish more research articles. Finally, he stated that money spent on research and development is unsatisfactory compared with that in other OECD countries. He also shared the relevant statistical data with me to support his claim(s). He added that Turkey's financial contribution is not commensurate with its scientific outputs. Prof. G. mentioned that nano-related technologies are expensive and finance plays an important role in production output. His response was that there is an open door policy to collaborate with other scientists locally to the extent that his location in the network is pivotal.

- We interviewed Prof. H., a senior at the Engineering Chemistry Department of Hacettepe University, who was not as informative as the previous interviewee. He was reluctant to express his response on the map. His concern generally focused on the diffusion of education in Turkey. 
- Prof. I. from the Chemistry Department of the same University was more informative. Prof. I. published his first paper in 1974. According to him, Istanbul Technical University was the first to motivate his staff financially in order to publish scientific articles. Since then, scientific publication trends have become more fashionable. He argued that since faculty members spend a great amount of time teaching undergraduate courses, the quality of research decreases. For example, in terms of number of patents and scientific publications, UNAM and NANOTAM (research institutes) are more productive, since most researchers spend most of their time exclusively on research. Finally, his response to the graph was that, since he participates in publications which were initiated by other researchers mostly, his name does not appear as much as other researchers do in the map.

- We interviewed Assistant Prof. J. from the Metallurgy Department at Çankaya University. Although new in the Department, she has published scientific articles. Her response to the graph was that she wishes to have a collaborative cluster in the near future. On the other hand, she stated that she is in the network structure even though on the edge of the network where she has collaborated with a few authors.

In summary, every interviewee responded differently to the map. There is no consistency in their responses. Every interviewee seems to have perceived the image according to the structure in which the interviewee was situated. For example, if a cluster is connected and dense, the applicant's response is more informative. However, this is not always the case as one of the applicants is placed as pivotal point.

We discussed earlier that knowledge can be presented in terms of a discourse. Moreover, discourse is presented as a message that facilitates the flow of information in a society. A more qualitative approach is applied to applicants' responses. An online survey was conducted using the Google Docs website. Participants: five junior scientists from Sabanci, METU, Bilkent, TOBB-ETU and Çankaya universities were asked to answer several semistructured open-ended questions (see Appendix D). After interviews, they were shown the co-authorship map of their own university. Then, answers were compared with each other 
(excluding senior scientists' responses) to the question using Latent Semantic Analysis located at "http://lsa.colorado.edu/" in which one-to-many sentence comparison was carried out and coherence comparison was calculated ${ }^{14}$ (Table 17 below). For example, we asked: "Where would you like to see yourself in this social structure map? ${ }^{15}$ We apply oneto-many comparisons to see how interviewees' responded positioned at "http://lsa.colorado.edu/" using a topic space: General Reading_up_to_1 ${ }^{\text {st }}$ _year_College (300_factors) located at "http://lsa.colorado.edu/".

Table 17. One-to-many similarity comparison based on the question "Where would you like to see yourself in this social

\begin{tabular}{cl}
\hline $\begin{array}{c}\text { Similarity } \\
\text { Cosine }\end{array}$ & \multicolumn{1}{c}{ structure map?" } \\
\hline 0.61 & "I like to be close to Rasit Turan in Physics Department METU." \\
& METU." \\
0.21 & $\begin{array}{l}\text { "I like to be well-connected with researchers whom I respect as scientists and as } \\
\text { human beings." }\end{array}$ \\
0.24 & $\begin{array}{l}\text { "I like to have my own cluster, but I like to collaborate with other clusters in order } \\
\text { to have a flow of information among clusters" }\end{array}$ \\
0.26 & "With my friends that I know from school and my thesis PhD thesis advisor"
\end{tabular}

Note: Only the first sentence and its similarity with other sentences is calculated and shown here.

We made some changes to the sentences. For example, the sentence "I like to be close to Raşit Turan in Physics Department METU" was changed to "I like to be close to Physics Department in Middle East Technical University”, since Raşit Turan and METU do not exist in vector space. We included (1) similarity matrix between the two texts, (2) vector length of the text, that is, the mean of all word similarity vectors from the similarity matrix and (3) word count, that is, the number of the words in the sentence where possible score ranges from 0.0 (the lowest) to 1.0 (the highest). There are 20 distinct combinations to choose 2 sentences at a time.

\footnotetext{
${ }^{14} \mathrm{http}: / /$ lsa.colorado.edu

${ }^{15}$ Note: I attached a snapshot of the network structure separately for each university
} 


$$
(5 \vdots 2)=20
$$

The mean of all observations resulted roughly in 0.31 , which may be interpreted as $31 \%$ of similarity among sentences occurred without redundancy in a vector space. We also applied pairwise comparison to answer the question: "With whom do you usually collaborate in scientific activities? And why?" (Table 18). Informants were informed about our research and had seen the co-authorship map network who work on nano-related technology in Turkey.

The mean of the sentence-to-sentence pairwise similarity is 0.35 , which is slightly higher than that from previous sentences. We also re-arranged the list and the results were the same. Furthermore, a regression analysis on three variables resulted in a positive correlation. We can conjecture that there is a similarity of sentence-to-sentence within a vector space.

Table 18. One-to-many similarity comparison based on the question "With whom do you usually collaborate in scientific activities? And why?"

\begin{tabular}{cl}
\hline $\begin{array}{c}\text { Similarity } \\
\text { Cosine }\end{array}$ & \multicolumn{1}{c}{ Sentences } \\
\hline 0.41 & "Colleagues who work on related areas." \\
& "With my friends that I know from school and my thesis PhD thesis advisor." \\
0.21 & "I prefer ones having strong theoretical background rather than experimental groups" \\
& $\begin{array}{l}\text { "I prefer to collaborate with friends in the field, both domestic and international, Trust is essential } \\
\text { and supersede expertise in importance. This also comes from colleagues with similar work habits } \\
\text { and expectations on the right way to conduct scientific research. For example, authorship in } \\
\text { manuscripts is a minefield and can easily give rise to misunderstandings." }\end{array}$ \\
& $\begin{array}{l}\text { "Nanotechnology and materials science are both collaborative subjects. Therefore, one needs to } \\
\text { collaborate." }\end{array}$
\end{tabular}

Note: Only the first sentence and its similarity with other sentences is calculated and shown here. 


\subsection{SUMMARY OF THE FINDINGS}

In chapter 4, we discovered that Turkish Government has been investing heavily on nanorelated technology since 2005, and has included nanotechnology as its national development plan. In order to shed light on diffusion of the nano-related technology in Turkey, we downloaded records using a compound query from WoS in two periods: 20002005 and 2006-2011, and then we applied SNA methods, co-citation analysis and co-words analysis to map and investigate the relational properties and cognitive development of nano-related technology.

We selected the top 15 universities with highest co-occurrences in terms of centrality in each period: 2000-2005 and 2006-2011, and then we calculated their network properties, degree centralities and PageRank coefficient using Gephi. Furthermore, we overlaid the map of profile publications for selected universities according to WoS categories on science map of two periods: 2000-2005 and 2006-2011, and then mapped the scientists who were instrumental in diffusion of nano-related technology in Turkey. Similarly, we applied co-word, and later on, factor analysis on selected topic abstracts of scientific articles published in periods 2000-2005 and 2006-2011 to investigate, and to map of the cognitive development of nano-technology in Turkey. We provided the author co-citation analysis. Last but not least, the Latent Semantic Analysis was applied on sentences compiled form informants in order to quantify their responses.

\subsection{COMPARISON OF FINDINGS WITH RELEVANT STUDIES}

Özel (2010) studied and mapped the knowledge diffusion among scientists in the subject field of "Business Management" throughout 1923-2008. He emphasized that his exemplary case enabled him to elaborate on the socio-political, economical and historical facts, which have had an impact on a scientist's collaboration in terms of scholarly publications. He argued that citation analysis lacks data on interpersonal communication or relationships among scientists. However, it can be discussed by co-authorship analysis. In this thesis, as mentioned earlier, the co-citation analysis can be supplemented by coauthorship analysis. Therefore, we did not investigate co-citation analysis in detail. 
However, co-citation analysis was used to some extent in terms of Turkish scientist, collaboration in periods 2000-2005 and 2006-2011. Moreover, Özel extensively applied co-word and co-authorship methods to map the trends and properties of network structure while he did not elaborate why scientists collaborate. In this thesis, we applied ethnographic methods to shed light on the preceding question. We applied Latent Semantic Analysis technique to measure the words latency in the document. Hence, we shed light on scientists' attitudes who conduct research on nano-related technology toward collaborative work in Turkey.

In this endeavor, research questions pertinent to some of the Zuccala's (2004) study on Singularity theory: (1) what are the topics that comprise the intellectual structure of Singularity Theory research? (2) What is the co-authorship structure of Singularity Theory research and how does it relate to the intellectual structure of this subject? Although she interviewed scientists who work on Singularity theory as a qualitative method, in this dissertation we attempted to quantify the interview results by using Latent Semantic Analysis to investigate the researchers' collaborative behavior in the network structure.

In another exemplary case, Milosevic (2009) studied the development of nanotechnology and nanoscience over a 35 year period (1970-2004) using Nano Bank database in the United State of America. She approached the problem by investigating the following questions; to name just two, (1) what are the social network properties of nanoscience/nanotechnology? (2) What are the trends in journals publishing nanoscience/nanotechnology related research? In this research endeavor, we also applied the relevant questions. In addition, we measured to some extent, the scientist's behavior by utilizing Latent Semantic Analysis technique.

In the context of ethnographic methods, Leleu et al. (2011) applied LSA to open-ended responses collected from the Millennium Coherent Study participants composed in 20012006 to explore substantial health concerns that may not have been covered by the structured survey. They were able to extract the significant meaning of their responses, and then draw words that they then grouped, in a cluster to be categorized to an area of concern 
to be studied further. As mentioned earlier in this study, we attempted to apply LSA technique on semi-structured questions in order to find, to some extent, the scientists' similarity behavior in terms of collaboration in a scientific area.

William (2012) used the Latent Semantic Analysis software located at (http://lsa.colorado.edu), in order to apply one-to-many comparison on the text. He utilized the "General_Reading_up_to_1st_year_college" corpus of which is relevant to the method used in this dissertation in the ethnographic analysis section.

At the national (macro) level, Aydoğan-Duda (2012b) gathered a group of authors who discussed the emergence of nanotechnology in developing countries explicitly, Turkey, Latin America, India, China, and Iran. Moreover, case studies from each country attempt to show the importance of nanotechnology has on his/her country national development plan. Hence, they have explained the importance of knowledge diffusion of nano-related technology from academia to the main stream of society, more importantly, its commercialization. 


\section{CHAPTER 5}

\section{CONCLUSION}

\subsection{SUMMARY}

The hypothesis of this research was the statement that facilitating the diffusion of nano-related technology in the scientific community was effected by interaction among scientists in research projects, and researchers' attitudes toward collaborative works, which create substantive bonds between them. We applied a compound text query to extract records from WoS in nano-related technology from 2000-2005 and 2006-2011 in Turkey. First, we used Rogers' theory of diffusion of an innovation where channel of communication is accepted as co-authorships among scientists locally and internationally. Second, to test the first hypothesis we examined the "small world" phenomenon within the social network structure of scientific field and its attributes in namely two periods: 20002005 and 2006-2011. Third, we measured and contrasted network properties of each period in terms of their degree centralities (betweenness, degree, closeness and PageRank). In addition, we applied co-word analysis and factor analysis to track scientific trends in nanorelated technology between 2000-2005 and 2006-2011 in Turkey. Finally, using Latent Semantic Analysis method, we asserted the hypothesis that scientists whose behavior towards collaboration is almost similar in the social network are inclined to have stronger positions in the network structure.

Rogers' model of the diffusion process was used to conceptualize the procedure in terms of the co-authorship of scientists who work on nano-related technologies. Furthermore, we overlaid the top 15 universities' map, which have the highest degree centralities in the network structure on science map using Web of Science categories to shed light on scientific subject fields, which are instrumental in the diffusion of nanotechnology in Turkey. We conducted ethnographic interviews: 5 senior and 5 junior 
scientists whose activities on nano-related technologies were reflected on co-authorship maps. We recognized the prominent scientists in the co-authorship network structure who are instrumental in nano-related technology in Turkey. Furthermore, by utilizing journalto-journal citation and co-citation analysis, we have identified those knowledge domains in which scientists have participated.

\subsection{CONCLUSIONS}

The first research question was: "What are the key areas of nanotechnology in Turkey, for example, metallurgical, pharmaceuticals, medical devices, high technical industry, and so on?" We approached this question by analyzing the bibliometric data from WoS, and then, we overlaid 15 universities' research activities maps using WoS subject categories on the map of science. The overlaid maps show each university's publication of nano-related technologies in each subject category. Even universities with low degree centrality published in multidisciplinary subjects involving nano-related technologies. Then, co-word and factor analysis was applied to words that appeared in the title of articles in each period: 2000-2005 and 2006-2011. Results showed that nanotechnology/nanoscience is a trans-, inter-disciplinary research field dealing with Materials Science, Physics, Chemistry and Biology, among others. We can infer that Materials Science and its subfields and to a lesser extent, Medical Sciences are key areas of nanotechnology. Crystallography is also an important subject field in nano-related technology in Turkey.

The second question was that: "Do co-authorship social network structures exhibit smallworld network structure? We approached this question by assessing social organization (relationships) among scholars who collaborate with each other in developing scientific

outputs in terms of scientific articles. Results indicate that co-authorship network of scientists comprises small world properties in that the network structure is composed of well-connected nodes, although the overall connectedness of the network structures is low. Furthermore, we mapped the co-authorship of each university, identifying each university's prominent and influential scientists using degree centrality and PageRank. Although the overall density of the social network is low for both periods, there are dense 
sub-clusters within the entire network structure which resulted in "small world" phenomenon in the social network structure. For instance, we showed that while betweenness centrality is low, the closeness and degree centralities increased in each period, which are the indication of small-world phenomenon in the network structure.

The third question was: "How significant is the rate of diffusion of nano-related technology according to network properties results in two periods: 2000-2005 and 20062001?" We approached this question by contrasting number of new adopters in each period. Although the number of new adopters rose gradually in each period; nevertheless, the number of multiple fraction authored papers have increased from 2000-2005 to 20062011, reflecting collaborations among scientists whose work included nano-related technology in Turkey. For example, we found out that Büyükgüngör has authored scientific papers with more than those other scientists in the network structure including scientists who did not appear at the top 15 authors in terms of degree centralities. However, they were recognized as instrumental nodes in the diffusion of nanotechnology in the network structure.

The fourth question was: "To what extent do scientists share a common vision (behavior) on nano technology?" We interviewed five junior scientists and five senior scientist collected, analyzed and elaborated on their responses to two questions using Latent Semantic Analysis method. The overall mean of similarity between responses was about $30 \%$. However, the goodness of the fit was more than 0.75 , indicating that both senior and junior scientists perceive collaboration in a similar manner.

In other words, the aim of the research was to unravel the diffusion process in Turkey by investigating extracted records from WoS between 2000-2005 and 2006-2011 using both qualitative and quantitative research methods. Rogers' theory of diffusion process was used as a blueprint to track nano-related technology in academia by means of coauthorship network analysis. Moreover, it was observed that scientists have intentions to work both internationally and nationally. For example, scientists prefer to collaborate with their counterparts in European countries and North America. In addition, locally, 
nanotechnology institutes at prolific universities mostly collaborate with their sister universities within the networks, thus creating cohesive clusters in the network structure.

\subsection{STRENGTHS AND WEAKNESSES OF THE THESIS}

This is the first study carried out in Turkey assessing the diffusion of nano-related technologies. Although information scientists have used mixed methods to study scientific indicators, which we mentioned in relevant studies in the preceding chapter, no one has yet applied the Latent Semantic Analysis in analyzing ethnographic discourses. As mentioned earlier, there have been articles or theses in which LSA was utilized. The qualitative results show that the level of similarity among scientists' behaviors is at $30 \%$. The number of interviews was small, however. The responses compiled from interviewees have created an incubator-prototype which can be enhanced further. The co-authorship network may not necessarily illustrate the diffusion process holistically. Nevertheless, it describes the notion of information sharing and collaboration behavior of nanotechnology scientists. In this endeavor, co-citation analysis was briefly covered; nevertheless, it was revealed that cocitation analysis solely does not illuminate the diffusion of nano-related technology in Turkey. Network of scientific collaboration manifests "small-world" which facilitates the diffusion of nano-related technology structure through acquaintance.

TÜBİTAK and the MoD are two of the governmental agencies that support research institutes in universities. One way to expand collaboration is through communication which accelerates the diffusion of nano-related technologies in Turkey. Yet, we discovered that scientists seem to be reluctant to collaborate, unless they become more observant of the teamwork. We collected and assessed their comprehension of co-authorship network regarding collaboration through interviews and by using Latent Semantic Analysis methods. We can say that the longevity plays an important role for a person to become a hub in his/her cluster. However, becoming a hub in a cluster does not necessarily mean that one becomes a pivotal point, thereby facilitating the flow of information from one cluster to another cluster in the network. 


\subsection{RECOMMENDATIONS}

Although Turkey has included research and development in nano-technology in her national plan, there are some key points to be implemented which would accelerate the diffusion of nano-related technology. They are as follows:

- Applying new methods (i.e., ethnographic interviews) in evaluating research activities;

- Encouraging scientists whose positions are not significant in the network to participate in research activities in order to create synergy among research institutes;

- Utilizing brokers to participate more in research activities to stimulate academic exchange among all institutes, nationally and internationally; and

- Promoting research on Bio-Nanotechnology fields and its derivatives in Health Sciences.

\subsection{FUTURE WORK}

As revealed earlier, governmental agencies have invested on research and technology, specifically nano-related technology. Our personal observation is that TÜBİTAK and MoD have been supporting research in universities. However, further studies are needed to investigate other variables that may affect the level of outputs in terms of scientific articles in academia. Latent Semantic Analysis technique was used as a tool for exploring discourses in this dissertation. It could be useful to apply this technique to other research involving discourse analysis. The current study can be enhanced or extended by interviewing more scientists or by contrasting results with other countries for a better picture of Turkey's performance in nano-related technologies. 


\section{BIBLIOGRAPHY}

Aydoğan-Duda, N. (2012a). Branding Innovation: The Case Study of Turkey in Ekekwe, N. \& Islam, N. (Eds.). Disruptive Technologies, Innovation and Global Redesign Emerging Implications.(pp. 238-248)., Hershey, PA: IGI Global.

Aydoğan-Duda, N. (2012b). Nanotechnology: A Descriptive Account. Making it to the Forefront in Aydogan-Duda, N. (Ed). Nanotechnology: A Developing Country Perspective. 1, (pp. 1-4). New York: Springer.

Aydoğan-Duda, N., \& Şener, I. (2010). Entry Barriers to the Nanotechnology Industry in Turkey in Ekekwe, N. (Ed). Nanotechnology and Microelectronics: Global Diffusion, Economics and Policy. (pp. 167-173). Hershey, PA: IGI Global.

Barabasi, AL., \& Albert, R. (1999). Emergence of Scaling in Random Networks. Science Magazine, 286 (5439), 509-512

Börner, K., Chen, C., \& Boyack, K. (2003). Visualizing Knowledge Domains. Annual Review of Information Science and Technology, 37(1), 179-255.

Burt, R.S. (1992). Structural Holes: The Social Structure of Competition, Cambridge, MA: Harvard University Press

Callon, M., Courtial, J.P., Turner, W. A., \& Bauin, S. (1983). From Translations to Problematic Networks: An Introduction to Co-word Analysis. Social Science Information, 22(2), 191-235.

Cartwright, D., \& Harary, F. (1977). A Graph Theoretic Approach to the Investigation of System-Environment Relationships. Journal of Mathematical Sociology, 5(1) 87-111.

Chen, C. (2004). Searching for Intellectual Turning Points: Progressive Knowledge Domain Visualization. PNAS, 101 (Suppl. 1), 5303-5310.

Chen, C., Chen, Y., Horowitz, M., Hou, H., Liu, Z., \& Pellegrino, D. (2009). Towards an Explanatory and Computational Theory of Scientific Discovery. Journal of Informetrics, 3(3), 191-209.

Crane, D. (1972). Invisible Colleges: Diffusion of Knowledge in Scientific Communities. Chicago, IL: University of Chicago Press.

Darvish, H.R. (2011). Assessing the Diffusion of Nanotechnology in Turkey: A Social Network Analysis. Collnet Journal of Scientometrics and Information Management, 6(1), 175-183.

Deerwester, S.T., Furnas, G.W., Harshman, R.A., Landauer, T.K., Lochbaum, K.E., \& Streeter, L.A. (1989). Computer Information Retrieval Using Latent Semantic Structure. United States Patent 4,839,853 (June 13, 1989). 
Deerwester, S.T., Furnas, G.W., Landauer, T.K., \& Harshman, R. (1990). Indexing by Latent Semantic Analysis. Journal of the American Society for Information Science, 41(6), 321-407.

Emirbayer, M., \& Goodwin, J. (1994). Network Analysis, Culture, and the Problem of Agency. American Journal of Sociology, 99(6), 1411-54.

Feynman, R.P. (1960). There's Plenty of Room at the Bottom. Caltech Engineering \& Science. Retrieved, Feb.14, from http://calteches.library.caltech.edu/1976/1/1960Bottom.pdf

Foucault, M. (1991). Discipline and Punish: The Birth of a Prison. London: Penguin.

Freeman, L.C. (1996). Some Antecedents of Social Network Analysis, Connections, 19(1) $39-42$.

Freeman, L.C. (2004). The Development of Social Network Analysis: A Study in the Sociology of Science. Vancouver: Empirical Press.

Fulcher, E. (2005). What is Discourse Analysis? Retrieved, Feb. 14, 2014, from http://www.eamonfulcher.com/discourse_analysis.html

Garfield, E. (1988). Theory of Technology's Role in Economic Growth Brings MIT's Robert M Solow the 1987 Nobel Prize in Economic Sciences, Current Contents 11(17), 123-128.

Girvan, M., \& Newman., M. E. J.(2002). Community Structure in Social and Biological Networks, PNAS, 99(12), 7821-7826.

Granovetter, M.(1974). Getting A Job: A Study of Contacts and Careers. Cambridge, Mass: Harvard University.

Kostoff, R.N., Koytcheff, R.G., \& Lau, C.G.Y. (2007). Global Nanotechnology Research Literature Overview, Technological Forecasting \& Social Change, (74), 1733-1747.

Kostoff, R.N., Stump, J. A., Johnson, D., Murday, J.S. , Lau, C.G.Y., \& Tolls, W.M. (2006). The Structure and Infrastructure of Global Nanotechnology Literature. Journal of Nanoparticles Research, (8), 301-321

Kuhn, T. S. (1970). The Structure of Scientific Revolutions. Chicago, IL: University of Chicago Press.

Landauer, T. K., Foltz, P. W., \& Laham, D. (1998). An introduction to Latent Semantic Analysis. Discourse Processes, 25(2-3), 259-284.

Leleu, T.D., Jacobson, I.G., LeardMann, C.A., Smith, B., Foltz, P.W., Amoroso, P.J., Derr, M.A. \& Ryan, M.A.K. \& Smith, T.C. (2011). Application of Latent Semantic Analysis 
for Open-ended Responses in a Large, Epidemiologic Study. BMC Medical Research Methodology, 11(36).

Lewin, K. (1951). Field Theory in Social Science. New York: Harper.

Leydesdorff, L. (2001). The Challenge of Scientometrics, The Development, Measurement, and Self-Organization of Scientific Communications. Florida: Universal-Publishers.

Leydesdorff, L. \& Etzkowitz, H. (1998). The Triple Helix as a Model for Innovation Studies (Conference Report), Science \& Public Policy, Research Policy 25(3), 195203.

Leydesdorff, L., \& Persson, O. (2010). Mapping the Geography of Science: Distribution Patterns and Networks of Relations among Cities and Institutes. Journal of the American Society for Information Science \& Technology, 61(8), 1622-1634.

Leydesdorff, L., \& Rafols, I. (2009). A Global Map of Science Based on the ISI Subject Categories, Journal of the American Society for Information Science and Technology, 60(2) 348-362.

Leydesdorff, L., Welbers, K. (2011). The Semantic Mapping of Words and Co-words in Contexts, Journal of Informetrics, 5(3) 469-475.

Lievrouw, L.A., Rogers, E.M., Lowe., C.U., \& Nadel, E. (1987). Triangulation as a research strategy for identifying invisible colleges among biomedical scientists. Social Networks, 9(3), 217-248.

Mehta, M., (2002). Nanoscience and Nanotechnology: Assessing the Nature of Innovation in These Fields. Bulletin of Science, Technology and Society, 22(4), 269-273.

Milgram, S. (1967). The Small World Problem. Psychology Today, 1(1), 61-67.

Milojević, S. (2009), Big Science, Nano Science? Mapping the Evolution and SocioCognitive Structure of Nanoscience/nanotechnology Using Mixed Methods. PhD Dissertation, University of California, Los Angeles.

Moody, J. (2004). The Structure of a Social Science Collaboration Network: Disciplinary Cohesion from 1963 to 1999. American Sociological Review, 69(2), 213-238.

Moreno, J. (1934). Who shall Survive? Sociometry, 6(3), 206-213.

Motoyama, Y., \& Eisler. M.N (2011). Bibliometry and Nanotechnology: A Meta-analysis. Technological Forecasting \& Social Change, 78(7), 1174-1182.

Newman, M. E. J. (2000). The Structure of Scientific Collaboration Networks. PNAS, 98 (2), 404-409.

Page, L., \& Brin, S. (1998). The Anatomy of a Large-scale Hypertextual Web Search Engine. Computer Networks and ISDN Systems, 30, 107-117. 
Otte, E., \& Rousseau, R. (2002). Social Network Analysis: A Powerful Strategy, also for the Information Sciences. Journal of information Science, 28(6), 443-455.

Özel, B. (2010). Scientific Collaboration Networks: Knowledge Diffusion and Fragmentation in Turkish Management Academia, PhD Dissertation, Bilgi University, Istanbul.

Pritchard, A. (1969). Statistical Bibliography or Bibliometrics? Journal of Documentation, 25(4), 348-349.

Price, D. J. de Solla. (1965). Networks of Scientific Papers. Science, 49(3683), 510-515.

Rafols, I., \& Leydesdorff, L. (2011). The Local Emergence and Global Diffusion of Research Technologies: An Exploration of Patterns of Network Formation, Journal of the American Society for Information Science and Technology. 62(5), 846-850.

Rafols, I., Porter, A. L., \& Leydesdorff, L. (2010). Science Overlay Maps: a New Tool for Research Policy and Library Management. Journal of the American Society for Information Science and Technology, 61(9), 1871-1887.

Rogers, E. M. (2003). Diffusion of Innovations. 5th ed. New York: The Free Press.

Rousseau, R. (1997). Sitations: an Exploratory Study. Cybermetrics. Retrieved, Feb.14, 2014, from http://cybermetrics.cindoc.csic.es/articles/v4i1p4.pdf

Saville-Troike, M. (2003). The Ethnography of Communication: An Introduction, 3d ed. Malden, MA: Blackwell Publishers.

Scott, J. (2000). Social Network Analysis: A Handbook. 2nd ed. London: Sage.

Tonta, Y., \& Darvish, H.R. (2010). Diffusion of Latent Semantic Analysis as a Research Tool: A Social Network Analysis Approach. Journal of Informetrics, 4 (2), 166-174.

Uzun, A. (2006). Science and technology policy in Turkey: National strategies for innovation and change during the 1983-2003 periods and beyond. Scientometrics, $66(3), 551-559$.

Valente, T. (1995). Network Models of the Diffusion of Innovations. Creskill, NJ: Hampton.

Valente, T. (1996). Social Network Thresholds in the Diffusion of Information. Social Networks, 18(1), 69-89.

Wasserman, S., \& Faust, K. (1994). Social Network Analysis: Methods and Applications. Cambridge: Cambridge University Press.

Watts, D. (2003). Six Degrees: The Science of a Connected Age. New York: W. W. Norton \& Company. 
Watts, D.J. (1999). Networks, Dynamics, and the Small-World Phenomenon. American Journal of Sociology. 105 (2), 493-527.

Watts, D. J., \& Strogatz, S. (1998). Collective Dynamics of "small-world" Networks. Nature, 393 (6684), 440-441.

Wellman, B., \& Berkowitz, S. D. (1997). Social Structures: A Network Approach. 2nd ed. Cambridge: University of Cambridge.

White, H. D., \& McCain, K. W. (1998). Visualizing a Discipline: An Author Co-citation Analysis of Information Science, 1972-1995. Journal of the American Society for Information Science, 49(4), 327-355.

William, MA. (2012). Intrinsic Advance Primers: An Investigation of the Effects of Personalized Extraneous Multimedia Upon Intrinsic Interest and Student Achievement, PhD Dissertation, Kent State University. Retrieved, Feb. 14, 2014, from https://etd.ohiolink.edu/ap:10:0::NO:10:P10_ACCESSION_NUM:kent1342732010

Zuccala, A.A. (2004). Revisiting the Invisible College: A Case Study of the Intellectual Structure and Social Process of Singularity Theory Research in Mathematics, $\mathrm{PhD}$ Dissertation, University of Toronto. Retrieved, Feb. 14, 2014, from http://individual.utoronto.ca/azuccala_web/AZuccala-Thesis.pdf 


\section{APPENDICES}

\section{APPENDIX A: QUERY FORMATION USED TO FIND THE PUBLICATIONS OF TURKISH RESEARCHERS ON NANOSCIENCE AND NANOTECHNOLOGY ON THE WEB}

- TS=(NANOPARTICLE* OR NANOTUB* OR NANOSTRUCTURE* OR NANOCOMPOSITE* OR NANOCOMPOSITE* OR NANOWIRE* OR NANOCRYSTAL* OR NANOFIBER* OR NANOFIBRE* OR NANOSPHERE* OR NANOROD* OR NANOTECHNOLOG* OR NANOCLUSTER* OR NANOCAPSULE* OR NANOMATERIAL* OR NANOFABRICAT* OR NANOPOR* OR NANOPARTICULATE* OR NANOPHASE OR NANOPOWDER* OR NANOLITHOGRAPHY OR NANO-PARTICLE* OR NANODEVICE* OR NANODOT* OR NANOINDENT* OR NANO-INDENT* OR NANOLAYER* OR NANOSCIENCE OR NANOSIZE* OR NANO-SIZE* OR NANOSCALE* OR NANO-SCALE* OR NANOROBOT*) AND $\mathrm{AD}=($ TURKEY) NOT TS $=($ NANOMET* OR NANO2 OR NANO3 OR NANO4 OR NANO5 OR NANOSEC* OR NANOSECOND* OR NANOMETERSCALE* OR NANOMETER LENGTH*)

- $\mathrm{TS}=((\mathrm{NM}$ OR NANOMETER* OR NANOMETRE*) SAME (SURFACE* OR FILM* OR GRAIN* OR POWDER* OR SILICON OR DEPOSITION OR LAYER* OR DEVICE* OR CLUSTER* OR CRYSTAL* OR MATERIAL* OR SUBSTRATE* OR STRUCTURE* OR ROUGHNESS OR MONOLAYER* OR RESOLUTION OR PARTICLE* OR ATOMICFORCE MICROSCOP* OR TRANSMISSION ELECTRON MICROSCOP* OR SCANNING TUNNELING MICROSCOP*)) AND AD= (TURKEY) NOT TS=(NANOMET* OR NANO2 OR NANO3 OR NANO4 OR NANO5 OR NANOSEC* OR NANOSECOND* OR NANOMETERSCALE* OR NANOMETER LENGTH*)

- $\quad \mathrm{TI}=($ nano*) AND SO=((BULK “AND” GRADED NANOMETALS OR CURRENT NANOSCIENCE OR FROM NANOPOWDERS TO FUNCTIONAL MATERIALS OR FULLERENES NANOTUBES “AND” CARBON NANOSTRUCTURES OR FULLERENES NANOTUBES "AND” CARBON NANOSTRUCTURES OR FUNCTIONAL MOLECULAR NANOSTRUCTURES OR IEEE TRANSACTIONS ON NANOBIOSCIENCE OR IEEE TRANSACTIONS ON NANOTECHNOLOGY OR INORGANIC POLYMERIC NANOCOMPOSITES "AND” MEMBRANES OR JOURNAL OF COMPUTATIONAL “AND” THEORETICAL NANOSCIENCE OR JOURNAL OF NANOPARTICLE RESEARCH OR JOURNAL OF NANOSCIENCE "AND" NANOTECHNOLOGY OR MICROSYSTEM TECHNOLOGIES MICRO “AND” NANOSYSTEMS INFORMATION STORAGE "AND” PROCESSING SYSTEMS OR NANO LETTERS OR NANOPOROUS MATERIALS IV OR NANOTECHNOLOGY OR ON THE CONVERGENCE OF BIO INFORMATION ENVIRONMENTAL ENERGY SPACE “AND” NANO TECHNOLOGIES PTS 1 "AND” 2 OR PHYSICA E LOW DIMENSIONAL SYSTEMS NANOSTRUCTURES OR PRECISION ENGINEERING JOURNAL OF THE INTERNATIONAL SOCIETIES FOR PRECISION ENGINEERING "AND" NANOTECHNOLOGY OR SYNTHESIS “AND” REACTIVITY IN INORGANIC METAL ORGANIC "AND” NANO METAL CHEMISTRY OR JOURNAL OF NANOSCIENCE AND NANOTECHNOLOGY OR NANOTECHNOLOGY OR ACS NANO 
OR NANO LETTERS OR JOURNAL OF NANOPARTICLE RESEARCH OR NANOSCALE OR NANOSCALE RESEARCH LETTERS OR SMALL OR PHYSICA E LOW DIMENSIONAL SYSTEMS NANOSTRUCTURES OR INTERNATIONAL JOURNAL OF NANOMEDICINE OR JOURNAL OF COMPUTATIONAL AND THEORETICAL NANOSCIENCE OR JOURNAL OF NANOMATERIALS OR MICRO NANO LETTERS OR MICROSYSTEM TECHNOLOGIES MICRO AND NANOSYSTEMS INFORMATION STORAGE AND PROCESSING SYSTEMS OR IEEE TRANSACTIONS ON NANOTECHNOLOGY OR JOURNAL OF BIOMEDICAL NANOTECHNOLOGY OR SYNTHESIS AND REACTIVITY IN INORGANIC METAL ORGANIC AND NANO METAL CHEMISTRY OR NANO RESEARCH OR DIGEST JOURNAL OF NANOMATERIALS AND BIOSTRUCTURES OR NATURE NANOTECHNOLOGY OR NANOMEDICINE OR NANOMEDICINE NANOTECHNOLOGY BIOLOGY AND MEDICINE OR NANOSCIENCE AND NANOTECHNOLOGY LETTERS OR MICROFLUIDICS AND NANOFLUIDICS OR PRECISION ENGINEERING JOURNAL OF THE INTERNATIONAL SOCIETIES FOR PRECISION ENGINEERING AND NANOTECHNOLOGY OR CURRENT NANOSCIENCE OR JOURNAL OF NANOPHOTONICS OR NANO OR NANOTOXICOLOGY)) AND AD=(TURKEY) NOT TI=(NANOMET* OR NANO2 OR NANO3 OR NANO4 OR NANO5 OR NANOSEC* OR NANOSECOND* OR NANOMETERSCALE* OR NANOMETER LENGTH*)

- TS=((NSOM OR CHEMICAL VAPOR DEPOSITION OR CVD OR CHEMICAL VAPOUR DEPOSITION OR XRAY PHOTOELECTRON SPECTROSCOPY OR DIFFERENTIAL SCANNING CALORIMETRY OR X-RAY DIFFRACTION OR XRD OR SURFACE PLASMON RESONANCE OR "NEAR" FIELD SCANNING OPTICAL MICROSCOP*) SAME (SURFACE* OR FILM* OR LAYER* OR SUBSTRATE* OR ROUGHNESS OR MONOLAYER* OR MOLECUL* OR STRUCTURE* OR RESOLUTION OR ETCH* OR GROW* OR SILICON OR SI OR DEPOSIT* OR PARTICLE* OR FORMATION OR TIP OR ATOM* OR GOLD OR AU OR POLYMER* OR COPOLYMER* OR GAAS OR INAS OR SUPERLATTICE* OR ADSORPTION OR ADSORB* OR ISLAND* OR SIZE OR POWDER OR RESOLUTION OR QUANTUM OR MULTILAYER* OR ARRAY* OR NANO*)) AND AD=(TURKEY) NOT TS=(NANOMET* OR NANO2 OR NANO3 OR NANO4 OR NANO5 OR NANOSEC* OR NANOSECOND* OR NANOMETERSCALE* OR NANOMETER LENGTH*)

- $\quad$ TS=((AFM OR ATOMIC FORCE MICROSCOP* OR SCANNING ELECTRON MICROSCOP* OR SEM OR SCANNING TUNNELING MICROSCOP* OR STM OR SELF-ASSEMBL* OR SELF-ORGANIZ* OR TRANSMISSION ELECTRON MICROSCOP* OR TEM ) SAME (SURFACE* OR FILM* OR LAYER* OR SUBSTRATE* OR ROUGHNESS OR MONOLAYER* OR MOLECUL* OR STRUCTURE* OR RESOLUTION OR ETCH* OR GROW* OR SILICON OR SI OR DEPOSIT* OR PARTICLE* OR FORMATION OR TIP OR ATOM* OR GOLD OR AU OR POLYMER* OR COPOLYMER* OR GAAS OR INAS OR SUPERLATTICE* OR ADSORPTION OR ADSORB* OR ISLAND* OR SIZE OR POWDER* OR RESOLUTION OR QUANTUM OR MULTILAYER* OR ARRAY* OR NANO*)) AND AD=(TURKEY) NOT TS=(NANOMET* OR NANO2 OR NANO3 OR NANO4 OR NANO5 OR NANOSEC* OR NANOSECOND* OR NANOMETERSCALE* OR NANOMETER LENGTH*) 
- TS=(NANOMECHANICAL OR NANOELECTRONIC* OR NANOHARDNESS OR NANORIBBON* OR NANOBELT* OR NANOGRAIN* OR NANOCABLE* OR NANOCHANNEL* OR NANOSHEET* OR NANODIAMOND* OR NANOMAGNET* OR NANODISK* OR NANOSHELL* OR NANOCONTACT* OR NANOREACTOR* OR NANOIMPRINT* OR NANOHOLE* OR NANOWHISKER* OR NANOCHEMISTRY OR NANOGRAPHITE OR NANOELECTRODE* OR NANOGRANULAR OR NANOFOAM* OR NANOMETER-SIZE* OR NANOCOLLOID* OR NANORING* OR NANOPHOTONIC* OR NANOSENSOR* OR NANOELECTROSPRAY* OR NANOBRIDGE* OR NANOMETER-SCALE* OR NANOBIO* OR BIONANO* OR HIPCO) AND AD=(TURKEY) NOT TS=(NANOMET* OR NANO2 OR NANO3 OR NANO4 OR NANO5 OR NANOSEC* OR NANOSECOND* OR NANOMETERSCALE* OR NANOMETER LENGTH*)

- $\mathrm{TS}=($ MOLECUL* MOTOR* OR MOLECUL* RULER* OR MOLECUL* DEVICE* OR MOLECULAR ENGINEERING OR MOLECULAR ELECTRONIC* OR COULOMB STAIRCASE* OR QUANTUM DOT* OR QUANTUM WELL* OR QUANTUM WIRE* OR COULOMB BLOCKADE* OR MOLECULAR WIRE*) AND $\mathrm{AD}=(\mathrm{TURKEY}) \mathrm{NOT}$ TS=(NANOMET* OR NANO2 OR NANO3 OR NANO4 OR NANO5 OR NANOSEC* OR NANOSECOND* OR NANOMETERSCALE* OR NANOMETER LENGTH*)

- $\mathrm{TS}=(\mathrm{NANO} *)$ AND AD=(NANO* NOT NANOPHOTON*) AND AD=(TURKEY) 


\section{APPENDIX B: SUBJECT CONSENT FORM}

The purpose of this research is to assess the diffusion of nanotechnology in Turkey using social network analysis. The objective of this research is to understand the collaborative structure of scientific domain.

Hamid Derviş (darvish@ cankaya.edu.tr, darvish@ hacettepe.edu.tr) is conducting this interview for his $\mathrm{PhD}$ thesis. His advisor is Prof. Dr. Yaşar Tonta of the Department of Information Management from Hacettepe University. Also, other jury members are Prof. Dr. Serap Kurbanoğlu from the same Department and Prof. Dr. Aydın ERAR from Mimar Sinan University.

\section{SUBJECT CONSENT:}

As a candidate for this study:

1) I understand that there are no misuses of the information under any circumstances with my role as a candidate

2) I understand that I have the option of refusing to answer

3) I have the option of continuing or not continuing my role as an informer

4) I understand that I have the voluntary option of allowing or not allowing my name to appear in the thesis

5) I the undersigned: agree / do not agree (circle one) to allow the researcher,

Hamid Derviş to use my name in his written Ph.D. research report.

Interviewees' Signature:

E-mail address: 


\section{APPENDIX C: STRUCTURED INTERVIEW QUESTIONS}

1) When did you hear the term nano in your subject study?

2) How long have you been working on nano-related technologies?

3) Which area of nano-technology are you working now?

4) The term "nano" is a relatively new terminology, what would you be working on if the term nano was not introduced? Describe a collaborative nano-related project that you are working on?

5) Does each project get supported financially? If your answer is yes, to what extent? If no, what has been the outcome of the scientific output (Journal Article)?

6) Is there a relationship between financial support and the publication output of the project you have been working on?

7) With whom do you usually collaborate in scientific activities? And why?

8) Is there any one that you would like to collaborate in the field of nano-related technology locally or internationally?

9) Where would you like to see yourself in this social structure map? I would like to see myself as having graduate students. Consequently as being more productive, who was your $\mathrm{PhD}$ advisor?

10) Have you kept working on your $\mathrm{PhD}$ thesis or new topics? Do you collaborate still with your advisor?

11) Are you advising any graduate or under graduate students currently?

12) Do you easily communicate with everyone in your field in your university or outside university? Who are they? 


\section{APPENDIX D: SEMI-STRUCTURED INTERVIEW QUESTIONS}

1. Would you elaborate on state of nanotechnology research in Turkey?

2. Do you see a major correlation between financial support and research activities in terms of scientific publications in your department?

3. Would you please share your opinion about scientific collaboration after seeing the co-authorship map of your university?

4. Do you collaborate nationally or internationally on research activities? What is your preference?

5. How can we improve the nanotechnology awareness in Turkey especially in academia? 


\section{APPENDIX E LIST OF WORDS USED IN NANOTECHNOLOGY: 2000-2005}

Rotated Component Matrix ${ }^{\mathrm{a}}$

\begin{tabular}{|c|c|c|c|}
\hline \multicolumn{4}{|c|}{ Component } \\
\hline Words & 1 & Words & 2 \\
\hline CHEMICAL & .999 & PLASMA & .999 \\
\hline QUANTUM & .999 & TREATMENT & .999 \\
\hline $\begin{array}{l}\text { STEEL } \\
\end{array}$ & .998 & CONDUCTING & .990 \\
\hline HYDROGEN & .997 & CERAMIC & .982 \\
\hline COPOLYMER & .992 & SOLGEL & .982 \\
\hline FIELD & .992 & LAYER & .945 \\
\hline PROPERTIE & .984 & OPTICAL & .945 \\
\hline ELECTRICAL & .973 & SURFACE & .945 \\
\hline COATING & -.968 & WEAR & .901 \\
\hline LASER & .954 & NANOPARTICLE & -.901 \\
\hline TURKEY & .951 & POLYMERIZATION & .894 \\
\hline ION & .941 & POLYMER & -.891 \\
\hline ALLOY & .928 & POWDER & .885 \\
\hline BEHAVIOR & .928 & MECHANICAL & .883 \\
\hline THIN & .925 & MOLECULAR & .883 \\
\hline SYNTHESIS & .920 & SCANNING & .883 \\
\hline METHACRYLATE & .920 & CHARACTERISTIC & .879 \\
\hline CRYSTAL & .916 & CELL & .866 \\
\hline OXIDE & .914 & WIRE & -.866 \\
\hline FILM & .913 & MICROSCOPY & .845 \\
\hline DOT & .912 & BASED & .826 \\
\hline NANOTUBE & .902 & COMPOSITE & .825 \\
\hline CARBON & .891 & MATERIAL & .817 \\
\hline ACID & .873 & MAGNETIC & .786 \\
\hline CHARACTERIZATION & .872 & ELECTRIC & -.764 \\
\hline ADSORPTION & .866 & PREPARATION & .754 \\
\hline SPECTROSCOPIC & .866 & ELECTROCHEMICAL & .737 \\
\hline THERMAL & .866 & SILICON & .721 \\
\hline STRUCTURAL & .840 & MEMBRANE & .721 \\
\hline ANALYSIS & .836 & & \\
\hline ELECTRON & .830 & & \\
\hline FIBER & .826 & & \\
\hline PROCE & .817 & & \\
\hline ATOMIC & .807 & & \\
\hline STRUCTURE & .800 & & \\
\hline ELECTRONIC & .796 & & \\
\hline METAL & .792 & & \\
\hline COMPLEXE & .772 & & \\
\hline RESIN & .756 & & \\
\hline SUBSTRATE & .756 & & \\
\hline MICROSTRUCTURE & .756 & & \\
\hline SPECTRA & .756 & & \\
\hline TEMPERATURE & .756 & & \\
\hline
\end{tabular}




\begin{tabular}{|l|l|l|l|}
\hline EFFECT & .746 & & \\
\hline METHOD & .729 & & \\
\hline WEAR & .901 & & \\
\hline NANOPARTICLE & .901 & & \\
\hline POLYMERIZATION & .894 & & \\
\hline POLYMER & -.891 & & \\
\hline POWDER & .885 & & \\
\hline MECHANICAL & .883 & & \\
\hline MOLECULAR & .883 & & \\
\hline SCANNING & .883 & & \\
\hline CHARACTERISTIC & .879 & & \\
\hline
\end{tabular}

Extraction Method: Principal Component Analysis.

Rotation Method: Varimax with Kaiser Normalization.

a. Rotation converged in 8 iterations. 


\section{APPENDIX F: LIST OF WORDS USED IN NANOTECHNOLOGY: 2006-2011 Rotated Component Matrix ${ }^{a}$}

\begin{tabular}{|c|c|c|c|c|c|}
\hline \multicolumn{6}{|c|}{ Component } \\
\hline Words & 1 & Words & 2 & Words & 3 \\
\hline COPOLYMER & .766 & DETERMINATION & .683 & ELECTRON & .687 \\
\hline COMPLEXES & .697 & STEEL & .673 & DOT & .676 \\
\hline CRYSTAL & .674 & WELL & .655 & MORPHOLOGY & .654 \\
\hline THERMAL & .653 & AQUEOU & .651 & ADSORPTION & .644 \\
\hline SPECTROSCOPIC & .650 & ZNO & .642 & ENERGY & .641 \\
\hline CHARACTERISTIC & .643 & PARTICLE & .626 & PREPARED & .620 \\
\hline PREPARATION & .641 & MATERIAL & .625 & QUANTUM & .619 \\
\hline METAL & .636 & TEMPERATURE & .620 & ELECTRICAL & .610 \\
\hline POLYMER & .636 & CELL & .618 & MODIFIED & .610 \\
\hline OXIDE & .629 & BASED & .617 & CARBON & .608 \\
\hline STRUCTURE & .629 & MECHANICAL & .683 & NANOTUBE & .599 \\
\hline TURKEY & .627 & PHASE & .673 & ELECTROCHEMICAL & .598 \\
\hline COMPLEXES & .626 & COMPOSITE & .655 & TREATMENT & .598 \\
\hline FIBER & .625 & MAGNETIC & .651 & NANOCOMPOSITE & .597 \\
\hline STUDIES & .621 & DOPED & .642 & ACID & .594 \\
\hline STRUCTURAL & .619 & PLASMA & .626 & NANOPARTICLE & .591 \\
\hline SURFACE & .616 & ALLOY & .625 & & \\
\hline MEMBRANE & .615 & LASER & .620 & & \\
\hline SOLUTION & .611 & BASED & .618 & & \\
\hline CATALYST & .610 & MECHANICAL & .617 & & \\
\hline FIELD & .608 & & & & \\
\hline OPTICAL & .605 & & & & \\
\hline THIN & .604 & & & & \\
\hline NOVEL & .604 & & & & \\
\hline ION & .603 & & & & \\
\hline BEHAVIOR & .602 & & & & \\
\hline MOLECULAR & .599 & & & & \\
\hline APPLICATION & .590 & & & & \\
\hline CONTAINING & .590 & & & & \\
\hline METHOD & .589 & & & & \\
\hline CHEMICAL & .589 & & & & \\
\hline COATING & .587 & & & & \\
\hline INFLUENCE & .587 & & & & \\
\hline DEPOSITION & .580 & & & & \\
\hline
\end{tabular}

Extraction Method: Principal Component Analysis.

Rotation Method: Varimax with Kaiser Normalization.

a. Rotation converged in 3 iterations. 


\section{APPENDIX G: THE MOST COLLABORATING UNIVERSITIES WORKING ON NANO-RELATED TECHNOLOGY (2000-2011)}

\begin{tabular}{|c|c|c|}
\hline Freq & \multicolumn{2}{|c|}{ Universities } \\
\hline 56 & Cumhuriyet Univ & Dokuz Eylul Univ \\
\hline 52 & Eskisehir Osmangazi Univ & Ondokuz Mayis Univ \\
\hline 50 & Ankara Univ & Hacettepe Univ \\
\hline 48 & Gazi Univ & Middle E Tech Univ \\
\hline 47 & Ankara Univ & Gazi Univ \\
\hline 40 & Gazi Univ & Hacettepe Univ \\
\hline 35 & Bilkent Univ & Gazi Univ \\
\hline 34 & Dokuz Eylul Univ & Ege Univ \\
\hline 30 & Gebze Inst Technol & TUBITAK Marmara Res Ctr \\
\hline 28 & Ondokuz Mayis Univ & Uludag Univ \\
\hline 27 & Fatih Univ & Gebze Inst Technol \\
\hline 27 & Celal Bayar Univ & Ege Univ \\
\hline 26 & Anadolu Univ & Hacettepe Univ \\
\hline 25 & Firat Univ & King Saud Univ \\
\hline 25 & Dicle Univ & Middle E Tech Univ \\
\hline 25 & Ankara Univ & Selcuk Univ \\
\hline 23 & Dumlupinar Univ & Eskisehir Osmangazi Univ \\
\hline 23 & Akdeniz Univ & Inonu Univ \\
\hline 22 & Ahi Evran Univ & Gazi Univ \\
\hline 22 & Bilkent Univ & Nanyang Technol Univ \\
\hline 22 & Hacettepe Univ & Middle E Tech Univ \\
\hline 22 & Baskent Univ & Hacettepe Univ \\
\hline 22 & Adnan Menderes Univ & Hacettepe Univ \\
\hline 22 & Atilim Univ & Middle E Tech Univ \\
\hline 21 & Ankara Univ & Cankaya Univ \\
\hline 21 & Istanbul Tech Univ & Koc Univ \\
\hline 21 & Istanbul Tech Univ & Univ Washington \\
\hline 21 & Dumlupinar Univ & Ondokuz Mayis Univ \\
\hline 20 & Ege Univ & Hacettepe Univ \\
\hline 20 & Adnan Menderes Univ & Ege Univ \\
\hline 19 & Ondokuz Mayis Univ & Sinop Univ \\
\hline 19 & Istanbul Tech Univ & Marmara Univ \\
\hline 19 & Fatih Univ & Royal Inst Technol KTH \\
\hline 19 & Bilkent Univ & Middle E Tech Univ \\
\hline 19 & Balikesir Univ & Uludag Univ \\
\hline 19 & Istanbul Tech Univ & Yildiz Tech Univ \\
\hline 19 & Ankara Univ & Middle E Tech Univ \\
\hline 18 & Anadolu Univ & Firat Univ \\
\hline 18 & Anadolu Univ & Eskisehir Osmangazi Univ \\
\hline
\end{tabular}

